\title{
PCTURING MIRACLES OF
}

\section{PLANTANDANIMAL LIFE}

ARTHUR C. PILLSBURY 
From the collection of the

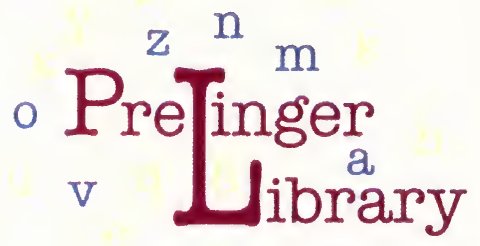

t

$\mathrm{p}$

San Francisco, California 2006 
2

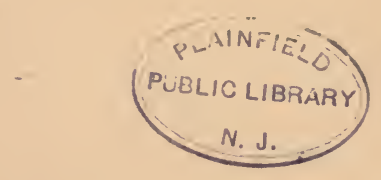




\section{PICTURING MIRACLES}

OF

PLANT AND ANIMAL LIFE

బิก 



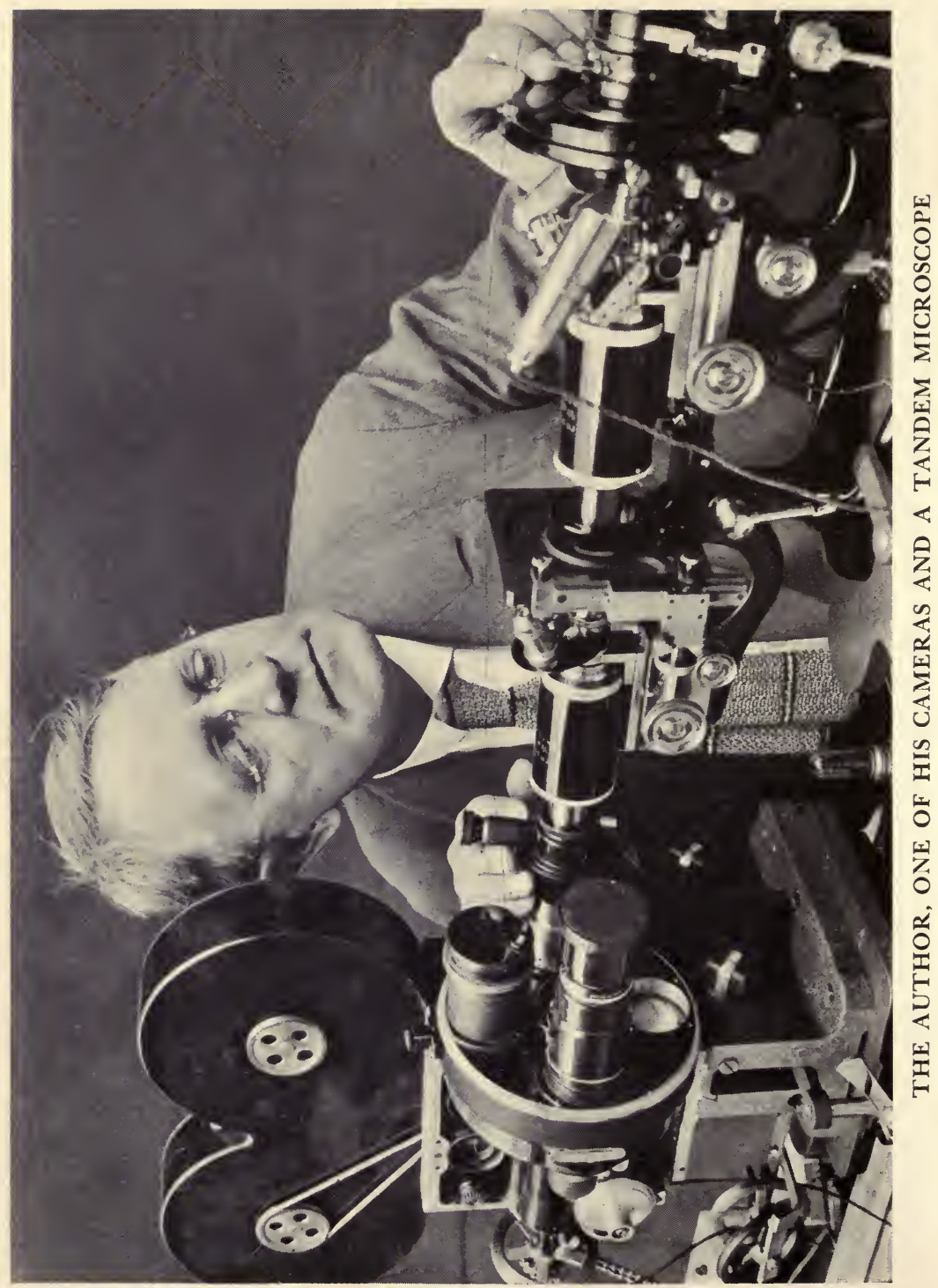




\title{
PICTURING MIRACLES
}

\section{$\mathrm{OF}$}

\section{PLANT AND ANIMAL LIFE}

\author{
$B Y$ \\ ARTHUR C. PILLSBURY
}

WITH 66 ILLUSTRATIONS

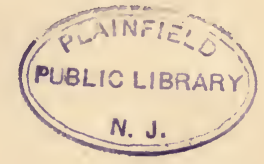

PHILADELPHIA

J. B. LIPPINGOTT COMPANY

LONDON 
COPYRIGHT, 1937, BY

ARTHUR G. PILLSBURY

MADE IN THE

UNITED STATES OF

AMERICA

RMar'37\%
87448 


\section{E D I C A T I O N}

To my dear wife, Etheline, who since the destruction in 1906 of San Francisco and most of our earthly gear, has been my good comrade and inspiration, this book is lovingly dedicated 


\section{F O R E W O R D}

To us, who standing by, have watched Arthur C. Pillsbury's career, the element of adventurous achievement has always been well in the forefront of our observation. Whether, as in its early unfolding, it took him floating alone in his Peterboro canoe, through seemingly endless days and nights down the dark and sullen reaches of the Yukon, or skittering over flashing crests of its Rapids-floating airily in a tiny silken white balloon over San Francisco Bay-"wrestling with the angels" and the Power of Darkness inherent in the muck and slime of a tide marsh landing, but always saving his precious filmsor of many weary miles and days in mountains and plains, gathering thousands of picture impressions of the power and glory which is theirs-of days and years of patient laboratory exploitation through the keen, undeviating eyes of his microscopes and cameras, to bring us his progressive interpretation of many of Nature's beautiful and so nearly hidden ways of the fulfilling of Her design-as his life's work goes out through consciousness, so this record of it is for all who care to know and remember.

Etheline D. Pillsbury 



\section{CONTENTS}

INTRODUCTION

How the Lapse-Time Method Started.

I LAPSE-TIME PHOTOGRAPHY

A Description of Equipment.

II FLOWERS

Their Reactions as Pictured by the LapseTime Camera.

III POLLENIZATION

Peculiar Methods of Several Flowers, and in - Spirogyra.

IV FIRST STEPS IN MICROSCOPIC MOTION PHOTOGRAPHY

The Story of the Spider Lily Pollen.

V MICROSCOPIC MOTION PHOTOGRAPHY

Necessary Apparatus Cost, Tandem Outfit, Special Handling.

VI CACTUS AND SUCCULENTS

How to Tell Them Apart. Experiences in Picturing Them.

VII THE LEAF

A Wonderful Machine. A Journey Across a Leaf $1 / 8$ " Wide.

VIII BREAD MOLD

A Life Story of This Wonderful Plant. 
IX X-RAY MOTION PICTURES

How the First Motion Camera Pictures Were Made.

X UNDER-SEA PHOTOGRAPHY

What Is Required; Wonderful Experiences, Dangers, Etc.

XI MARINE LIFE

The Urechis with Cell Division of Its Egg.

XII A TRAVELING CAMERA

What It Does.

XIII THE FLY

History, Structure, Etc., and Method of Picturing It.

XIV TECHNICOLOR AND OTHER METHODS 191 Methods Described in Detail; Polarized Light and Other Kinds.

XV CHEMICAL FARMING

Growing Plants without Soil or Cultivation, with Instruction and Formula. 


\section{L L US T RAT I O N S}

THE AUTHOR, ONE OF HIS CAMERAS AND A TANDEM MIGROSCOPE Frontispiece

THE GOLDEN-BANDED LILY 22

THE OPENING OF AN IRISH ELEGANCE ROSE 22

LILIES AS THEY OPEN 26

BOTH SIDES OF A LAPSE.TIME UNIT $3^{6}$

BLUE FLAG IRIS

STREAM ORCHID $4^{8}$

MARIPOSA TULIP

SCARLET MONKEY FLOWER

WASHINGTONIAN SIERRA LILY

DANDELION SEED BUDS

EVENING PRIMROSE 52

WATER HYACINTH

EVENING PRIMROSE. HALF DOME IN THE DISTANCE

THE PASSION FLOWER

CALIFORNIA POPPY

AZALEA BUDS

$5^{8}$

RHODODENDRON

60

WILD PARSNIP

62

BLUE LUPINE

62

BROWN-EYED SUSAN IN A MEADOW OF THEM 62

THE INFLUENCE OF STRYCHNINE ON FLOWERS 66

THE INFLUENCE OF ASPIRIN ON FLOWERS 66 WILD PITCHER PLANT 
LADY SLIPPER ORCHIDS 68

SAMOAN GIRL HOLDING COCOANUTS 82

GETTING SPECIMENS OF SPIROGYRA 82

THE MOTION STORY OF SPIROGYRA 86

MALE AND FEMALE CELLS IN THE LONGATTA SPIROGYRA $\quad 88$

$\begin{array}{ll}\text { WHEAT } & 94\end{array}$

BEANS 94

THE AUTHOR IN HAWAII AND THE SPIDER LILY 96

$\begin{array}{ll}\text { SPIDER LILY POLLEN } & 96\end{array}$

MOTION PICTURE OF THE SPIDER LILY 98

THE ENTIRE MICROSCOPIC UNIT 104

A DESERT HILLSIDE OF OPUNTIA 116

HALF A DOZEN KINDS OF CACTI GROWING TOGETHER 116 MOST CACTI REQUIRE TWO DAYS TO OPEN 118

NIGHT-BLOOMING CEREUS 120

VENUS FLY-TRAP 120

LEAF 1/8 INCH WIDE, MAGNIFIED 500 TIMES 128

LEAVES OF BUCKEYE UNFOLDING FROM CLUSTER 128

BREAD MOLD SPORES INFEGTED WITH BACTERIA 136

FOUR BREAD CRUMBS INFECTED WITH MOLD 136

SPORES GERMINATING AND TUBES GROWING 136

SHADOWGRAPHS OF A ROSE-BUD OPENING 144

RAT IN LEAD TUBE $\quad 14^{8}$

$\begin{array}{ll}\text { SHADOWGRAPH OF RAT'S FOOT } & 148\end{array}$

THE HARBOR AT PAGO PAGO 154

THE EYEMO CAMERA FOR UNDER-SEA WORK 156

$\begin{array}{ll}\text { STARFISH EATING } & 15^{8}\end{array}$ 
STONE TREES OF CORAL

$15^{8}$

PROFILE OF ANEMONE

158

THE ANEMONE

160

THE BARNACLE

162

STARFISH EATING. STOMACH ENFOLDING PIECES

164

20-RAY STARFISH

164

WHITE ANEMONE

166

SEA PEN

166

SEA URCHIN

166

FEATHER DUSTER 168

CELL-DIVISION IN THE EGG OF THE URECHIS 172

A TRAVELING CAMERA THAT PRODUCES A STEREOSCOPIC MOTION PICTURE IN NATURAL COLOR

178

UNIT FOR PICTURING IN NATURAL COLOR AND POLARIZED LIGHT

POTATOES GROWN BY PROFESSOR W. GERICKE 


\section{PICTURING MIRAGLES}

$\mathrm{OF}$

PLANT AND ANIMAL LIFE

ลีก 


\section{N T RODUGTIO N}

To explore is to seek, and to picture is to gather the evidence so all can see and benefit. The exploration may be in far, unknown countries, the ocean bottom, or minute life under the microscope. To picture plant and animal life and its movements has become the life work of the author.

Movement in plant life was known but not understood or registered to any extent until the lapsetime camera was used to picture it. This opened an entirely new field of research explorations.

Beauty, Form, and Color, the Rhythm of movement, express art everywhere. The story of a bud opening, a leaf unfolding, a seed germinating, all the various steps of its life struggle for perpetuation, is as interesting and poignant as one's own life's happenings. Step by step the lens has registered on a sensitive film of a lapse-time, motor-driven motion camera, recording in that way in a comparatively few seconds life efforts that may take days or even weeks to happen.

A book is written, representing years of research and thought; you read it in a few days. A flower grows, a season's combined efforts of sunshine, water and soil. The result, seeds to carry on to another 
year, perpetuating its life of beauty and usefulness. Only a few can see it, but a motion picture, starting at either end of its life history, shows one step, then another. Later they are joined in their natural sequence, and in a few moments the story is told, to be seen.

Man looks at a flower in passing; the eye would soon tire in trying to watch its growth or change of position, but the lapse-time camera, running at a speed to record in the time we have to see it, registers every change of position day and night with a tireless lens eye, and all from the same chosen position, writing on the film what happens in lines, expressing position, growth and color until finally death, or better call it, when its parts have fulfilled their life's duty, passing on into another form.

A beam of light for a brush, a silver salt for paint, a transparent ribbon of celluloid for the canvas, chemicals to render it visible and permanent, the thousands of individual sketches, taken at uniform intervals of figured seconds or minutes, then projected some 1,440 a minute on the screen, the result, true and lasting representation of form, color and also sound.

Such are the modern results. Starting as I did, in the corner of a small crowded room, with a homemade camera run with a small motor, fitted with a 
reduction gear of changeable speed, each flower subject an unknown problem, as regards time of opening, speed of growth, size at maturity, combined with elements of photography, lighting and correct exposure, the after treatment of negative and print and combining all of these and many others to get an artistic, pleasing result. In the forthcoming chapters I am going to endeavor to tell you how each one was handled, how the picture was painted.

My photographic experience when I commenced my flower work in 1912 was varied. As a student at Stanford University, where my "Major" was mechanical engineering, where President Hoover was a classmate, I snapped with the smallest box kodak, a class rush, making sixty good pictures in that exciting hour. Over two thousand of these tiny solio prints were sold. That led to larger cameras-a $4 \times 5$, then an $8 \times 10$ plate camera-that had been taken for a debt; the bellows leaked, it had no shutter. I patched the bellows, designed and built a shutter which gave the foreground, where it is needed, more time than the sky. It worked wonderfully well, and was worthy of mechanical refinements, and presentday use. Then I got the idea of a panorama camera, which my professors said would not work-that the idea was wrong-that the image would blur with a moving lens. I went ahead with the idea, designed 
and built it, but did not apply for a patent: the first revolving lens panorama camera, one taking a picture $10 \times 3^{6}$ inches, embracing almost a half circle.

On the strength of the pictures made with this camera, I was appointed Official Government Photographer with the Census Bureau in Alaska during the gold rush in '98 and '99; then three years on the San Francisco Examiner, after which I entered into business for myself, making the only set of pictures of the actual burning of San Francisco, then balloon pictures of the ruins of our beloved city by the Golden Gate, and the only successful pictures among hundreds of competitors, of the arrival of the Fleet. Building up a great business in scenic pictures as official photographer in Yosemite National Park, at this time, I designed, made and had a patent granted on an automatic photo printing machine that reduced costs of photographic work over three fourths and improved the quality greatly. From 1906 to 1927 I held a government photographic concession in Yosemite National Park, where in 1912 I started taking motion pictures of the wild flowers of the Sierra. I had bought an old, almost worthless camera, remodeled it and began getting scenic pictures. Those of the waterfalls were wonderful, full of action, but the grand old cliffs were not as good, having no movement except that shown by the jerky move- 
ment of all cameras of those days. I conceived the idea of making the individual pictures in the film at one or two second intervals and at once my pictures of the cliffs sprang into life, the clouds went drifting by and their shadows on the cliffs added to the lifelike appearance. It took much more skill to judge the speed of the clouds in order to produce on the screen a slow, steady movement-otherwise they would race across the screen when projected at the normal rate, then, of sixteen pictures a second. The method had wonderful possibilities for all sorts of slow moving subjects.

At this time I had made still pictures of many of the Sierra flowers, and they, like motion pictures of the cliffs, lacked life and movement. So I decided it was feasible to do in motion pictures of the flowers what I had done to the cliffs in giving them action, picturing the movements of the clouds and cloud shadows on their stationary sides. The flowers had their own natural movements if I could only picture them.

It was, of course, impossible to make pictures at uniform intervals by hand day and night, of the flower buds as they opened, nor could it be done out of doors, as the wind would blow them about between exposures and the light could not be uniform. So I designed a motor gear to run the camera and 
arranged so that I could get any speed I wanted transmitted through a belt to a wheel on the camera that replaced the crank.

Having figured out these requirements, I kept notes on the flowers, when they started to open and how long it took. I realized a scene had to be very dramatic to hold the interest for over thirty seconds, and a film thirty seconds, or thirty feet, long contains 480 individual pictures, so if it took a flower four days to open it was only necessary to divide the 5,760 minutes in four days by the 480 desired pictures, which gave twelve minute intervals between each picture. Now, since sound on film is almost universal, projection speed has increased to 1,440 pictures (ninety feet per minute) and a new exposing formula developed to give the correct footage required.

I soon found that flowers if properly handled would live and grow in my laboratory by electric light, just as they do out of doors in their natural habitat; that they opened and closed at their accustomed hours. I found I could almost set my watch by their opening, so regular was the accomplishment of their processes of survival.

The mastery of all this phenomena of floral life required a great deal of time and study. My training in mechanical engineering at Stanford taught me to look on each step as an engineering problem-to 


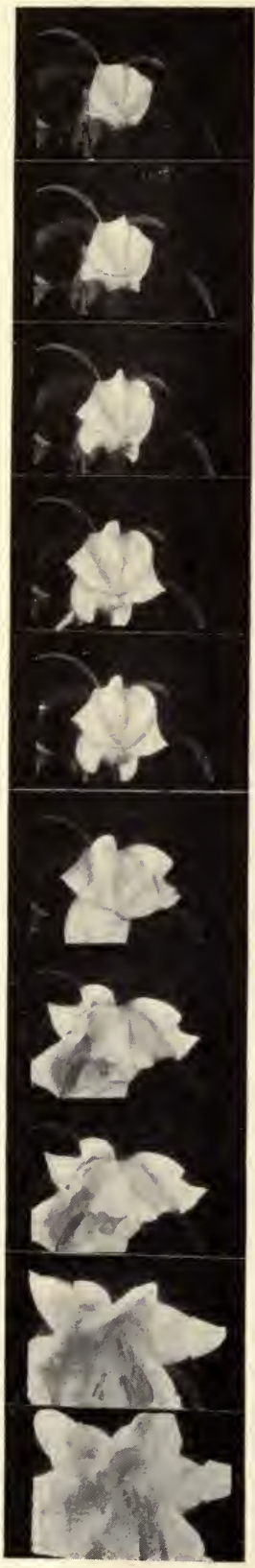

The Golden-banded Lily

The Bud clings together at the Tip until it suddenly Flies Apart and is soon Wide Open

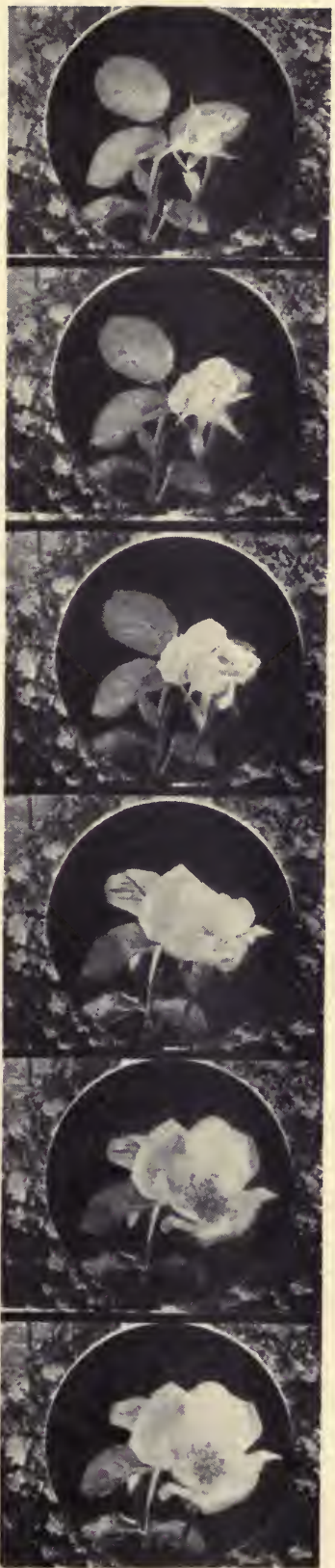

Stages in the opening of an Irish Elegance Rose 
. 
work it out from that standpoint, the mechanical steps first, designing a reduction gear that would run constantly day and night with the least liability to accident and the necessary changes of speed for the fast or slow growing flowers. If the flower grew faster or slower at certain periods of its life, or if the actual dying or changing into its seed pod took too long, I must speed it up on the screen by slowing the camera down.

The first motor gear I built is still running after twenty years of service. The motor has worn out and been replaced twice, but the gearing is as good as ever.

All the steps in this lapse-time photography presented their many difficulties which must be overcome-the lighting, the effect of the light on the growth of the plant or flower, the tiring of the plant by the continuous twenty-four hour duplication of day, what its size and position would be on the film during its entire life and the correct exposure at the various speeds at which the camera was running. A motion picture camera exposes the film by a revolving shutter passing in front of it, the open part of the shutter allows the light to pass and make the exposure, the solid part stops the light while the film is moving forward for the next picture. So the amount of light is governed by the width of the 
opening as it revolves, the speed at which it passes the film and the lens opening and also the brightness of the illumination. So if the camera is running very slowly on a slow growing flower the width of the slot, or open part of the shutter, must be very narrow and the lens diaphragmed down to a small opening. Only a great amount of experience with infinite patience will teach these various steps and the success of the picture must depend greatly on the ability to foresee how it is going to look at all stages of its pictured life.

The kind of film and color screen used governs the correct color rendering. The red flowers require a much greater color separation than yellow or white ones. Now with panchromatic film and a careful use of Wratten filters it is possible to get a red flower and its white seed pod side by side and obtain the correct color values in each. This, of course, does not mean that the picture would be in its natural color, but in a true color rendering in the black and white tones, and red or yellow flowers would not print black as they do in using the old type kodak film.

This early work was carried out as a hobby in my Yosemite studio. Only the most cramped space was available-the camera on a narrow shelf so it could slide back and forth, the flower in the corner and just room to squeeze in beside the camera to focus 
it and tend the flower. The results were shown in the little evening entertainments we gave the Yosemite tourists on our open porch. A few flowers at first, the number increasing year by year, until all of the more distinctive ones were pictured. Combining these with a reel of scenic pictures and a few slides constituted our contribution to service for the tourist. It was this training, operating the projector, stereopticon and talking at the same time which has enabled me to finance, from lecture trips, the very much more scientific work developing from this small beginning.

One of the first reactions of seeing a reel of flowers growing and opening was to instill a love for them, a realization of their life struggles so similar to ours, and a wish to do something to stop the ruthless destruction of them which was fast causing them to become extinct. At that time no attempts were made to protect the flowers in any National Park, but soon enough agitation was started to show the necessity for it, and Mr. Lewis, the superintendent of Yosemite, asked me to name six flowers most necessary to protect. This was done and the next year six more were added to this number.

About that time Wild Flower Conservation Societies took up the matter, and women's clubs all over the country were interested in protecting them. 
The Yosemite Park service had been mowing the meadows for the small amount of grass they could get as food for the service horses, killing off the meadow flowers in that way. It happened that there was a conference of Park Superintendents and the Director of Parks in Yosemite that fall. I showed my pictures, talked conservation and the necessity of all parks to protect them as a very valuable asset. I had still pictures of the meadows taken in early days in '95 showing them covered with flowers waist high and the same meadows as they were at this time. As a result, the next day all flowers and all living things were protected in every National Park, and the mowing machine, as the people in Yosemite expressed it, "was put on the blink."

Over 1,200 flowers have been botanized in the small area of 1,400 square miles, perhaps a larger number than in any similar area in the world, starting as it does at 2,000 feet elevation and going up in zones to over 14,000 feet. It gives almost every possible climatic condition, so if you are too late to find a flower in one elevation zone, it may be at its prime in the next one above. Obviously Yosemite was a wonderful place for my special hobby, but the hobby outgrew its swaddling clothes. In other words, the average flower took four days to picture and often a week, and as a result thirty seconds on the 


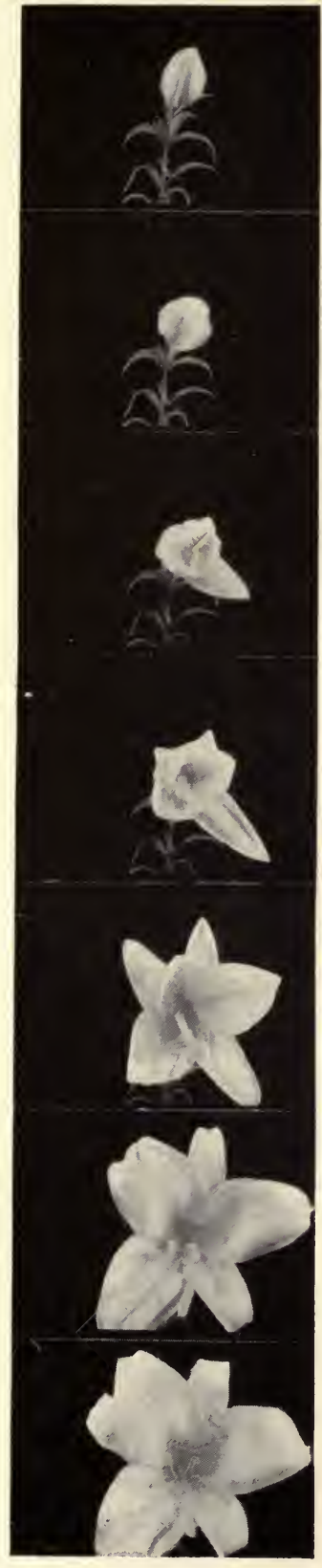

Lilies as they Open The Bud Giving Promise of the Beauty of the Flower

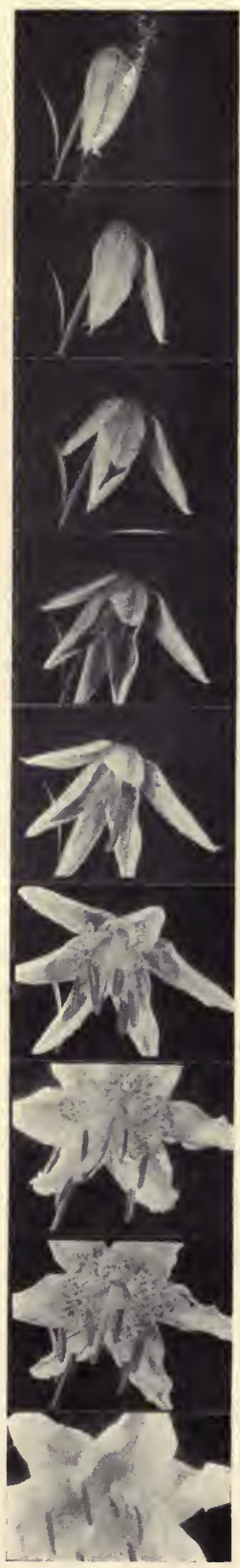




\section{.}


screen, with one camera running all the time day and night for the season, was only about ten minutes total result on the screen, and I was always needing the camera for out-of-door pictures showing the flowers in their natural habitat, when my only camera would be tied down on a long run on some slow opening flower in the laboratory.

The first crude camera had long since gone into the discard, one made to order taking its place, then a Pathé, followed shortly by an Ackley which proved ill-suited for my special work and which was too heavy for field work. The Professional Bell and Howell, costing about $\$ 2,400$, was the ideal equipment for the laboratory and field if the location could be reached by car or horse. Then the spring motordriven hand camera came out and the Bell and Howell Eyemo made it possible to reach the more inaccessible places on foot, but the camera for $m y$ special kind of work has not yet been put on the market. It must have a way of focusing on the aperture on subjects within one or two inches of the lens. It must have an adjustable shutter, giving control of the width of the shutter opening, and it must have motor spring, crank and one-to-one drive and be within reasonable weight limits. It is hardly possible enough camera men would want a standard size 
camera with those attachments, so it would not pay to make it.

Some of these devices I have made and installed on my Eyemo and all the others will be, before my next intended trip, so all the other cameras can be running in the laboratory on the lapse-time subjects and one camera can do every possible kind of outside work. 


$$
\text { I }
$$

LAPSE-TIME PHOTOGRAPHY

ข้อ 


\section{I}

\section{Lapse-Time Photography}

BEFORE starting in lapse-time picture work one should be well grounded in other branches of photography, an expert in judging the correct exposure under all conditions and the dramatic value of a picture, in timing the camera to produce in a condensed form the action that may take in life minutes, hours, days, or weeks to happen, and which he wishes to show in a given number of seconds. The added expense may be nothing if the work is done by hand for short action pictures, and the more complicated lapse-time units may be homemade if one has mechanical ability. I have seen all sorts of devices, from water dripping into a balanced tank that tipped over when full, tripping the camera to make one exposure, to electrical methods that worked (sometimes).

If one wishes to picture cloud movements, a sunrise or sunset, the hand method is advisable, as exposures made at two or three second intervals, unless the clouds are moving very rapidly, will give in half an hour's time some twenty seconds on the screen. A football stadium taking an hour to fill up 
may make an interesting picture, lasting thirty seconds when projected. So first estimate the time the action will take and then make uniform exposures by hand, using a rigid tripod or support at the exposure intervals to give the required footage without any additional expense, only a little labor and patience. But if growing plant life is to be pictured, a mechanical device is necessary. It would hardly be possible to make uniform exposures hour after hour for even a week that most flowers would require. It is, of course, necessary to have a camera capable of making one picture at a time either by turning a crank or otherwise, and in getting an outfit the most important step is first to get a good one, equipped with all the mechanical attachments necessary. There is no economy in getting poor tools and expecting good results. It could not be done. So I would advise, after deciding on the size of film you wish to use, getting the best one obtainable. On the market now are the Eastman Special, described in chapter on Technicolor and Other Methods; the Bell and Howell, and a few others not so well known. Go to the dealers and have them demonstrate these goods. You want a camera taking $16 \mathrm{~mm}$. film, making with motor spring drive exposures from eight to sixty-four a second, and at one winding about forty feet of film. It should have, among 
other things, an adjustable shutter from closed to wide open; a hand crank making eight pictures a turn; also a one-to-one shaft for lapse-time work. It must have a detachable magazine or method of focusing without exposing the roll. One cannot estimate the position or focus of subjects a few inches from the lens by scale. It should have lens extensions enabling a focus from/infinity to an inch or less from the subject. An outfit doing this cannot be had for less than $\$ 500$ at present. For lenses the camera should have a wide angle, of one-half inch focus; the regular one inch one and a telephoto of two to four inch focus, all of the best make and fastest speed. The telephoto will be used the least but is very necessary when required. Also an extra magazine is very necessary if doing color work, as one can be loaded with Kodachrome film and the other with type A Kodachrome for pictures made with artificial light.

My present lapse-time motor gear is an evolution from the first one. When I started the work I had a continuous running motor, geared down so that by shifting belts I could get a change of speed from thirty pictures a second in microscopic work to thirty minutes between each picture. The lights were shining on the subjects continuously, burning considerable electricity, and tiring the plant. The continuous running of the motor, from days to weeks at a time, 
soon wore it out so that if a light burned out, a belt broke, or the motor ran hot-or any of a dozen other things happened-or if the plant refused to grow, the picture was spoilt and it all had to be done over again. Then as it was necessary to change the speed intervals, that meant changing the exposure which was very difficult to control to get a uniform negative of many hundreds of pictures. The exposure is made by an adjustable slot moving by the film. If the intervals were short, it moved rapidly and at twenty or thirty minute intervals you could hardly see it move. So control of the exposure was done by narrowing the width of the slot-a very difficult way of getting the correct amount of light on the film. If the slot were $1 / 8^{\prime \prime}$ wide and it took several minutes to revolve by the film, it was quite a different matter from one which was 2 " wide passing in perhaps less than a second.

So the engineering problem was: How to get uniform exposures regardless of the intervals at which they were taken, and to be able to change the exposure intervals at will, depending on how fast or how slowly the plant or subject was growing or changing its position. I bought a small telechrome motor for \$4. Its shaft projected out about an inch and made a revolution in one minute when connected up with the electric light current. A small 
one-to-thirty worm gear was connected up with it that made its shaft make one revolution in thirty minutes. A good-sized wheel, 6" in diameter, was fitted to it and then taper pins were carefully fitted into its rim all equally distant from its center. One pin would pass a given point every thirty minutes, or as they could be put in as close together as required-they could be close enough to have one pass every minute, or 5-10-20 or 30 minutes, as often as desired. Just above this slowly revolving wheel was hung a pendulum-like rod. At its upper end, projecting above the wheel, a mercury tube switch almost balanced was installed. The pegs in the wheel came along slowly, hitting a projecting arm on the pendulum and caused the mercury to run to one end of the tube, which made an electric connection without sparking. This started a small motor that was geared down to make a shaft run one revolution in thirty seconds or a minute, as I desired, while the long end of the pendulum was lifted up and held at its highest point, high enough to keep the mercury in its end of the tube giving an electric connection, running the small motor connected with a reduction gear-running it until it had made one complete revolution. This one revolution was connected with a chain belt and sprockets to the camera, giving one picture or frame. At the same time the motor started, 
the electric lights came on, giving the correct amount of illumination required for the exposure. Just as the same shaft that was connected with the camera by its chain belt made its complete revolution an arm kicked off the holding lever of the pendulum. Stopping itself it would swing back to its vertical position, the mercury would flow away from the connecting end of the tube without a spark as most switches do when the current is broken (the sparking soon corrodes and gives trouble), the lights would go out, the motor stop and nothing more would happen until the next taper pin in the so-called clock wheel came along and started the chain of operations again-in one minute or in 30 , depending upon how many taper pins you had in the wheel. This description may seem complicated but by looking at the picture you will see that it is very simple, and the camera always takes the same time for each exposure, regardless of the interval between them which can be changed by removing or inserting more taper pins. If the rim of the wheel is at least $1 / 4^{\prime \prime}$ thick and the standard taper holes made carefully, just putting them in with the fingers will hold them, or small screws will answer the same purpose.

It is very simple to make a device that will start a motor and camera, but the trouble comes in getting it to stop at just the right moment, and with the 

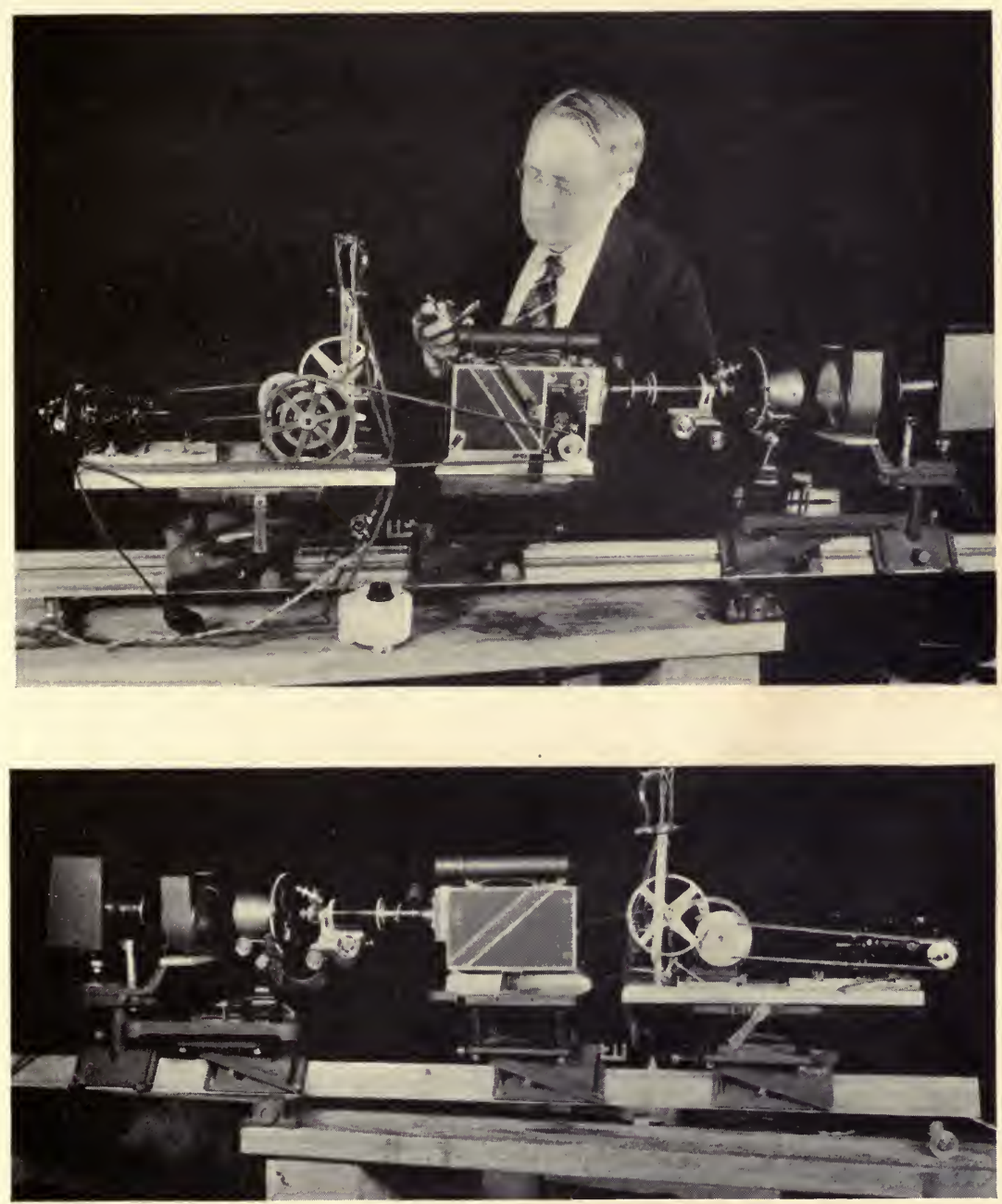

BOTH SIDES OF A LAPSE-TIME UNIT

Camera, Microscope, Dark Field Illuminator, Water cooling Cell and Light for Picturing any Subject in Natural Color 

chain belt and the device above you are sure the camera shutter is always closed when it stops, and a uniform exposure given.

Holding the pendulum up is necessary till the shaft that connects with the camera has made its complete turn, otherwise the pendulum would drop down, breaking the connection as soon as the taper pin in the moving wheel, that lifted it, had passed. If the wheel is carefully made with the pins all equal, it will swing the pendulum just a little higher than the point at which it is caught and everything works without a sound and is positive.

I have made a dozen or more of these lapse-time devices, but this is the simplest and cheapest and can be made to do all sorts of things automatically day and night. If I am running on a long story of three months' duration, like from seed to fruit, which will show on the screen in perhaps a couple of minutes, a second and stronger motor can be connected and if the plants are growing in a greenhouse it can be converted into a dark room. Electric lights come on, giving the uniform exposure day and night, a picture is made, the lights go out, and the dark room becomes a greenhouse, allowing the plants to grow in natural conditions for twenty or thirty minutes and then for perhaps three minutes the chain of operations goes on again, keeping it up day and 
night. In such a long run, where a camera is tied down for that length of time, every possible precaution should be taken to get the best results; lighting effects, a test exposure made, and everything fastened securely. Then with inspection and oiling the parts and watering the plant, the film and exposure part is so exact in uniformity that you can be sure of good results from the photographic standpoint. For the plant you must have anticipated everything it will do-growing to fill up the frame of the picture-and have provided all of the accessories that it will require, and not have to build a trellis or other things after the picture has started. The beauty and smoothness of a picture depends upon the care exercised in its preparation and the amount of film used in each stage of its life.

Deciding upon the proper interval used to make the exposures governs the success of the result very greatly. If the intervals are as long as thirty minutes most plants will grow and sway considerably in that time so the result will be jerky on the screen; if the interval had been twenty minutes the action on the screen might have been too slow but much smoother. It is seldom in growing plants that pictures can be made successfully at as great an interval as thirty minutes. An orchid that grows very slowly and with very little swaying movement can be pictured at that 
speed, or even at intervals of one hour. A four-week run at two pictures an hour, giving 1,440 pictures or sixty seconds' run, will, if done in natural color, give a picture that will hold the interest for that long, but it must be especially good to be worth even thirty seconds' time on the screen, which would have meant one hour inter vals for a period of one month.

In California the average wild or cultivated flower takes five days to make-that would mean at ten minute intervals, six pictures an hour, 720 in five days-and at twenty-four pictures a second, the standard projection time in the theaters, thirty seconds on the screen. If the same rule were followed for $16 \mathrm{~mm}$. and the projection speed was on the old basis before sound came it would mean forty-five seconds' projection time, rather too long or slow. So in making lapse-time pictures you must figure what you are making them for. Our present standard speed is twenty-four a second, or as a home product is sixteen a second-each method has its uses. For lecture work a series of lapse-time pictures at sixteen would drag. If the same were shown at twenty-four some would complain that they were too short, which is always a good criticism. So in making your lapse-time pictures you must know when the bud starts to open, day or night; how long it takes before the petals fall; how much of it is worth picturing-as sometimes its 


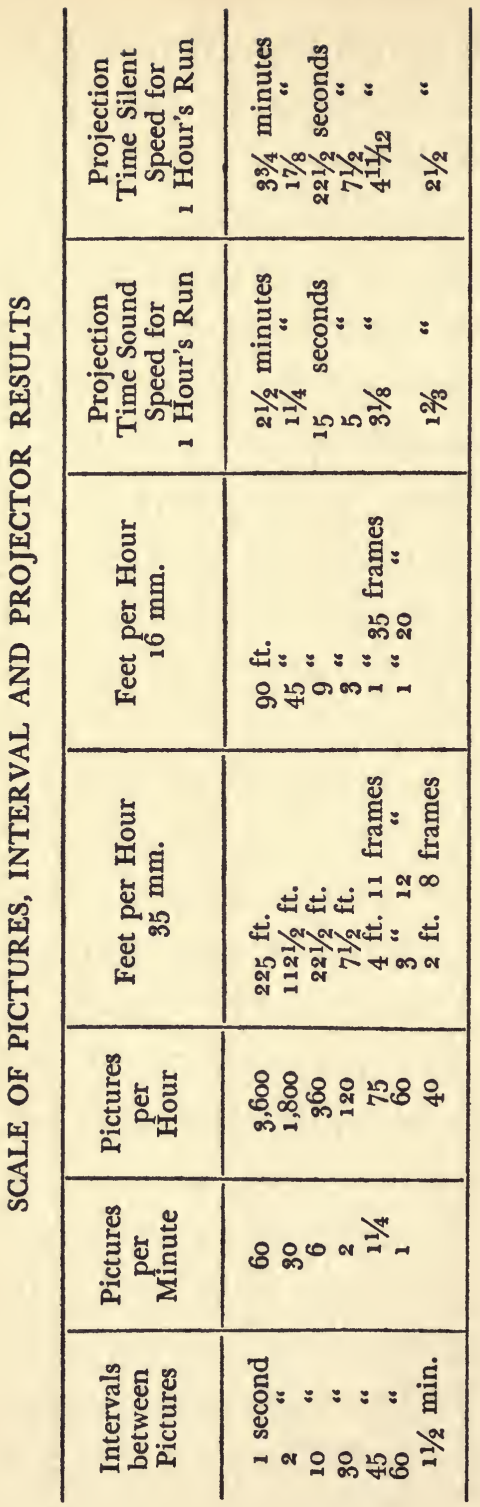

\begin{tabular}{|c|c|}
\hline 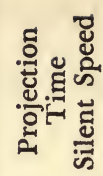 & 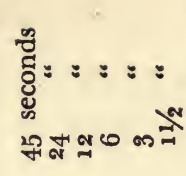 \\
\hline 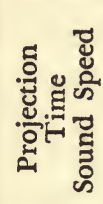 & 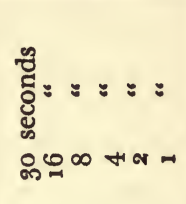 \\
\hline 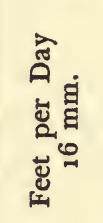 & 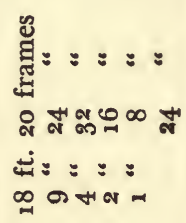 \\
\hline 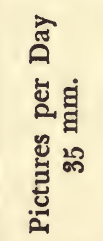 & 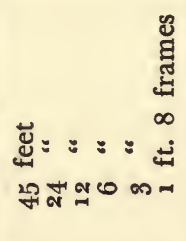 \\
\hline 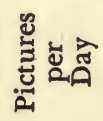 & 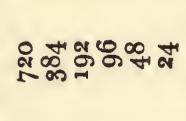 \\
\hline 总 & 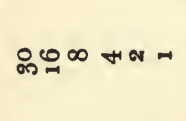 \\
\hline 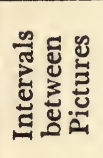 & 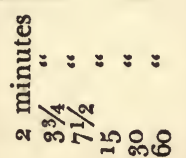 \\
\hline
\end{tabular}


death is more dramatic than its birth; and then how long the entire picture will hold the interest. No matter how short the picture is, if it is sold to a distributor (like Paramount) you will be surprised how they will cut it and still keep its high lights. As they buy by the cut foot you are sure the picture is ruined when the check comes, but when you see it on the screen it tells its story very smoothly.

From the scales given it is easy to figure out any required projection run for the subject. For example: At sound speed of 24 pictures a second, fifteen minute intervals for a week would be twenty-eight seconds on the screen which is ample for almost any flower opening if it takes a week for it to open. If it takes only one day, two minute intervals would give thirty seconds on the screen, and a picture must be wonderfully full of action to hold the interest for over thirty seconds, and both 35 and $16 \mathrm{~mm}$. pictures may be projected at either sound or silent speed, with the same comparative results, but much smoother at the sound speed. 
II

FLOWERS

⿵ี丶⿳一由八 


\section{II}

\section{Flowers}

IN writing of flowers and botanical subjects, I am doing it not as a botanist but as a student of the phenomena of plant life and the subjects described are a few of those I have seen and photographed. Intensive work on any subject tells its own story.

Of the Flowers of Yosemite the Snow Plant bears the same relationship to the people of the western coast as the Night Blooming Cereus does to the people of the Hawaiian Islands. A striking red spike, barren of leaves, but having bracts that are fringed with white and look as though they were frosted. The bell-shaped flowers often have their openings covered with the bracts till the pollen is ripe or the stigma receptive. There is something lacking in either its method of pollenization, or the insect especially adapted to act as its agent in that necessary duty, as its seeds seldom germinate. No definitely conclusive research work has been done on the snow plant, so we cannot say just why it is becoming more rare. It is a saprophyte and not a parasite as was at first believed, getting its substance from decaying vegetable matter. Appearing in the early 
spring months, seldom lower than 4,000 feet elevation and on up to 9,000 feet, the plant sometimes of only one or two spikes and as large as your wrist pushes up through the leaf mold under the pines, and grows to a foot or eighteen inches high. Occasionally it grows in clusters as large as eighteen inches in diameter with twenty-five or more spikes. The red spikes grow about an inch a day. Motion pictures taken at fifteen minute intervals for a week show the plant growing up through the picture in about thirty seconds and they also show the bracts moving away from the opening of the bell-like flowers.

The snow plant was one of the first flowers to be protected in Yosemite Park. Its brilliant red color and isolated habit made gathering it a temptation. There is now a fine of twenty-five dollars for picking it and it is also protected by a State law in California.

The Western Blue Flag Iris grows in great quantities in the Yosemite meadows, which during the blooming season in June are sometimes blue with them. The plant grows in clusters a foot to eighteen inches high. The buds, as large as your little finger, start to open about five o'clock in the afternoon. In the morning, when they have fully unfolded, they are wonderfully beautiful-just for a day is this beauty, for by nightfall they begin to fold up, their 

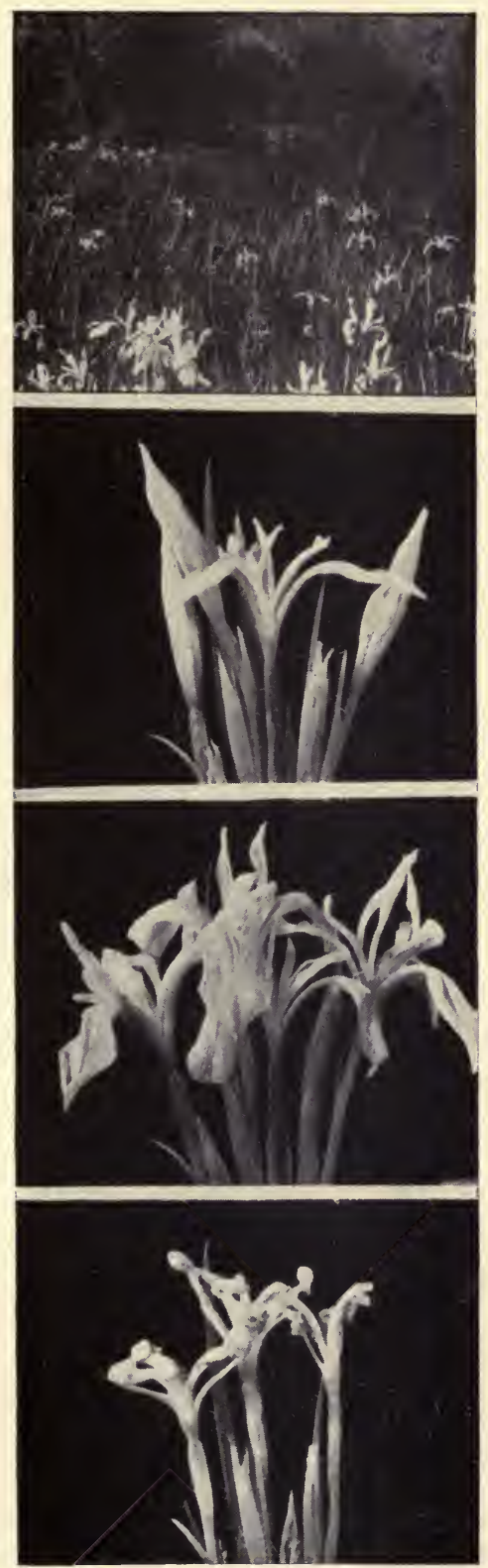

BLUE FLAG IRIS 
petals twisting into a hard knot, and pass on to a seemingly reluctant death, far more dramatic to witness than their birth. It is almost as though they were suffering. The pollen of the Iris is rather hard to germinate artificially. A small percentage of the grains start in water with $45 \%$ of sugar, but most of the grains explode in the process. The pistil develops into a large seed pod held vertically all winter; although the pod may split open, the seeds are still held in it until the spring rains rot the plant stalk and it falls over, allowing the seeds to run out into the damp soil. This Iris grows well scattered over the Pacific Coast States and I have seen great quantities of it in Nevada.

The Blazing Star, Mentzelia, grows in rocky river washes-rather an uninteresting, sticky, unfriendly sort of plant, two or more feet high, with gray-green leaves. The blossoms make up for the lack of beauty in the plant. They open into a lemon-yellow cluster of wonderful stamens that are all folded inside the petals and straighten out into a wide topped tassel. As the yellow petals open the orange colored and queerly shaped anthers wave back and forth, producing a wonderful effect. These blossoms are often six inches in diameter, attracting attention wherever growing. A first cousin grows well up on the mountain sides, too, often in great masses, but the blos- 
soms are not as large nor the petals as sharply pointed. They are more delicate in color and the plant not growing so tall is less noticeably interesting.

The Stream Orchid. Most of our wild orchids are now so rare in California it is quite an event to find a colony of them. They used to grow quite plentifully near the foot of Yosemite Falls, almost in the spray. Now I know of only one place to find the delicate greenish blossoms so beautifully touched with pink and orange. You are fortunate indeed, if after diligent seeking, you find a colony growing on a river's bank, their thin graceful stalks arched over the stream. These flower buds in the laboratory require four or five days for full blossoming. The Phantom Orchis, growing in the dense timber at about 7,000 feet, is another rare one. I have seen the ghostlike plant but once in my many years of tramping through the Sierras. This plant, six or eight inches high, was pure spectral white, something like the Indian Pipe. It is a saprophyte, living on decaying vegetation in the dark forest.

I will never forget the first Lady Slipper Orchids I found in Yosemite only a few steps off the beaten path on a hillside of wet red soil, streams of water oozing from the melting snow, a dozen or so in an area of not more than 20 feet. After looking at all of 


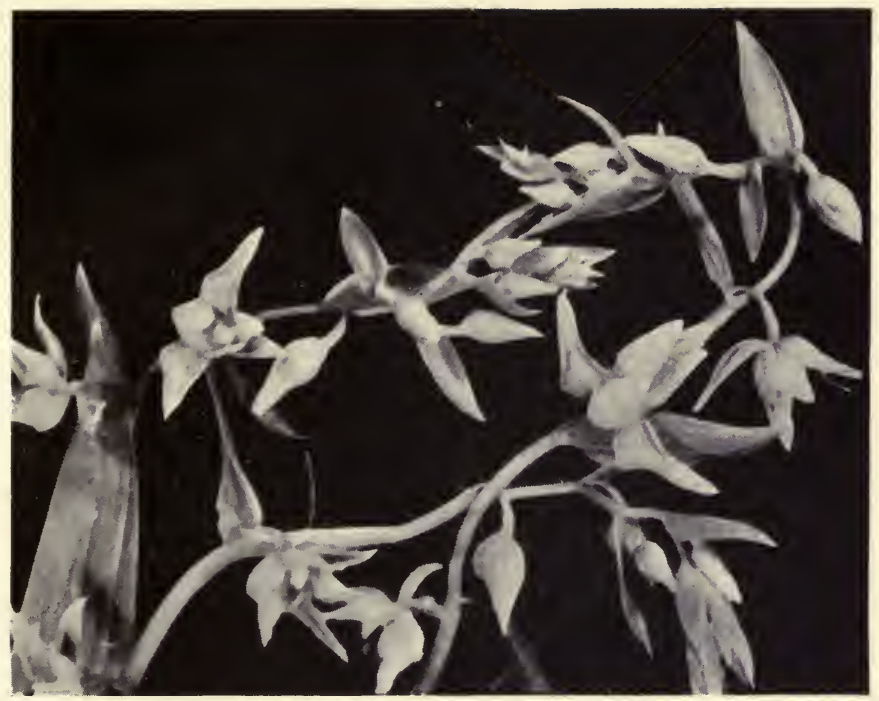

STREAM ORCHID

It has now almost Vanished from the Yosemite

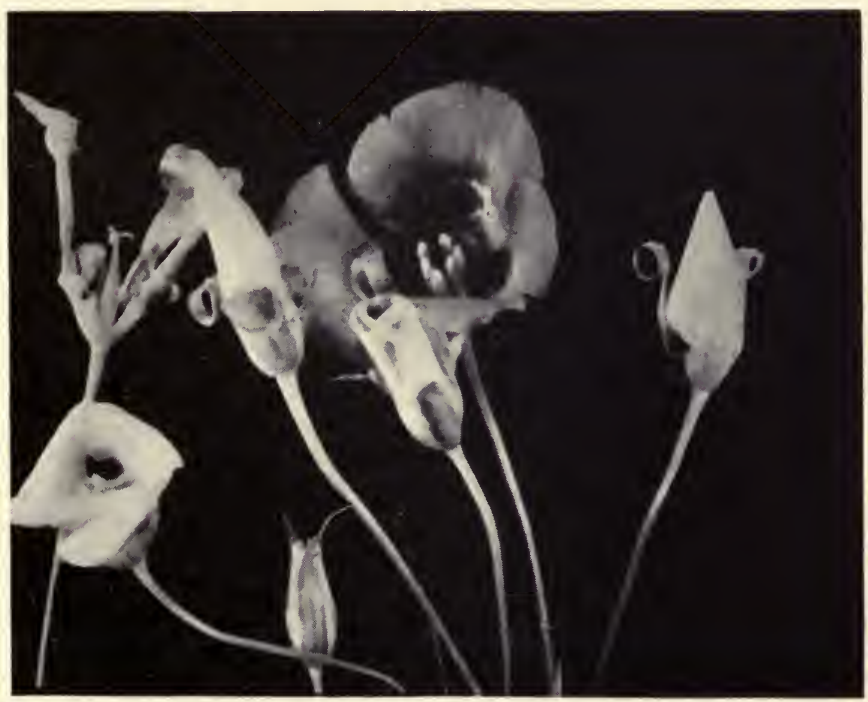


them, I carefully selected and took home one plant with two buds for my picture work so others might see it open and grow as the camera registered its slow development. That was my first experience with Lady Slipper Orchids and I did not know it took an average of three weeks for them to open. As the camera was timed for a four-day growth and as orchids depend greatly on their color for their beauty, the picture shows little action.

Mrs. Michaels, Yosemite Park botanist, and a true bird and flower lover, had shown me an owl's nest with two baby owlets. She made me promise never to go near the nest if anyone else was near, so I made her promise she would not pick or tell anyone of my Lady Slippers.

The Mariposa Tulip, next to the poppy one of the best-loved flowers in California, is of an infinite variety of colors. There are about fifty-two varieties growing from sea level up to eleven and twelve thousand feet elevation. I have seen them with a band of gold across each petal, exquisitely beautiful, colors varying through shades of reds, purples, yellows and white, always with its ever present crescent of rich, deeper hues. The buds open rather rapidly in the early morning hours. Their near closing every night is followed by a reopening the following day on to the fourth day when the petals drop off one by one, 
while the pistil grows rapidly into the seed pod within the next three days. These growth movements showing the petals waving back and forth are visible only in lapse-time motion picture work, and might well give the student of plant life pause to ponder the why and wherefore, for every movement has its meaning if we can but reason it out, in that continuous struggle of carrying on and of reproduction.

The Washingtonian Sierra Lily. You will find this Lily up in the higher mountains at elevations of seven or eight thousand feet. It grows up through the chinquapin and the manzanita brush. Often they are eight or ten feet high with a dozen blossoms on a single stem. The slightly greenish white blossoms are like most lilies in opening, the petals clinging together at the tip till the pressure gets so great they fly apart and the blossoms suddenly open. This Sierra Lily is very regular in its habits. Almost at eight in the evening that intensely interesting period happens and I know of nothing more absorbing than to watch that opening struggle. The fingerlong petals split between each one of them and the bud often gets twice as large in diameter, arching up in the center. You sit breathlessly watching, wondering how soon the petals are going to fly apart at the tip. Sometimes only one will break loose but usually all 


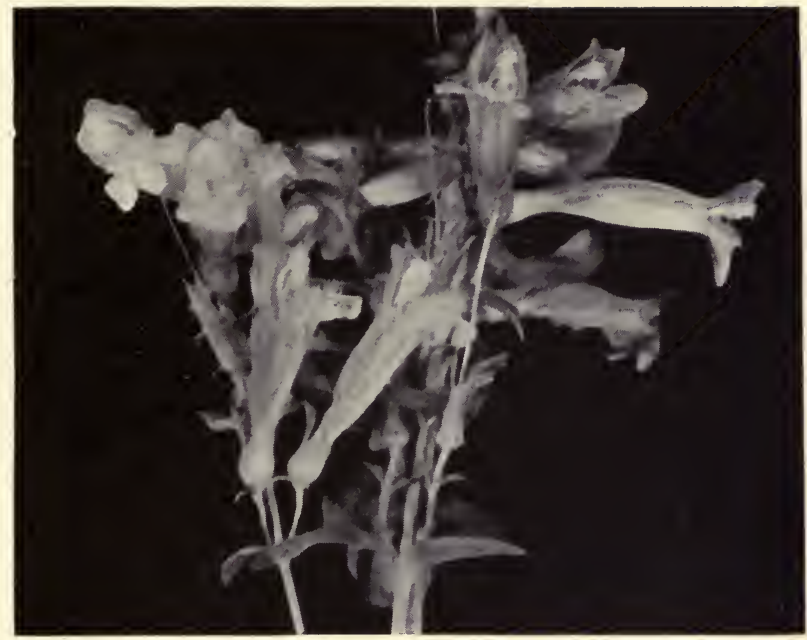

SCARLET MONKEY FLOWER

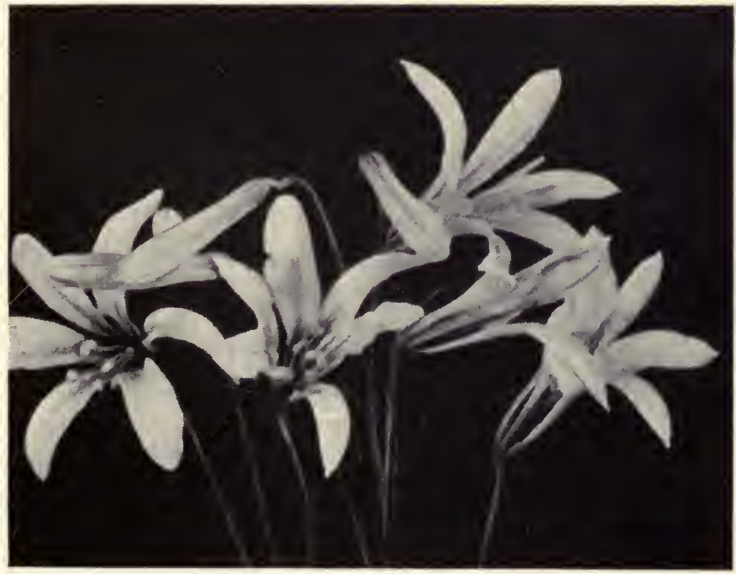

WASHINGTONIAN SIERRA LILY

It opens on Schedule at 8 o'clock in the Evening 

will let go at once and they fly back half way in an exciting moment. The anthers at once assume a position crosswise to the stamen and hang as though they were balanced on a tiny point. They commence to shrink in length, then they split down the middle and turn themselves inside out, leaving the pollen exposed as it ripens. This takes an hour or two and when fully ripe they are perhaps two-thirds as long as at first and balanced so delicately the slightest wind rocks them back and forth. They shed a good portion of their pollen and the blossom will last longer if they are not allowed to drop it on the stigma.

The flower or blossom is to most of us the one great and important thing in plant life. Most of our efforts with flowers are trying to improve by enlargement, color, odor, or arrangement of its parts; some one thing that will bring it into a separate class. The work that has been done by flower lovers is almost beyond comprehension. In Hawaii, for example, everyone loves flowers and out of three rather unpromising forms over six thousand named varieties of the Hibiscus, their territorial flower, have been originated.

Flowers have innumerable forms, colors and odors, but essentially they are the same. Given parts may be lacking in some forms. They may be bisexual 
or have male and female blossoms on the same plant, or the entire tree may have that distinction. A perfect flower having all the essential parts would have a calyx, or protection for the bud, the petals, few or many, the anther and the pistil.

Reproduction is carried on in several ways. The most common method is by fertile seeds and every part of the blossom and its movements are pre-ordained to that one end, to some way, somehow, transport its pollen grains from its anthers to the stigma of a similar flower and receive the tiny golden grains from its brothers and sisters in return. I have found the whole life story of a flower as dramatically intriguing as to watch nature unfolding step by step in our own lives or follow it chapter by chapter in a well-written novel.

Watch the struggle of a large bud to open. Make notes if you really wish to observe all and remember all that happens. Very little visible to the unaided eye occurs until just before its natural time of opening, which is always the same hour of the day or night, remarkably uniform in its habits. Fully ninety percent of the wild flowers start to open in the early evening or very early morning hours. One could set his watch by their opening or closing, their habits are so regular. Picking or digging them, bringing them into the laboratory and putting them in front 


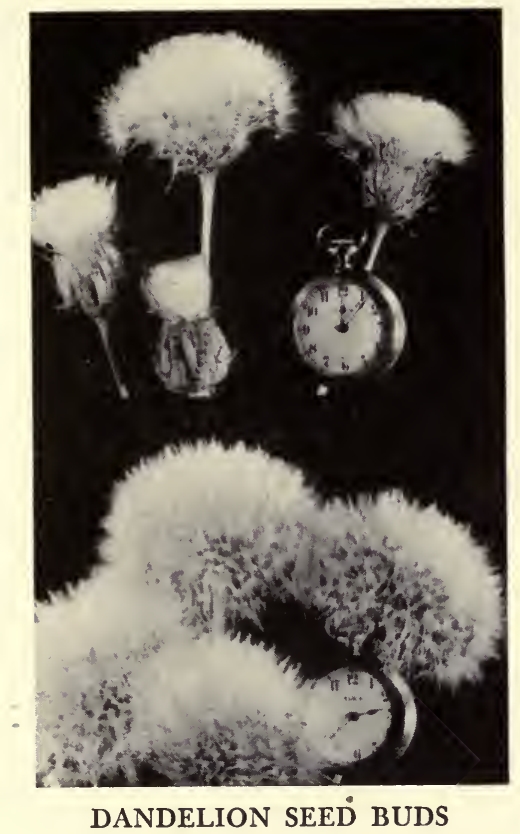

They Open in Three Hours, beginning about Noon

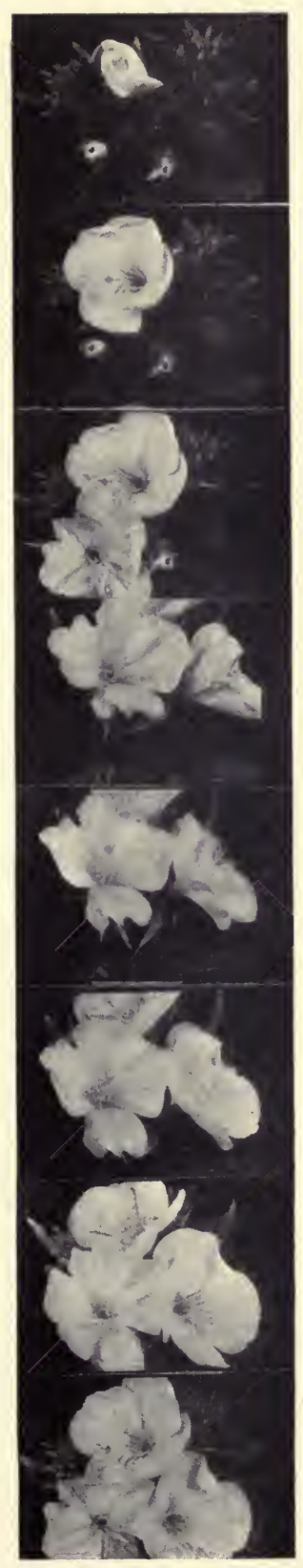

EVENING PRIMROSE

It Snaps Open in Fifteen Minutes in the late Afternoon 

of the slowly running motion camera, does not change their habits, but it does register in pictures more accurately than the eye can show, just what is taking place, even the smaller movements that the eye cannot detect.

The all-seeing eye of the camera sees that the bud begins to raise to its open blossom position. The stem is growing faster on one side than the other. Often the entire stem elongates just before opening. Then rather suddenly the calyx splits with a little snapping noise as in another. (The Evening Primrose.) You can hear it if you listen carefully. Next another crack shows in the calyx, then a short resting period during which it gathers strength for another movement. Growth seems to be in stages of rest and action. Next the camera's eye registers an enlargement of the bud as the yellow petals appear and the four-pronged pistil reaches out ahead of them. These changes are not gradual, but convulsive movements at intervals. Suddenly, after quite a period of apparent rest, the petals fly apart and almost fully open in but a few seconds.

This large yellow blossom of the Evening Primrose opens just before dusk and you can, given the good fortune to find yourself comfortably seated in some lush meadow among them, "Stop, Look and Listen," see, and faintly hear them open! Only about 
fifteen minutes from the first snap of the calyx to the full unfolding, looking down into the open flower, you see what seems a dew laden cobweb on an early morning, the fine threads forming a network around the anthers. You wonder why and unless you watch it during the night you would not discover the reason which is this:

The Evening Primrose's large yellow blossom attracts the great Sphinx Moth. It hovers like a humming bird over the blossom, unrolls its proboscis, extends it into the very base of the flower and while hovering above the blossom is very apt to get its rough honey pump entangled in the spider-web-like hairs, pulling them out with a mass of pollen attached. This filmy mass as the moth speeds on its way drags out behind and more than likely becomes entangled in the four-spiked pistil on its next evening call. So for the honey received they pay in transportation of the pollen grains.

Unhappily this Primrose is now almost extinct in the Yosemite meadows. The mowing machine took its toll and since it has been put on the protected list the deer have acquired a fondness for the leaves, not hesitating, either, at blossoms. The Primrose being a biennial requires two years to produce blossoms, and as the pollen does not germinate readily, between nature and conditions imposed in recent 


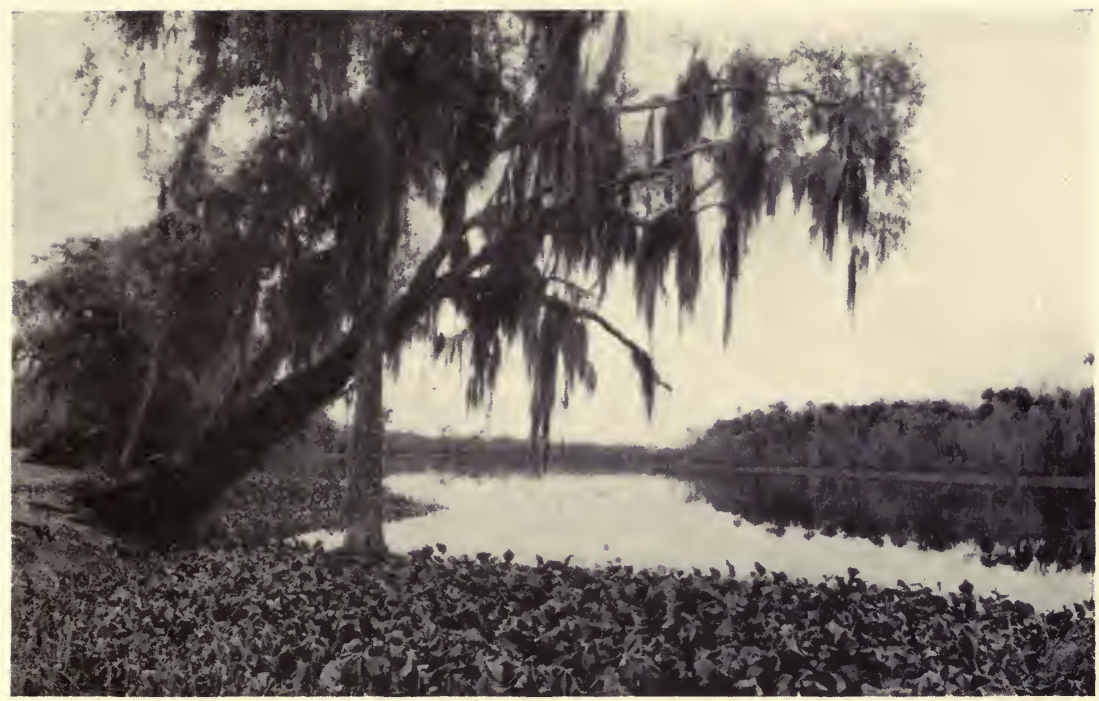

WATER HYACINTH

It often blocks the rivers in Florida

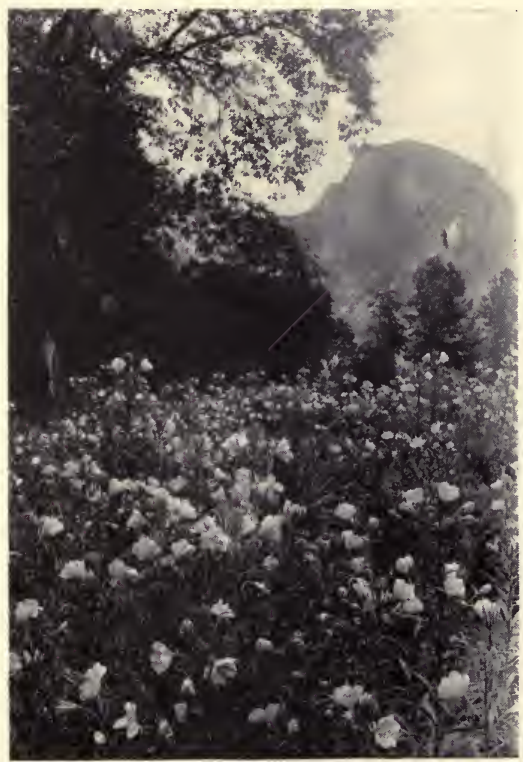

EVENING PRIMROSE

Half Dome in the Distance 


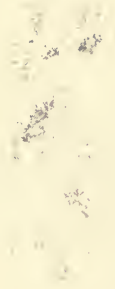


years it, in this lovely setting, seems almost on the way to extinction.

I have seen this same Primrose growing near St. Louis, Missouri; in fact, it is widely distributed over the world. Were it not for the fact that the blossoms fade in the early morning sunshine they would be used more extensively in our gardens, being so large and showy, and filled with a faint elusive fragrance.

The Water Hyacinth grows almost everywhere in warm countries, sometimes as an unmitigated pest. (I started work on it first in Honolulu, where it is blocking some of the smaller streams, but not doing any special damage. Lack of time prevented my accomplishing much at that time.) At the Missouri Botanical Gardens I found the buds started to open at nine o'clock in the evening and were fully opened the next morning into a beautiful blue spike. Also, it drank about one third of the water I had it in during the night, the leaves swaying back and forth all the time. The flowers are attractive and the plant in fish ponds or an aquarium very beautiful-the bright green leaves with their greatly swollen stems acting with their air vacuoles as floats, their blossoms like blue sails moving the plants from one side to another of their water homes, made them unusual and distinctive.

During the lecture vacation of the Christmas holi- 
days while touring Florida, we saw them as what the Floridians consider their greatest pest on the St. Johns River, a stream a hundred or two hundred yards wide-great islands of them that had broken loose from the rapidly growing plants along the shore came drifting down stream. These plant islands, often a hundred feet across and bound tightly into a solid mass by the entwining roots, would collide with other floating islands, be pushed ashore and block the river with a beautiful mass of green leaves and blue flowers. No steamer could penetrate the solid mass until the jam was broken up. The plant is about $99 \%$ water, so is of little use for food.

The Blue-eyed Grass of the Iris family is a dainty little blue flower that grows usually in damp places, but takes readily to cultivation. In our hill garden in Berkeley it moved in, settled comfortably near groups of English and Oriental Iris types, where it grows larger, longer stemmed and of brighter blue than as a wilding. An interesting personality, this little flower, never losing its primitive habits. It opens at 2 P.M. and closes at five with almost clocklike regularity and, like the iris, the petals twist into a hard knot as they die. If you put a dozen or more in water, choosing buds of the same development, they will open up like soldiers presenting arms. The 
actual opening is very quick. Then slowing the camera down during their brief life, they close almost like a flash on the screen. In real life the next morning the blossoms are a tight coil three fourths of an inch high, while another bud is growing up to fulfill its mission in life.

The Dandelion blossom, often one and one half inch in diameter, is beautiful enough to be exempt from the weed class. It is especially interesting if looked at and studied with a magnifying glass-the details of the flower are so unusual. The seed pods, opening about noon into a ball a couple of inches in diameter, give them a chance to dry out that the wind may blow them in all directions. Who as a child has not given a mighty blast while saying, "She loves me," and then a very light blow, "She loves me not"? Of course, she loved him if they all went floating away the first time.

The Western Azalea ranks among the foremost shrub entrants for the beauty prize. In Yosemite along the river bank and in some of the moist meadows, during June and July, the great clusters-white, rose, pink, a dozen or more flowerets in a cluster, anthers and pistils curved up beyond the petals and the entire shrub, blossoms and bright green foliage reflected in the stream, possibly El Capitan or the Bridal Veil Falls in the distance-make a combina- 
tion of almost unequaled beauty. I will never forget a long tramp through the alders and aspens, yellow pines and firs, wild grapevines as large as your arm and a hundred feet long growing up to the tree tops in their struggle to reach the sunshine, then suddenly coming out on the bank of the Tuolumne River, where were a great mass of Azalea in full bloom, a round pool with trout leaping into the air after flies, and a wonderful cascade as the river dashed into the pool-all within a distance of half a city block; a place which perhaps only a dozen auto tourists see in a year. The pool was a whirl of wild water, the falls dashing madly toward its journey down the river. The spot was such a combination of wonders-flowers, pool, falls, mountains and forest, sky and clouds-that the desire to test the fighting quality of the trout was irresistible and the long tramp and heavy pack were soon forgotten.

The Rhododendron is first cousin to the Azalea. It grows in the northern parts of California, Oregon and Washington. It is the state flower of Washington. It is somewhat larger than the Azalea and more highly colored. The buds of each take four days to a week to open, behaving as well in cut flowers in water as potted plants. Sometimes the clusters are as large as your head, rosepink to red, with the anthers upcurved and ending in what looks like tiny snakes' 

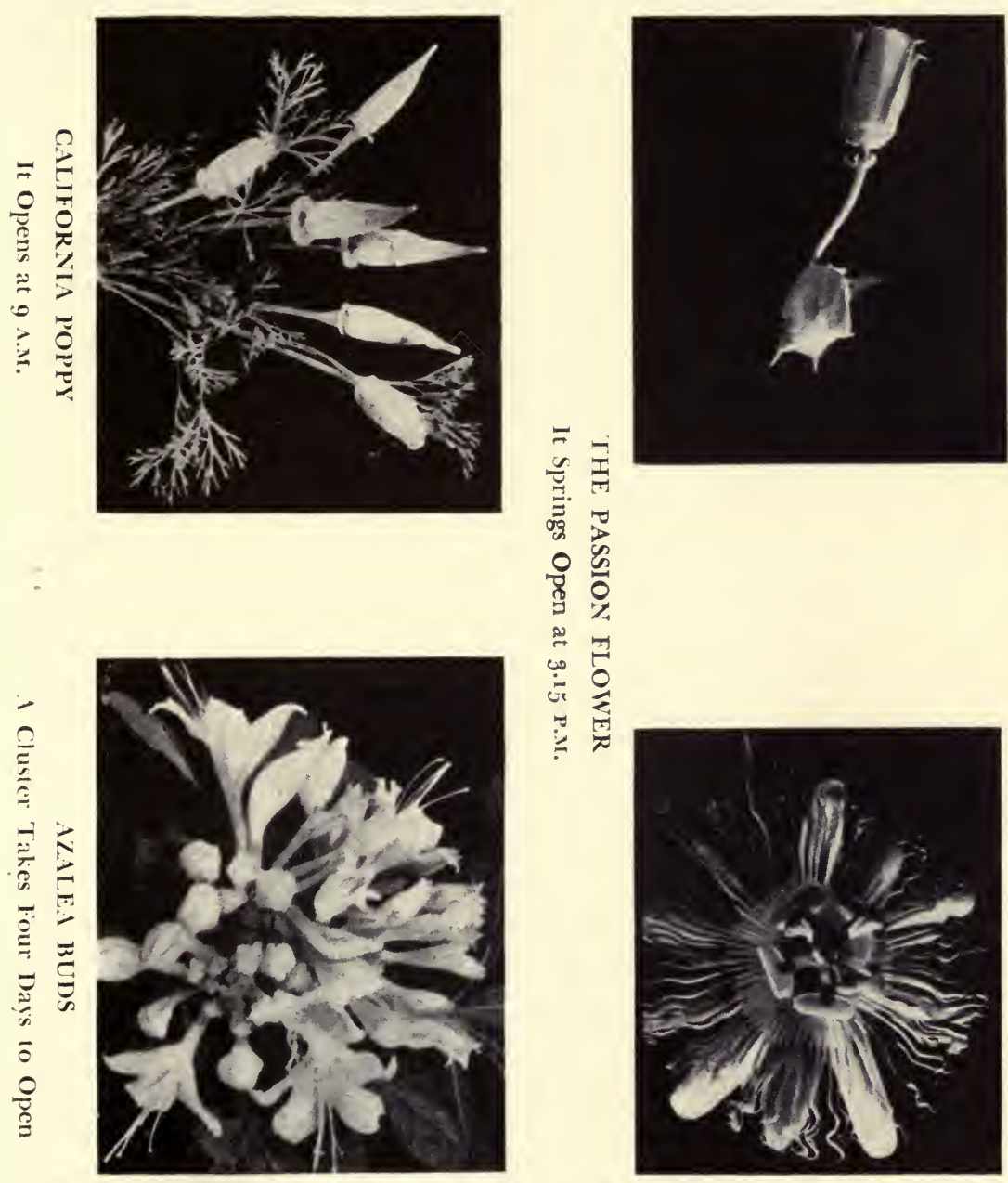

heads. In the forest or among the redwoods they are startlingly beautiful. An acre of them, cloud-capped Mount Hood, Baker or Rainier in the distance, creates a picture hard to resist even if you are down to your last film. The leaves are often two to ten inches long and, unlike the Azalea, are usually evergreen, while the Azalea are deciduous.

Monkey Flowers (mimulus) in the Snapdragon family are of the tiniest little dwarf flowers to high bushes. Nothing could be more dainty than a meadow carpeted with them. Each footstep may crush a hundred but in an hour they have lifted their colorful faces and in a day new ones take their places. The movement of a cluster in a lapse-time picture is astonishing by their exaggerated swaying back and forth-one opening, another dozing and folding into a knot. Often in the higher Sierra Mountains a bit of dry, gravelly soil will be covered with the velvetlike blossoms-the plant and its many blossoms only a couple of inches high. The Yellow Monkey Flower-mimulus luteus-grows in all sorts of places a couple of feet high and flowers all summer long. The Scarlet Monkey favors the banks of tiny mountain streams. Of all the family the pink tall-growing "Monkey" is the most delicately lovely, growing in moist places, even in the more slow-moving, small mountain streams. 
The Sneeze Weed is just one of the 10,000 Compositae scattered all over the world. It has golden yellow rays and a rich brown center. The tiny blossoms on the outer edge-a ring of them opening every night till they are all open. There are often, as revealed by the lapse-time camera, tiny thrifts, so small they would not be noticed by the casual observer, but seemingly particularly fond of this plant, hopping from one flower to another. The flowers seem to like the waste places best and I have seen them growing so thick they made a solid mass of color.

The Black Eyed Susan is like the Sneeze Weed, except it grows taller with deep yellow rays and a purplish brown conical center. All of these flowers are very slow in opening; it averages ten days for the rays to fully develop.

The Cone Flower grows in meadows around 7,000 feet elevation; at Crane Flat and on the Pohono trail in Yosemite are colonies of them blooming in midsummer. Often the center cone bearing the numerous flowers is an inch in diameter and as long as your finger. When the middle flowers are open, perhaps the bottom ones on the cone dying, leaving a ring half way up, they are especially beautiful. The plant is often four or five feet tall with large leaves sometimes a foot long and five inches 


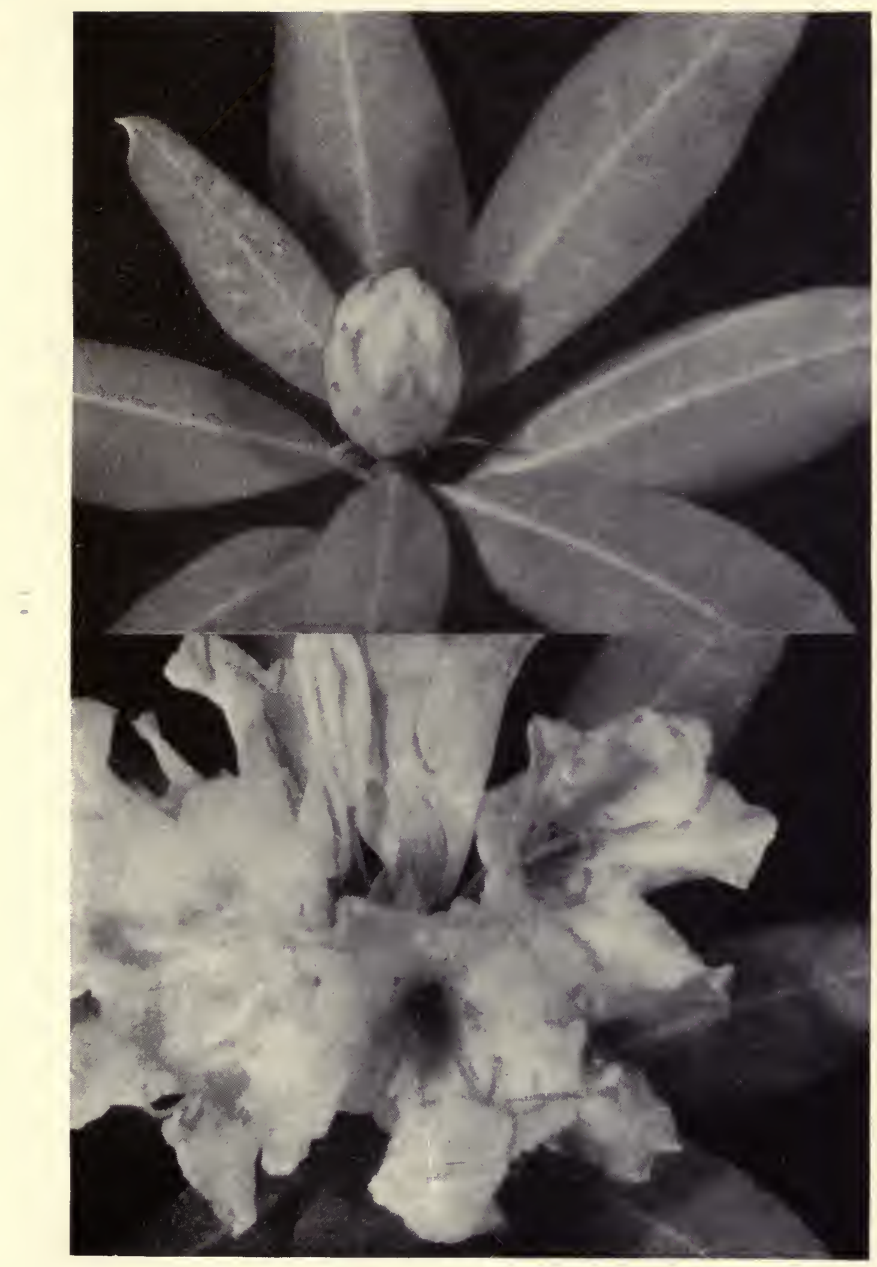

RHODODENDRON

From the Bud Cluster to the Open Blossom 

wide. They are comparatively rare, having been introduced from the Mississippi Valley, but I have seen them so thick it was an effort to push your way through a growth of them.

If in your July saunterings you should pass by Porcupine Meadows on the Tioga Road in Yosemite, leave your car and walk into the rather boggy meadows. Should the wonderful six-petaled starshaped Camass flowers be open you might think a bit of sky had come to earth, so blue are they! This should be in the afternoon. At other hours they would be invisible, so tight is each flower's folding. The plant is a foot or two high, a spike with several blossoms open at the same time. They wilt quickly, but picking a few younger spikes and keeping them in moist paper, I took them to my laboratory and the lapse-time camera caught them opening at 2 P.M. the next day, closing by four. The Mono Indians are very fond of the bulbs as food, so fond of them that in early days it led to numerous wars with the valley tribes, the dispute being who had the right to gather them. Care should be taken not to include in your repast bulbs of the white Death Camass-in comparison with which a brew of the bitter hemlock would be but faintly fatal.

The Knot Weed, or Alpine Smartweed, is another one of the high mountain meadow flowers, which 
add so much to the enjoyment of a trip over the Tioga Pass. You may find one meadow covered with Bog or Little Leopard Filies, another with Camass and the next one almost white with these balls of beauty swaying in the breeze; the buds, like pink beads, open into a round mass of tiny cream colored flowers. To know the flowers as you pass by is like meeting fellow human beings, to know their habits like meeting a friend and to know their innermost secrets like meeting a long lost brother or sister.

Lupines are so numerous in form, color, and habits, it is hard for anyone except an expert to name the eighty or more kinds we have in California. I have not succeeded in making lapse-time pictures of them as they invariably wilt in front of the camera in the four to eight days it would require. Nothing could be more beautiful than some of the patches of them on the Glacier Point and Oak Flat roads in Yosemite in late June or early July. They grow four or five feet high-a solid thicket of them-in a forest of pines and cedars with perhaps a few deer grazing in the meadow a short distance away.

I was making what I call a traveling picture of just such a scene last summer on Glacier Point Road. The camera was on a carriage, motor driven along a steel track, exposing as it moved. The result was a 

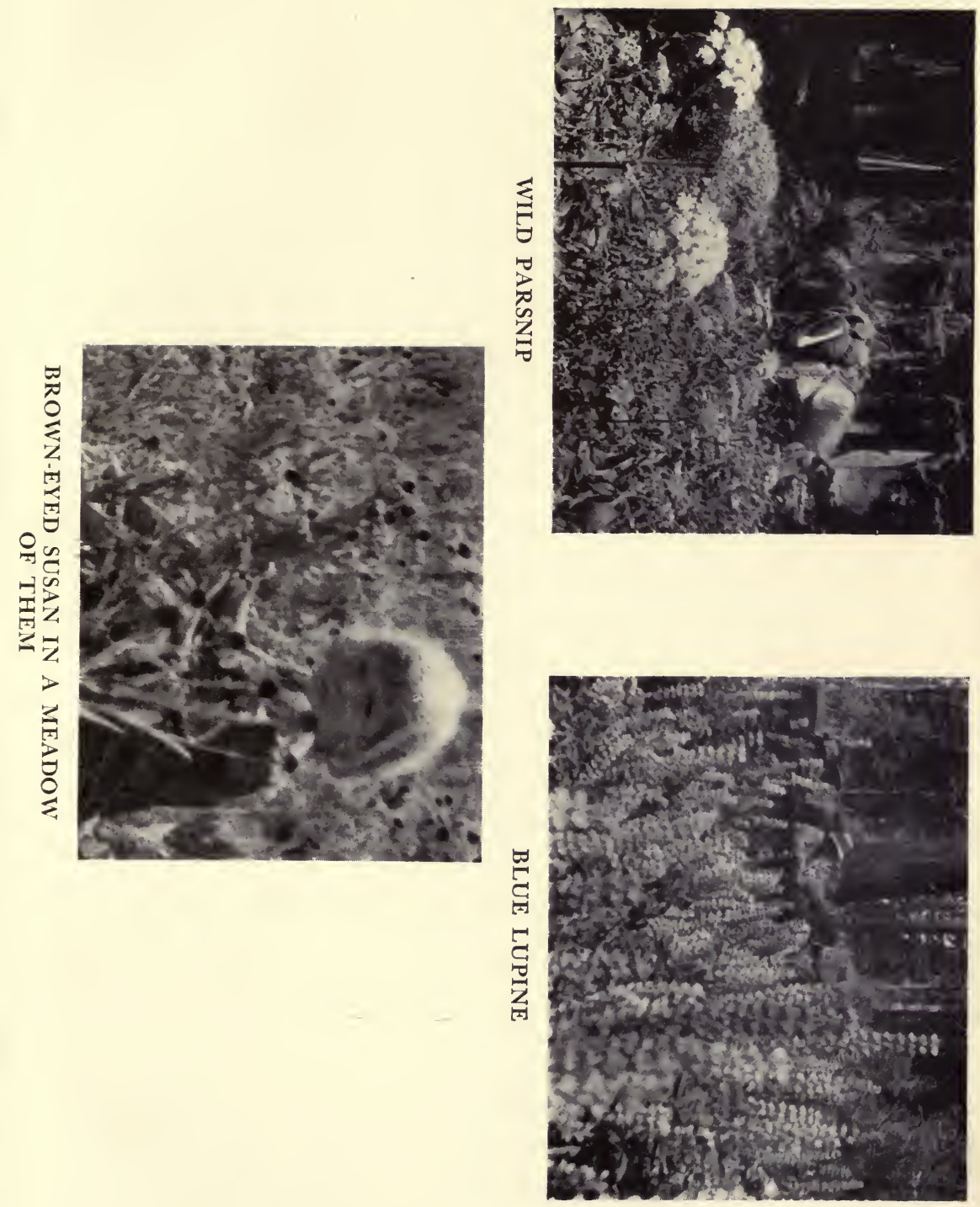
stereoscopic motion picture when projected. I had been working almost an hour setting up the rather complicated apparatus when I noticed the deer had left the meadow and were watching me over the top of the lupine. It was a wonderful sight-the combination of forest, lupine, deer and meadow. The deer soon found I was one of those queer bipeds that do all sorts of incomprehensible things but nothing they need be afraid of, so they went back to the juicy meadow grass, nibbling a flower or two on the way. The deer in the National Parks are an element to be reckoned with in the conservation of flowers. Since their complete protection, they have increased enormously and are very tame, eating from your hand, and the increase in numbers has developed a shortage of food, so they have acquired a fondness for flowers and the Evening Primrose and some others have suffered in consequence. The Park Service in Yosemite is trying to control their increase by exporting them to other sections, limiting to a reasonable number those in the floor of the Valley.

The Wild Parsnip is well scattered in California, often growing ten feet high in the Yosemite meadows, making a beautiful showing-the cream white blossoms in umbels often two feet across. When picked, unless with the greatest care, it wilts quickly; when cut it should be placed in water at once and 
then a second cut made under the water so no air can enter. The blossom cluster is four or five inches long and inclosed in a sheath which finally becomes a leaf in front of the lapse-time camera as it unfolds. It illustrates graphically the periodic growth of plants, growing quite rapidly for a time, then resting, then growing again. The camera, running at a uniform speed, shows this very accurately. The sheath inclosing the blossoms and also the stem, is covered with numerous rather long hairs, which prevent ants and other crawling insects from climbing the stem and robbing the blossoms of their pollen and nectar. Flowers must protect themselves from some insects and entice others if they are to survive. These hairs under the microscope show plainly the circulation of the protoplasm, especially with dark field illumination. The plants grow so thickly one can hardly penetrate a group of them but the deer have made little paths leading through them to their beds. In the heat of the day, if you tread very carefully, you might find them curled up in a ball sound asleep.

The California Poppy, our own state flower, will and does grow almost the world over, so widely have its seeds been scattered. Miles and miles of them, magic carpets of gold, cover hillside and valley. The early explorers, if they told of no other flower, al- 
Flowers

ways mentioned the "Golden Poppy." "Copo de Oro" the early Spanish settlers called them and cups of gold they are! More brilliantly colored, more satiny lovely, than any golden cup! The Indians thought the falling of the petals made the gold in our soil.

A poppy bed ten miles square has been seen from a distance of forty miles as a sheet of yellow and another of orange red from an equal distance. The color varies from white to almost red; in the mountains at two or three thousand feet they are a pale yellow. The poppy is so plentiful almost the year round, so dependable in its habits and dramatic in its opening, it is a good flower to experiment with. The buds hanging slightly pendent straighten upright. The stem grows noticeably just before opening on a normal, sunny morning at 9 o'clock. The sepals enclosing the bud, split at the lower end and then like a peaked cap are pushed upward by the expanding petals, finally popping off with considerable force, perhaps into the air a couple of inches, the released petals opening wide in a very few minutes. They close about 3 o'clock in the afternoon, opening again a little wider the second day, closing on schedule, and the third day are fully open. The petals wave back and forth gently as in a gesture of farewell and fall the fourth day, while the pistil 
grows during the next four or five days into the seed pod.

Putting poppy buds into a solution of a normal dose of aspirin dissolved in water side by side with others in tap water, those in the aspirin solution open a little quicker and a little wider, but instead of closing when the others do, their golden cups gently tip over and cease to be. Reducing the strength of the aspirin prolongs their period of life but slightly.

In bootleg whiskey the effect is much the same. The buds open quicker, and invariably pass on within an hour or so, depending upon its strength. It is very amusing to set up equally developed budsfirst water, then $100 \%$ of bootleg, then $50-25-10$ and $5 \%$ of bootleg, the camera showing the resultsdying one by one in proportion to the strength of the bootleg-those in water closing on time, perhaps delayed a little by the odor of the environment in which its companions find themselves. Strychnine has practically the same reaction you would expect a stimulant to have if administered to a person. The first two or three days the buds open quicker, not closing till 9 o'clock P.M. but after the third day when the effect has passed off, not looking nearly as well as those in water; only these and other experiments, extending over several periods of varying 


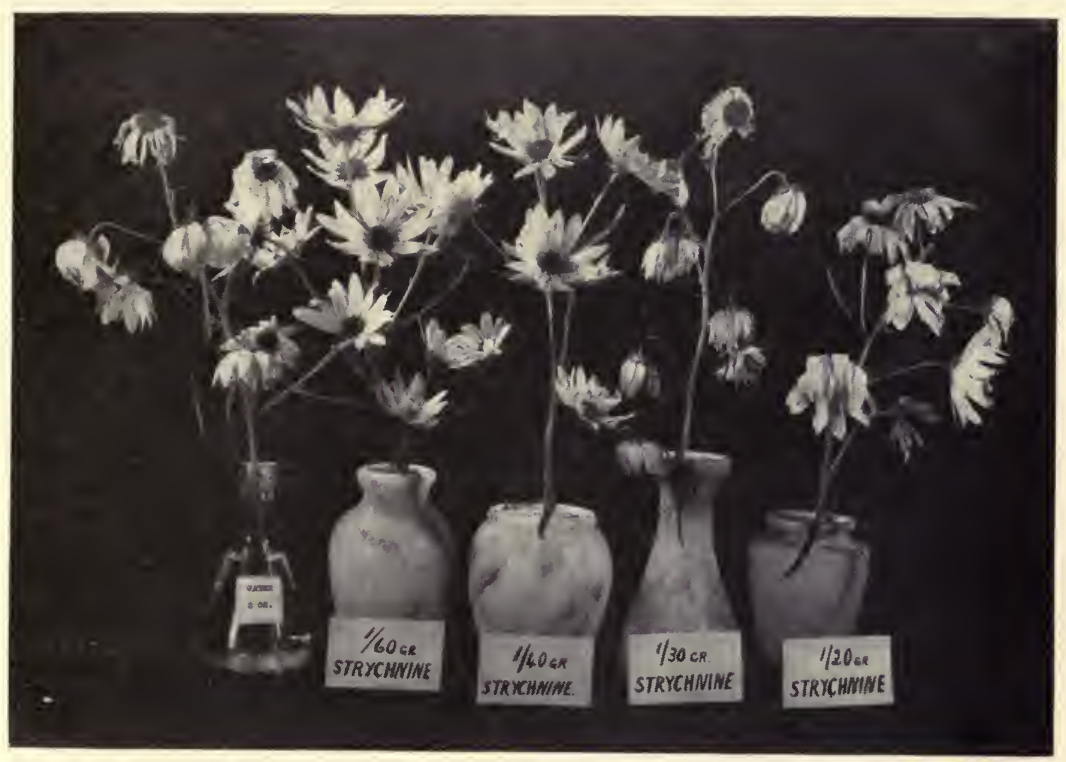

THE INFLUENCE OF STRYCHNINE ON FLOWERS Almost Identical with that on a $150-1 b$. Person

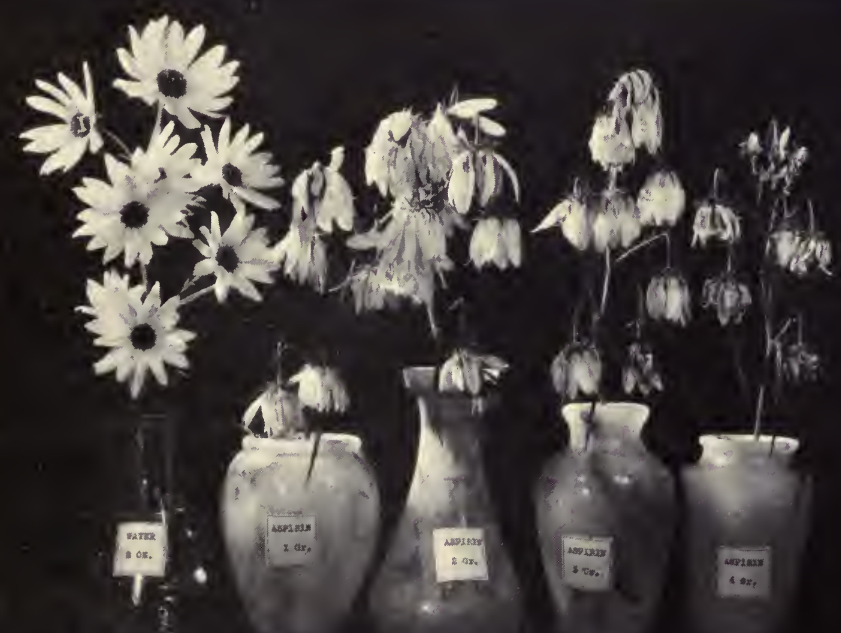




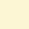


lengths, have convinced me that the reactions, from administration of drugs, are much the same in plant as in animal life, under like conditions.

I first became interested in the little Mimosa as a dainty roadside plant on Oahu, Hawaii, but it was not until later that I gave it particular attention. At the Missouri Botanical Gardens at St. Louis, Missouri, I made a number of interesting experiments with it. Disturb in almost any way one of the leaves and one by one they will fold up with a curious, withdrawing motion and drop down; soon the effect of the disturbance passes and the leaves reopen to normal. The same thing happens if you bring an ice cube or a hot iron near a leaf. All sorts of queer experiments can be carried out and photographed, if you wish. Bose, the Hindoo experimenter, says that a decided reaction takes place in the dainty almost fernlike plant when a cloud passes over the sun, leaving it in the shade for a short time. In the South Sea Islands, it is used extensively as a forage plant, the cattle in passing through it leaving a marked trail for a short time behind them. The blossoms are small, spherical and a beautiful reddish pink, but they refuse to open when cut and put in water-the branch wilts and dies quickly. Naturally the blossoms open at night, often so plentifully as to give the field a soft rosy glow. 
The Venus Fly Trap was a surprise, as I had expected quite a large plant; when I first saw the small leaves, no larger than a five cent piece, they were a disappointment. The leaves grow in pairs as though they were hinged together, the outer edge armed with stiff bristlelike hairs that are set like the teeth of a bear trap when the halves close. Each leaf has three small hairs in the center. If a fly or small insect lights on the leaf and touches the hairs, the two leaves close up at once, catching the insect, holding it till its body is absorbed. As the leaves are translucent, the camera shows this interesting action. A day later when the flesh is all gone, the leaves open to emit the undigested parts. By tickling the small hairs with a match or a small stone, the leaves close, but soon open, seemingly knowing they have been fooled. They will hold and absorb a bit of flesh or cheese and enjoy it. Is that instinct or intelligence? As the leaves have chlorophyll grains and so make their own food, in part at least, who can say but that they are in the midst of a transition stage, that is, gradually changing into animals; or they are losing their animal characteristics and becoming more like typical plants, just as other plants are doing-changing perhaps in a million years from water plants to land ones, or the reverse.

Pitcher Plants, Ranaceniaceae family. I will never 

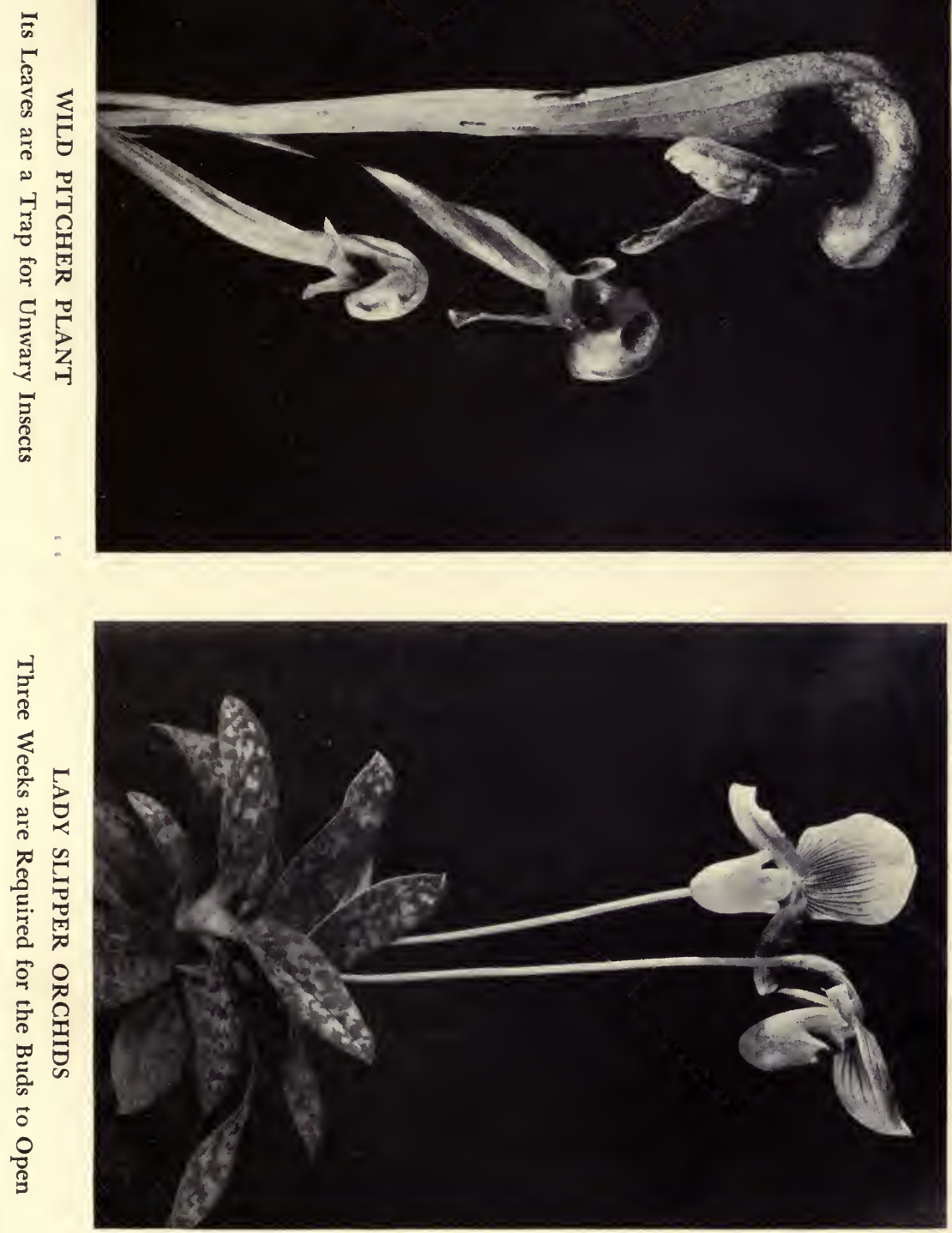

forget driving to Oregon over the old dirt road, before the new highway was finished, over Grant's Pass one hot day, and seeing on the hillside above us a colony covering almost an acre of these wonderful plants, the odd skull-shaped Darlingtonia. The sun was in front of us and its effect, shining through these weird, often three-foot leaves, was most wonderful. The blossoms were scarce at that season. We climbed the hillside, which was almost a bog, so many streams were coming down from the melting snow above, and examined the leaves. Many had the cap to the pitcher partly open and in nearly all there was from half an inch to an inch of liquid, and in most of them were dead insects-insects that in exploring to find where the rather fetid odor came from, slipped in and finding it impossible to climb out again against the depressed hairs, soon tired and were drowned in the liquid and gradually absorbed. The lapse-time camera on potted plants showed that the cap was very slow in lifting from the top of the pitcher, often taking a week or ten days. The last few years has seen them so commercialized as to threaten extinction, as the weird ghostlike leaves have a very great and peculiar appeal in these days when everyone is looking for new and different forms of plant life. 



\section{III}

POLLENIZATION

จ战 

Pollenization

MANY and peculiar are the methods used by flowers to increase the percentage of chance of giving and receiving those tiny golden spheres so necessary to their continued existence. The grasses and many trees depend on the wind, so enormous quantities are produced, trusting that one, it is safe to say, out of 10,000 will reach its desired haven.

Pollenization is one of those intriguing subjects, something that can be watched without seeing or listened to without hearing or fully understanding its entire reason for being. For many years it has been an accepted fact that to carry on in the higher order of plant life, grains of pollen from the anthers of kindred blossoms, possibly in the same flower, or from another plant or tree (as sometimes male blossoms grow only on separate trees or plants), must be carried by insects, wind, birds, or animals, from the anthers of one flower to the stigma of its own blossom or another. Bees are of the pollen carriers, seemingly the most intelligent and unremitting, in this so necessary work, of all the insect family. From Bible times down the centuries, these busy 
and on the whole well mannered creatures, have been held up as models of industry and wisdom. From early morn until dusk they may be watched, always going from one flower to another of the same kind, while the butterfly flits from one bright blossom to another, very likely of a different kind. The flower as recompense to the bee for its labor, feeds it with the choicest nectar, and a great surplus of pollen as food for its young, enticing it with gay colors and rare perfumes. Notice the bee at work; how it burrows into the blossom to reach its honey and how in doing so covers itself with pollen-legs, head, and body with innumerable tiny grains, plastering its legs with great masses to carry home to its hive to be removed by other bees and stored up for food for its young. What is more natural than that in its many visits, perhaps from forty to one hundred or more flowers an hour, a few grains will be rubbed off on the receptive stigma, and in the more or less sticky sweet secretion, the pollen grain captured in its inactive resting stage, will absorb enough moisture to start active life. This, in fact, is what does happen. A tube grows from it, life begins in it, protoplasm, the basis of all life, starts circulating, first in the grain, round and round, then out the tube, down it to the growing tip. The protoplasm increases in volume as the tube grows, moving in well defined 
channels in a never ending stream back and forth into the grain and out again, gathering who knows what in its continuous journey. Finally the nucleus, the male element in every pollen grain, but usually invisible, comes out and is carried along in the stream of protoplasm, down the growing tube which has, by the attraction of sex, grown the tiny distance to the stigma, through it and down the pistil, which may be only a fraction of an inch to over a foot long, till it reaches the ovary, in these protected, not yet explored recesses in living subjects of plant life. What happens when the nucleus and protoplasm mingle, is not well known, but the result is a new life, an embryo seed capable of carrying on, coming into existence, which after ripening and a resting period can, when the conditions are right, again spring into active life and bring forth one of its own kind.

Many of the trees, like the pine, and most grasses depend on the wind instead of the bee to carry their pollen from anther to stigma. "The wind blows where it listeth," so enormous quantities are produced. Nature, ever lavish, produces billions of this magic golden dust, trusting that possibly one in a million may fall and lie caught below by the waiting stigma. In corn, one of the grasses, as the pollen ripens, a shower of pollen drops every few minutes 
from the anthers above to the silken tassel of the ear below. The threads of silk are the pistil and stigma and although a foot long the tiny pollen grain can grow its entire length, giving a channel for the nucleus to meet, forming one perfect seed in the ear.

Although the bee serves many flowers, some blossoms have their own special one, each dependent on the other; one for food, the other for its life continuance. Flowers that bloom only in the night are usually white or yellow, colors more noticeable than others in the dark, so are invariably visited by some member of the night flying moth family. So many and peculiar are the methods used by flowers to increase the percentage of chance of giving and receiving those tiny spheres necessary to their continued existence that a lifetime would be too short to learn all their ways.

The Monk's Hood Orchid has a unique method. The honey bee to reach the nectar storehouse must climb under the hood for which it is named. The passage is low but not as low as it becomes after it has discharged its pollen when the receptive stigma almost rubs the bee's back. In crawling into this chamber, the bee's head touches what in effect is a figure 4 trap. This releases a large mass of sticky pollen. It is almost as large as the bee itself. The 
mass sticks to the bee's back which, startled, backs out and rubs off a sort of cap on the pollen mass, leaving it exposed. As hunger is the driving force in insects as it is in humanity, the bee, after regaining its composure, hunts another blossom of the same kind and crawls into one that has perhaps already discharged its pollen and has now a similar opening, so this mass still sticking on the bee's back is rubbed off where it will do the most good. You can duplicate the bee with your pencil, spring the trap and find the mass as large as the rubber on the pencil end sticking to it, or if you hold the pencil at an angle, the mass will be shot ten feet or more.

The percentage of successful pollenization in flowers seems very small, but it must be remembered that the flower through the ages has, by the survival of the fittest, developed these devices by which in nature it is able to maintain the balance of life. The flower will neither crowd itself out nor become extinct. Also, some special insect has through that same period of time adapted its life to that special flower, getting its livelihood from it, which is well illustrated in the White Smyrna Fig. It was imported into our country where the figs did not mature. The tiny blossoms inside the fig were not pollenated, so as a fig it was useless. Careful research found what was lacking and from Smyrna the insect was im- 
ported and now, the missing link in the chain of life being present, the fig blossom receiving the pollen with the aid of its necessary tiny insect, matures and ripens into delicious fruit.

The Milkweed is another interesting flower to follow through its method of pollenization. It has several insect friends, among them the fly, the bee and a small grayish moth. All of them will be seen working on the blossom and often in the afternoon hours when the insect is tired you will notice dead ones on the flower, which is the clue to their methods. Try to pull one of these dead insects off and you will find one or both legs are caught in the $\mathrm{V}$-shaped cracks between the five parts of the blossom and, when removed, there are two little yellow bags held together with a thread and fastened to their legs. The insects unless very tired at the end of a day's hard work gathering honey could pull themselves loose and the pinhead sized bags containing several hundred grains of pollen would dangle from their legs. Instinct compels the insect to continue work on the same kind of flower and those saddle bags of pollen dangling from his legs are, to say the least, a nuisance, so when he alights on the next milkweed blossom he thrashes around until the bags are broken open and the pollen scattered over the receptive stigma. 
Chance, yes, in a sense, but enough chance to keep the milkweed always with us. While we are talking of milkweeds, I will tell you another thing about them that the eye of the camera noticed first. When the pod opens to allow the seeds to escape they are quite damp. The seeds come out and are held captive to the tip of the pod until the sun and wind has dried them out. The seeds of this interesting milkweed are small, flat and brownish in color and each one has a tuft of long silver hairs attached to it. They are so light when dry, the hairs giving them so much surface, they float airily out into space. Being held captive by the tip of the pod allows them to dry out before being released by the wind when they are carried to great distances, giving them a better chance to choose a new homesite.

It is quite possible that some one plant in the line of heredity developed that trait of holding the seeds captive until they dried out. That plant and its children survived and the others passed on out into another form of existence.

Among the water plants other interesting methods of pollen dispersal and reception are wonderfully interesting to watch. The Vaucheria, an aquatic plant having a long thin leaf, is especially dramatic. The plant lives in the water a foot or two deep, the leaves floating on the surface. The small white fe- 
male blossoms grow to the surface on a spiral-like stem which just accommodates itself to the distance from root to surface, which may be of varying lengths. This stem allows the saucer-shaped blossom to reach the surface and then very gently submerges it. So the blossom, although on the surface, is pulled down just enough to be but a little below the level of the surrounding water. This is very slight but still it is downward to the blossom on all sides. About this time large numbers of male blossoms bearing pollen grains ripen, break off near the root and come floating to the surface. The chance of one of them reaching this slight depression and drifting down into it where the female is waiting may be one in a thousand but still it is enough to enable the plant to carry on. This process seems consciously performed and shortly afterwards the stem coils, pulling the blossom down to the bottom again where the fertile seeds mature and the chain of life goes on.

Flowers seem to know, as the higher forms of life do, that to retain their vigor and to be able to exist in the severe competition of life they must not use their own pollen as the fertilizing agent of the plant to be, but must produce their strong healthy seeds, giving them the ability to carry on, by cross-pollenization. Nature with her usual wisdom resorts to 
many methods to accomplish this end and prevent self-pollenization.

The Java Lily pistil may be said to almost break its back to get out of the way of its own anthers. When the flowers first open the pistil makes a square bend, getting above and entirely out of the way of its anthers below.

The Evening Primrose pistil appears before the blossom opens and before its own pollen ripens and as the sphinx moth is kcenly anxious to get the first sip of honey as the bud opens it is apt to deposit pollen from another flower long before its own matures.

The Cocoanut has a different method. The bud, or spathe, as it is called, is from eighteen inches to four feet long, cigar-shaped and as large as your arm. The shell-like husk containing the spike blossoms splits down the middle into branches which look as though they might have been carved out of ivory, so creamy white and glistening are they, and snap out branch by branch as the outer shell splits. These branches of the entire blossom spike are covered with hundreds of the male buds. After the entire spike is free of the containing husk, these male buds start to open. They are flowers with petals and anthers laden with pollen. It takes three weeks for the thousands of male buds to open, shed to the wind 
the portion of their pollen not already gathered by insects, and then drop off. After all the male buds have fallen, the female buds, the embryo cocoanuts, now about marble size and usually fourteen in number, send out their tiny pistils about one sixteenth of an inch and, because all the pollen-bearing buds are gone, they must depend on pollen from some other blossom on perhaps a distant tree, carried to it by the wind or honey bees.

Thus the cocoanut protects itself from self-pollenization and the dangers of inbreeding, which would be as disastrous to it in plant life as it is in animal life.

The honey bee is the flower's best friend. Instinct has taught this fuzzy buzzing creature to work on flowers of the same kind continuously, while the butterfly flits from blossom to blossom, regardless or careless of how she spends her short life. The busy bee works from dawn to dusk, storing her home with honey and pollen food for her young. The flower is her source of supply and to attract the bee in this mutual benefit partnership, she dresses herself in beautiful sweet-scented raiment, and as her whole life struggle is dependent on receiving just a few of those golden globes of pollen, she spreads her richest food, her honey, behind her own less attractive pollen and stigma. So the greedy bee, anxious for the best food 


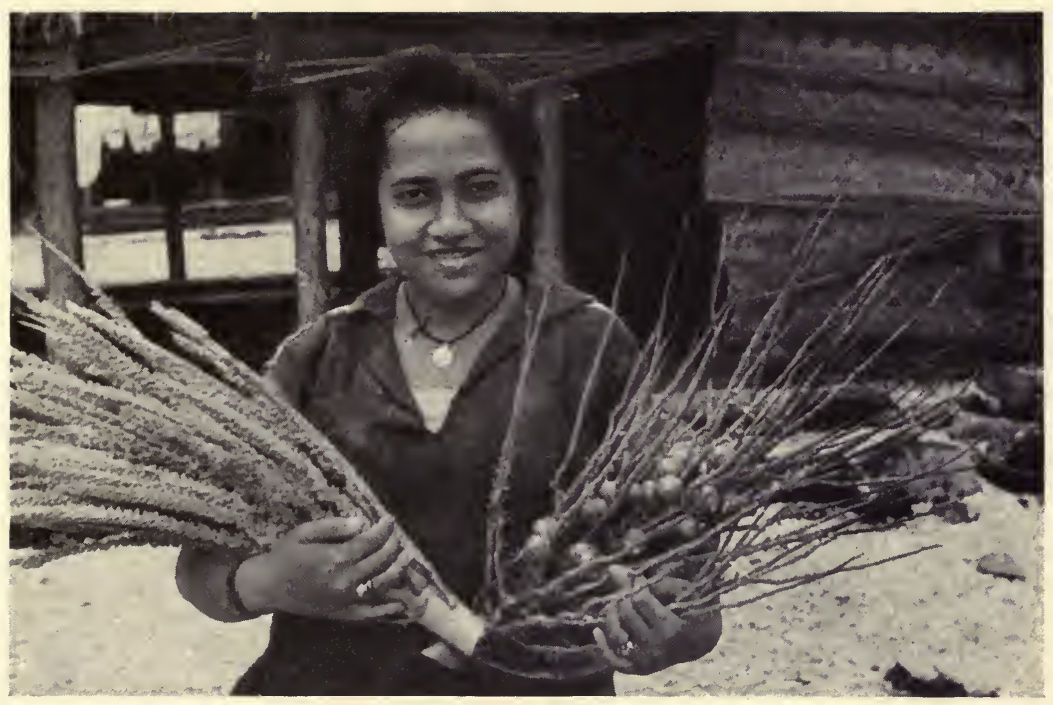

SAMOAN GIRL HOLDING COCOANUTS

Blossoms and Cluster in which the Male Buds have Dropped Off

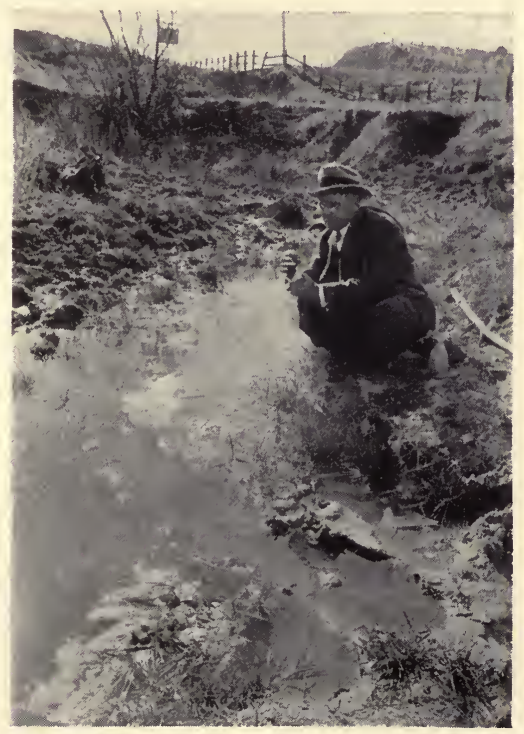

GETTING SPECIMENS OF SPIROGYRA 


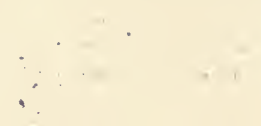


first, pushes by the less tasty morsels and in so doing pays in advance for her honey by possibly brushing off a few of those life-giving globes carried from some other blossom onto the receptive stigma.

The act accomplished, the price paid, life goes on to another stage. The flower wilts, it sheds its beautiful scented garments, and petal by petal, they fall to the ground unheeded, their destiny fulfilled. In some forms, the entire bell-shaped blossom, leaving the pistil alone, apparently dies we say; in reality it goes to sleep, to begin life in another form, passing on into another stage. In the dark of the hidden parts of the blossom, life, microscopically small, starts its link in the chain. The pollen grains absorb moisture from the sweetened "secretion" in the stigma. They germinate; the pollen tube as a channel for the male nucleus, grows down the pistil which may be microscopic, or over a foot in length. It may take it hours or even weeks but it persists toward its goal. The journey ended, the growing tube disintegrates, the nucleus escapes and mingles with the female nucleus and these two masses mingling, just as though they were boiling and stirred by an unseen necromancy, finally round up into the fertile seed.

For every fertile seed in the fruit or the often innumerable ones in the pod, a pollen grain must be 
deposited in its desired location, germinate, and the nuclei mingle to give them that power of fertility which enables them to sprout and carry on.

Visible action ceases shortly after the mingling of the nuclei and the ripening of the seed and another resting period follows. Seeds do not germinate readily before this resting and nature has taught them how long must be this time in which to store up energy to enable them to perform their link in their continuous chain.

The mingling of the nuclei of pollen has not been witnessed in life. Its action has been studied by killing the ovaries at various stages of life, staining them, making microtome sections and splicing them in order, and in that way getting an idea of what takes place. Staining may result in unknown changes and it does not show the action. The difficulties to overcome in trying to picture through the microscope and motion camera these hidden steps of the life chain are almost, if not quite, insurmountable. The ovary is surrounded by a more or less opaque dense tissue, the growing pollen tube and the nucleus of about the same color as the tissue, and to dissect the tissue away and keep the ovary alive and carrying on its life work has so far been found impossible, but without doubt, sooner or later a flower will be found having a thin transparent ovary, microscopic in size 
and a pollen tube and nucleus of slightly different color that will make it possible to picture the action going on in life. Is the result, if accomplished, worth the effort? As no bit of knowledge gained is ever lost, this bit of insight may open the door to a higher form of life which may lead onward still further.

The flowering plants and their ways of life are a step in advance of the Algae and their methods of functioning. That more visible step which can be watched and pictured in flowering plants, the nucleus in the pollen grain which is the male element seems to be all that is required to produce a fertile seed, that is, being combined with the female nucleus; although possibly some of the protoplasm with both nuclei are used in producing the seed. Among the Algae, Spirogyra is one of the most beautiful forms of plant life to work on. The plant grows in long hairlike filaments in stagnant water. The filaments are divided into cells with a spiral gamete between each partition dividing wall, the tiny nucleus suspended in the center. The filaments grow by cell division. They elongate, constrict in the center, a partition wall forms, dividing the gamete-protoplasm and nucleus in two smaller cells grow and carry on the life process. This growth is rapid in the younger stages-more difficult to observe as the filament matures. 
In nature the filaments sink to the bottom during the night and when the sun shines on them in the morning oxygen is manufactured, lifting the mass to the surface.

The top of the mass may be yellowish, green underneath and has a slimy feeling to the hand. In the spring of the year when in the conjugating stage, two filaments side by side and of the male and female sex, tiny connecting tubes grow from one cell to another. When they touch there is no opening between the connecting tubes, but they adhere to each other. Then the male gamete begins to round up and gathers into a mass near the connecting tube. Parts of the mass move forward and with a battering movement break down the partition wall. Sometimes this is accomplished by tiny particles bombarding the wall. This movement would not be noticeable to the unaided eye, but with a lapse-time motion camera taking pictures at a few seconds' intervals, projecting the pictures at their normal speed shows this battering movement very plainly. Finally the two ends of the connecting tubes being broken down, the entire gamete, the whole contents of the male cell, including the nucleus and protoplasm, pass over with a more or less intermittent movement. This combined mass takes about ten minutes to pass over, mingling with the gamete in the female cell. The 


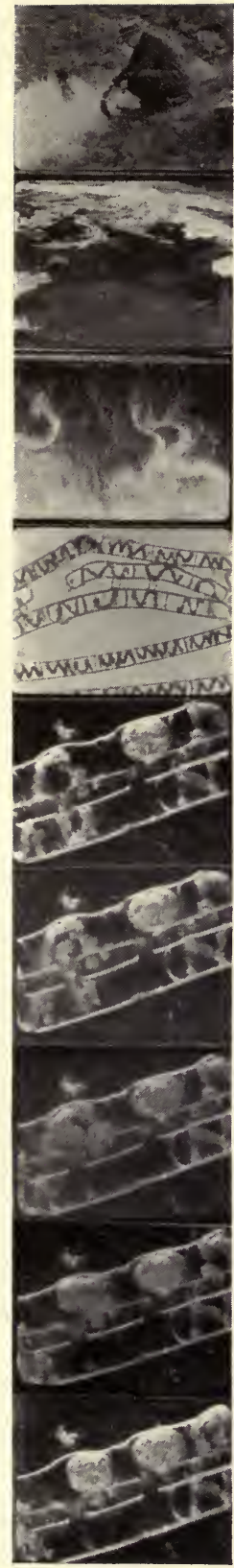

Gathering it

It Floats

during the Day

And Sinks at

Night

Filament

with Connecting

Tubes

The Male

Gamete (lower

left) Going over and Mingling

with the Female

and Rounding

up into the

Fertile Spore

Alternate Male

Cells on the

Left pass over

to Female on

the Right,

Forming a Spore
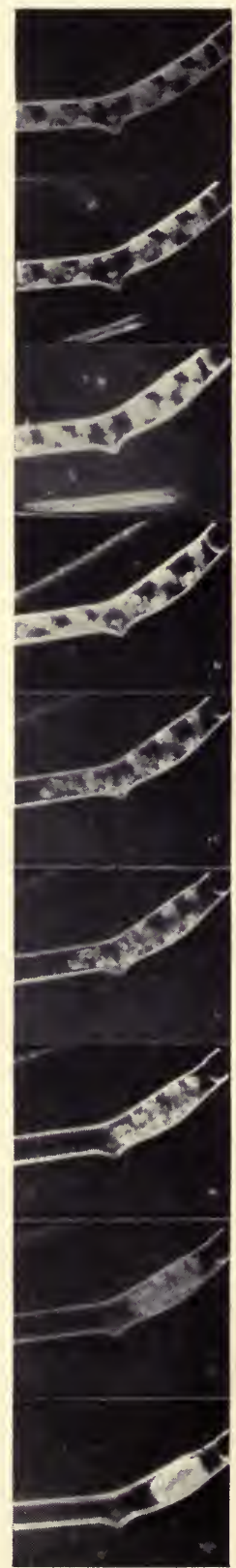

THE MOTION STORY OF SPIROGYRA AND CONJUGATION IN TWO FORMS 

picture recorded by the microscope and lapse-time camera, looks as though it were that of a boiling mass as it gradually rounds up into a compact round or oval-shaped spore-referred to as a spore-in effect a fertile seed. The visible action continues some five hours, gradually slowing down to its resting period. The male filament, now empty, disintegrates, while the cell walls of the female, one containing a fertile spore in each cell, seem to increase in strength, possibly protecting it during its resting period.

Just how long that spore must rest before it germinates into a new plant I do not know. I have watched them for weeks under the microscope trying to picture that link in their life story. I have found them in the dried mud but have not yet been able to picture it, completing the life cycle in that most beautifully interesting plant. It has taken four years to do what I have with it, and a week may complete the story, which is one reason the work is so fascinating, giving such an element of desire to succeed.

The Longatta Spirogyra has alternate cells in the same filament, male and female, so the union of the gametes takes place through a swelling in the cell wall at the partition. Both forms are easy to witness if you have patience enough. My method is to fasten with paraffin a glass ring on the slide, stand it on edge, put in two drops of water, then paint the edge 
of the glass ring with glycerine and on the cover slip place a small amount of spirogyra, and insert it on the glycerine smeared glass ring which will hold it in place. That gives you the subject mounted in a moist air chamber without being in the actual water, which is in the lower side of the ring.

I also found that under the low power lens and on the mechanical stage you can move the subject back and forth the width of the field, lower each time, hunting for a filament in the right stage and in an open clear space. If one is not found in the first specimen I remembered the old instruction to "try, try again" and did perhaps a dozen times, until I was sure that in the lot there was no good material. When I found what looked to be a likely specimen, with the revolving stage I worked it around until it occupied that part of the field of the camera I wished; everything looking favorable now, I found it advisable to remove the slide and put a couple of drops of paraffin on each side so there was no danger of the cover glass slipping during the hours I watched and photographed it.

From this point on was simply a matter of looking into the microscope at least every ten minutes, watching for any minute change in the male gamete. Just as soon as it starts to gather itself together to cross its cell toward the enlarged side of the cell wall, I put 


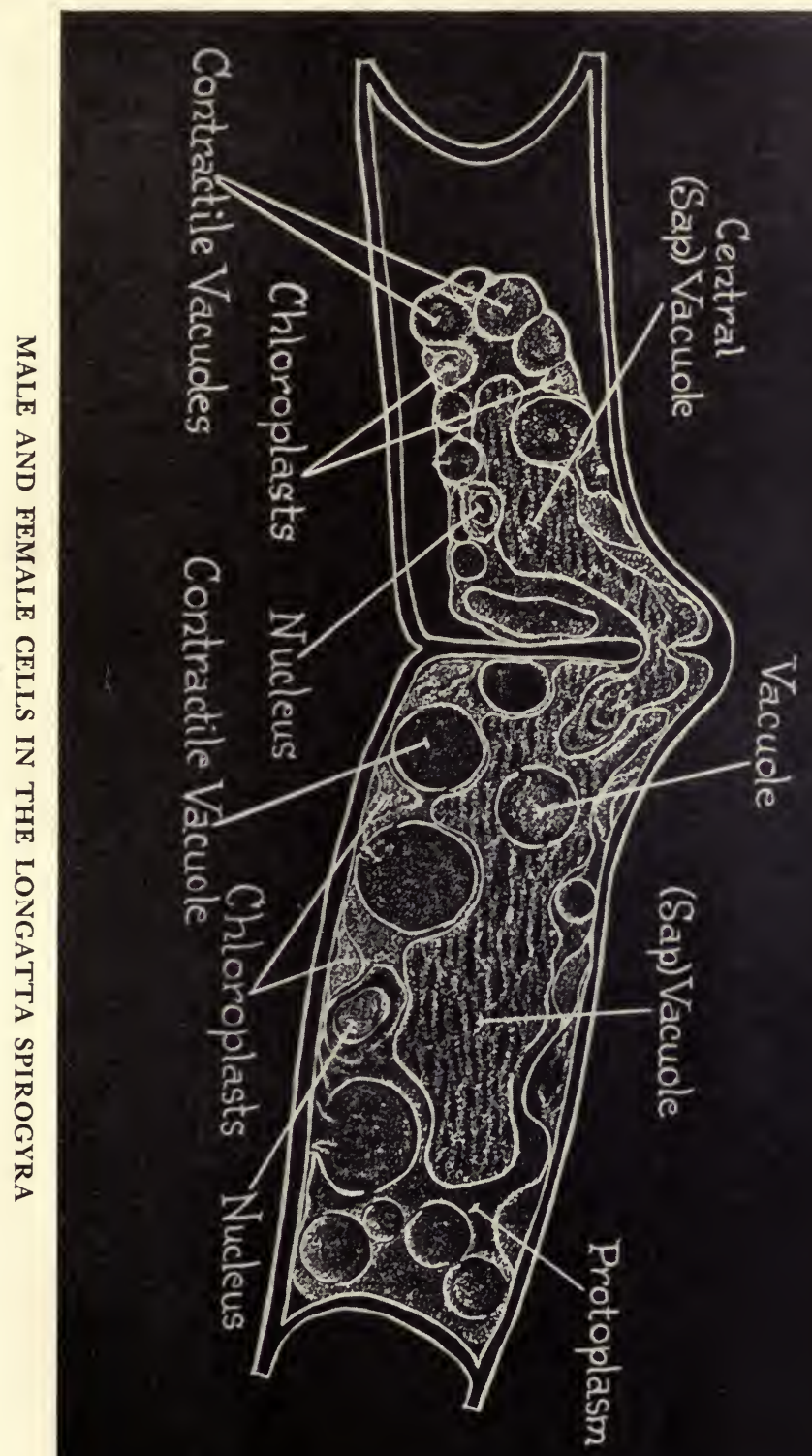


my faithful ally, the camera, into action and watched the male gamete battering down the still existing partition wall and passing over which required only ten or fifteen minutes. For this period the camera was running at a speed that gave about twenty or twenty-five feet on the screen. After the mingling of the gametes the speed of the camera was always slowed down gradually or once or twice as the movement of the gametes, at first very active in a boilinglike movement, gradually slows, as in retarding the camera speed increases the exposure, that must be reduced also. After any first attempt and the development of the negative, and its very close scrutiny, I always know about what to expect-I would probably get one of two scenes, each lasting thirty-five or forty seconds on the screen in a week's work. Quantity production rules do not help much in this sort of work. In fact they are a positive hindrance. Personally I worked at every opportunity for four years before I got my first picture, but now that I know what to look for and the kind of material to gather, I could improve on my five minute story on the screen in a month's work. To complete the cycle of life in the Spirogyra the essential stages are the germination of the spore after its resting period. I have watched them for weeks without success. The step following germination is a matter easy to accomplish 
if you have the patience. That step would be cell division in the cells in the rapidly growing filament. This is difficult as the magnification is great enough to fill up the field with a single cell and if lower magnification is used the action would not be as dramatic. 


\section{IV}

FIRST STEPS IN MICROSCOPIC

MOTION PHOTOGRAPHY

จิยन 



\section{IV}

First Steps in Microscopic Motion Photography

WORK of the sort described in the chapter, Opening, Maturity and Passing of Flowers, took many years to accomplish and seemed to be at about the limit of its possibilities, but the desire to picture all the steps in the cycle of life of a plant instead of just the opening of its bud, which was only one step-although an important one in its life story-urged me on to more exhaustive endeavors to try to picture the more hidden steps.

Watching the germination of seeds, the root growth and root hairs, the seed splitting open and the first leaves forming, the growth of the plant, the effect of geotropism on the growing plant and roots, the forming of the buds, their opening, the life of the blossom, its dropping off, petal by petal, and the pod growing behind it-all of this was of absorbing interest, but with all of these visible steps pictured, the hidden mass of what happened in the pollen grain; just what growth means and how it is accomplished; the circulation of the sap; protoplasm and its movements; the nucleus; the chromosomes; and a host of other things, as the mingling of the nuclei 
and the forming of the new fertile seed; all remained hidden from the eye and camera lens.

Dead stained sections had been made of these microscopic life processes and still pictures made of them; but staining, which killed them, may have produced changes, not in life, and it could not be known just how true they were to life conditions.

My first attempts to solve these mysteries were crude. I bought a binocular microscope of low power, thinking the camera lens could look into one eye piece while my eye at the other watched what was going on. This gave me up to twenty times magnification, not nearly enough except for small flowers, which I could photograph direct in the camera. by similar methods.

Dr. Harper Goodspeed, of the Botany Department of the University of California, was in Yosemite at the time. He became very much interested in what I was doing and told me if I would work at the University that fall he could arrange for my use a laboratory and all equipment he had. This I did and worked six weeks with his help, the first week with no results. I could not get my picture sharp. I stopped taking pictures and commenced experimenting with many sorts of combinations of lenses and methods, trying to get an image of a grain of pollen about a third of an inch in diameter in the camera, 


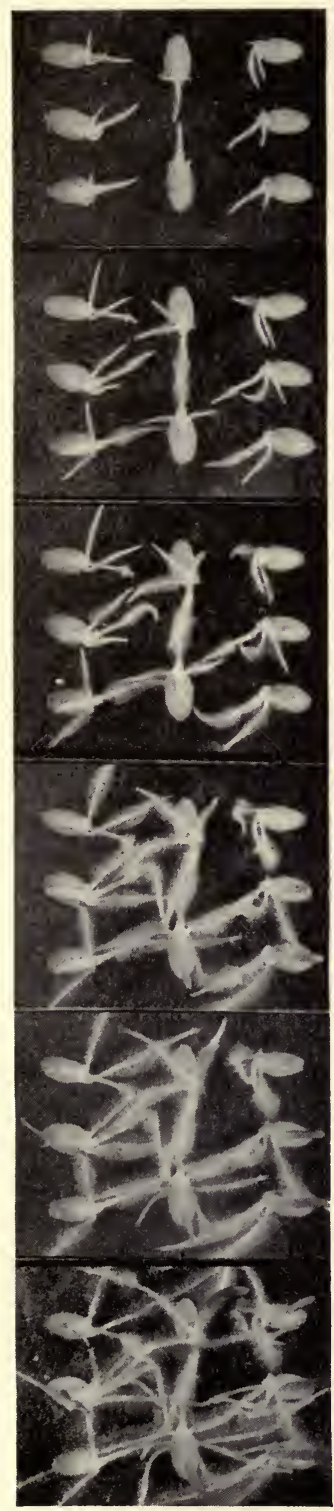

\section{WHEAT}

First the Roots

Then the Root

Hairs

Then the Leaves

\section{BEANS}

First the Roots Then the Cotyledons from which the Leaves Grow

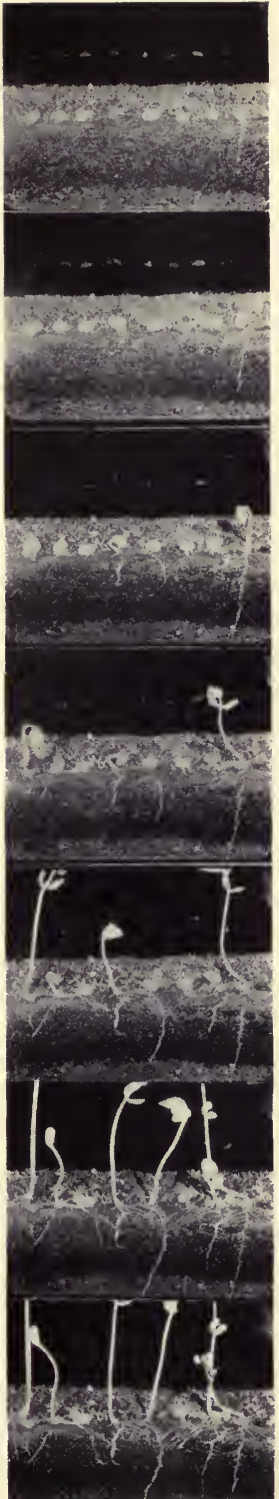



First Steps in Microscopic Motion Photography 95 which meant a magnification of about two hundred and fifty diameters. If I got the top of the grain sharp, the center and bottom would be out of focus and if the middle plane were sharp the top and bottom would be out. After many trials I found that by using a low power lens I could get a small image perfectly sharp. I focused on a piece of ground glass in place of the eye piece, then with a second microscope I was enabled to magnify that sharp image as much as I desired. I found that if I picked the image up from the ground glass, the result was granular, but that I could remove the ground glass and pick it up out of the air. That gave me the desired size of the object on the film and sharp in all its planes.

I made a wooden track with carriages sliding back and forth, fastened the camera at one end, the light at the other, then built carriages for each microscope; these were in perfect alignment from the light to the center of the film. The results were good, but not as perfect as I wanted. The student lenses were old and scratched and the condensers in poor shape and of an old style.

I bought the best compound microscope I could find and a set of achromatic lenses, eye pieces and condensers, and then started to take pictures of sweet pea pollen germinating in a drop of sweetened water. This brought immediate results and some 
wonderful pictures. Each day I made a new view and finished them as fast as they were made. On the last day I had four or five hundred feet. All the instructors who could crowd into the little makeshift basement laboratory were there to see the results and I was very anxious to get their reactions. After the short showing was over, Dr. Setchel, whose opinion I was most anxious to get, turned to Dr. Holman and said: "What have we just seen, Doctor?" It rather startled him and he began talking about Brownic movements in protoplasm. They all had seen something for the first time and they wanted to think about it before expressing an opinion, but were very sure there were unlimited possibilities for future work.

I realized that the very best equipment was necessary for this kind of work, so I placed an order for another microscope, a long steel bar that "floated" on springs at each end, iron carriages for each microscope and camera, special lights and carriages for them and a large assortment of other necessary attachments. I then started out on a lecture tour to earn the money to pay for them, and for a new camera suitable for the work.

That first unit cost over $\$ 5,000$ and was all ready for me three months later on my return. I used it in Yosemite that season and in the fall took it to Hon- 


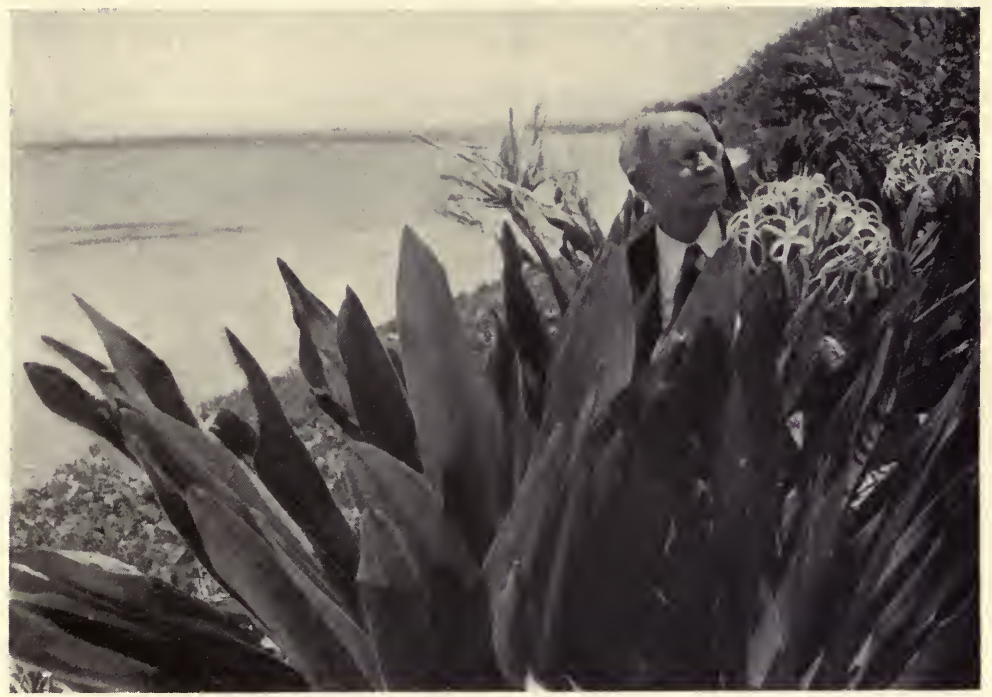

THE AUTHOR IN HAWAII AND THE SPIDER LILY

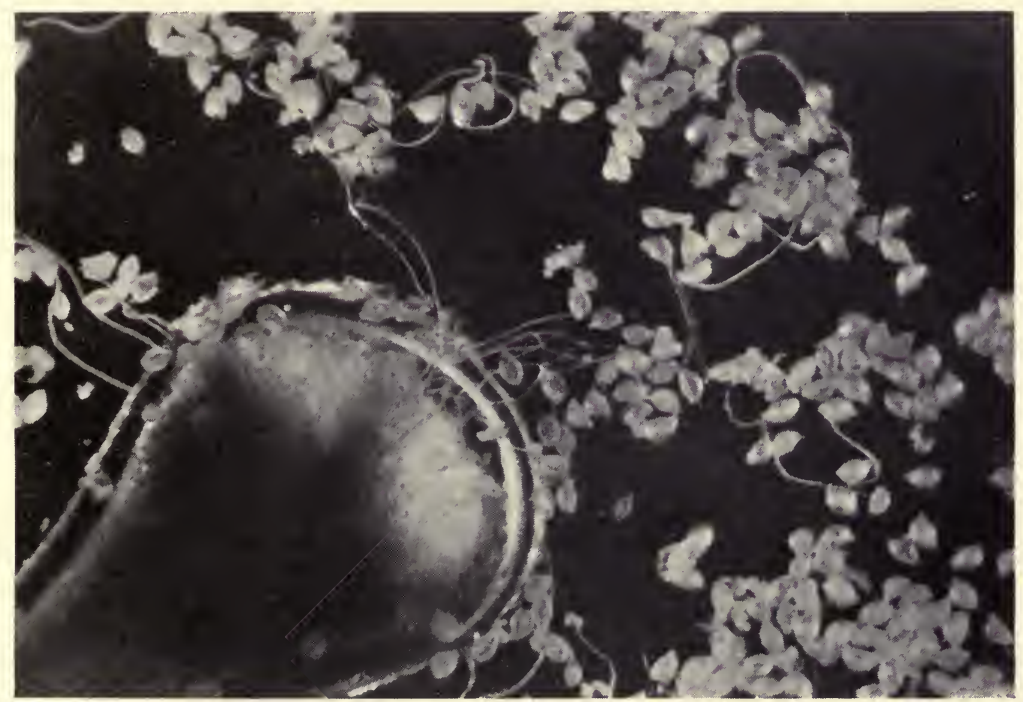

SPIDER LILY POLLEN SHOWING SEX ATTRACTION

Tubes that have Entered the Stigma. The more Distant Grains Outside Grow in any Direction 
. 
First Steps in Microscopic Motion Photography 97 olulu, where I worked on the subtropical flowers.

I made a practice of studying the pollen of every flower I worked on and the Spider Lily (Hymenocallis) pollen, I found, had a visible nucleus, one I could picture. That was the first time I, or anyone else, had seen the nucleus of pollen in life. The thrill of a lifetime! It was quite large, crescent shaped, and reddish in color and became visible in about twenty minutes after the grain was put in a drop of sweetened water. The camera pictured it swimming around and around inside the grain and going down the tube as it germinated.

Another wonderful thing about the pollen was that if I should cut a very tiny shaving off of the end of the stigma, put it on one side of a drop of sweetened water, sprinkle pollen grains around it, those nearest the stigma, in what might be called the zone of attraction, germinated first, while the pollen grains just a little farther away, outside of this radius would not start germinating for perhaps a half hour later. The tubes as they grew from the grains crossed the field and entered the stigma. No matter what the obstruction, they grew over or under it or pushed it to one side. Then to watch for the first time it had been seen in active life, the nucleus, the germ of life, as it came out of the grain, traveled down the tube and entered the stigma. To ponder the reason, the 
why and wherefore, of nature's struggles to carry on, the difficulties to overcome, make one realize that the Guiding Hand must control all life, that one cannot well be a student of life and an atheist.

This Spider Lily (Hymenocallis) pollen is the only one in over five hundred kinds with which I have worked in which I found a visible nucleus in a live specimen. The nucleus, the male element in flowering plants, is in every pollen grain, but had not until this time been visible except in dead stained subjects. The staining kills it but makes it visible, and just what changes take place in staining and killing are unknown. So studying the cut sections may not lead to the true conclusion of what really takes place. I felt that if they could be pictured in life, under conditions identical with nature, I could, with the aid of the lapse-time camera, without deviation, follow and make visible the slow natural movements of this phase of life. This I did, and so have been enabled to record a truer conception than is gained in any other way.

What happens to a grain of pollen in sweetened water can be followed very easily. If the right percentage of sugar is present, duplicating as nearly as possible the secretion from the stigma, it will absorb the mixture. Turgor, ever a driving force in nature, sets in, that is, the internal pressure is greater than 


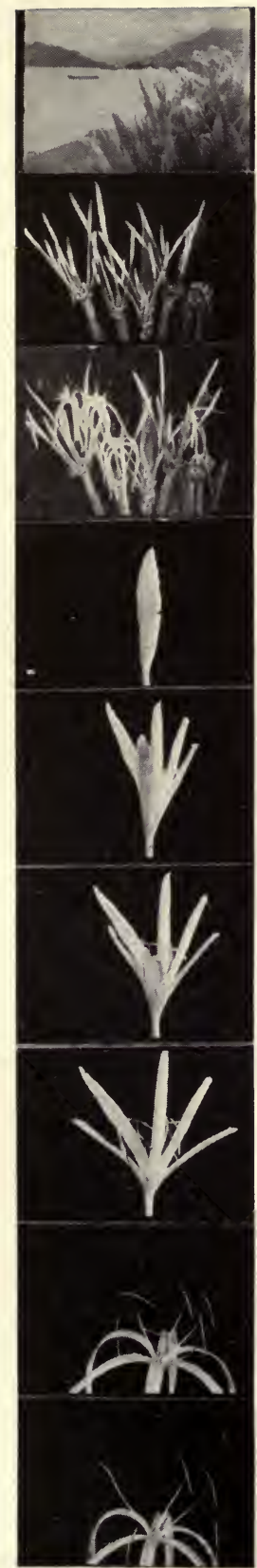

Pollen Grains

about $1 / 100$ inch

Grain, Tube and Protoplasm

Tubes will Push Aside an Obstacle

Dark Field Illumination

The Nucleus

Travels down the Tube to enter the Stigma

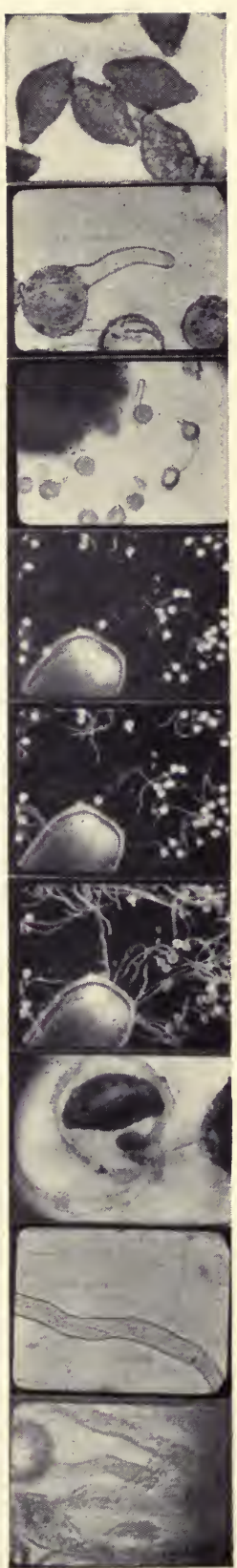




\section{.}


First Steps in Microscopic Motion Photography 99 the external; the pollen grain tries to expand, the outer skin not being elastic, bursts, and the inner skin pushes out through the opening and continues to grow in a tube-like shape, following the line of least resistance or growing toward the stigma. If it is near enough to attract it, the grain plus the growing tube is actually increased in volume on account of the water taken in. It really begins active life in the grain when the protoplasm, before inactive, or resting, starts moving very rapidly, flowing out of the grain into the tube, pushing its growing point ahead. It seems to follow a definite channel, down one side to the point and back on the other, entering the grain again in a never ceasing river of circulating life. Just how the grain by absorbing the sweetened water starts active from passive life is unknown, presumably just as a grain of wheat or a kernel of corn, given moisture and heat, achieves life and begins its growth.

The protoplasm seemingly in tiny globules having a more or less granular appearance, does not move at a uniform speed. It flows rapidly, almost stops, seems at times to turn and retrace its flow, then as if an obstruction were removed rushes forward again like a freshet released by the thawing of an early spring blockade. This circulatory movement goes on in the sweetpea pollen for four or five hours, less and 
less protoplasm returning into the grain until finally the grain empties itself. Then rather suddenly the cell walls collapse and the grain becomes a mere shadow of its former size. The tube then continues to grow till it enters the stigma, through it, and the length of the pistil into the ovary.

Down this tube some distance back from the growing point, the nucleus seems to drift with the protoplasm; it often stops and the granular globules of protoplasm can be watched passing and repassing it. This nucleus must have very much the same refractive power as the protoplasm and growing tube, as I have been unable to observe it except in the Spider Lily. In size it is about one third as long as the grain, jointed at both ends, which are made up of dark brownish masses. The length of the center portion is transparent and colorless. I have been able to picture its story from the time it becomes first visible in the grain while in its swimming-like motions around and around inside the grain cell, emerging and passing through the tube and entering the stigma. An enormous amount of research work could be done on this Crinum, familiarly known as "Spider Lily," adding immeasurably to our present knowledge of what really happens in that vital step of plant life. 


\section{V}

MICROSCOPIC MOTION PHOTOGRAPHY

จี 


\section{V}

\section{Microscopic Motion Photography}

AFTER being well started and getting successful lapse-time pictures of growing life the equipment for microscopic work may be assembled. Some wonderful pictures have been made by putting the camera on a soap box, level with the lens of the microscope and turning it by hand. But I would say it is impossible to depend on good results if you use that method. The most essential thing is extreme rigidness, ease of handling, and accuracy. I have seen a discarded lathe bed used successfully, but would advise the equipment made by the large microscope dealers, as it is not so expensive. See them all and then decide which best suits your needs, and purse. It should consist of a well-machined bar, tube, or triangular base for the carriages to slide on-six feet is ample length. The carriages to hold microscopes, camera, lapse-time motor gear, light, etc., should slide back and forth accurately and be so arranged that they may be raised and lowered with extension legs, and the more accurate adjustments with a micrometer device. That equipment bolted on a solid table, or better still, a plank fastened on con- 
crete piers imbedded in the cement floor, should give steady pictures.

The microscope should be of the best standard make. It should have mechanical stage, horizontal, and vertical movements and also revolving and centering devices. I have two. One cost $\$ 375$, without lenses or eye pieces, the other $\$ 15^{0}$, and the latter is in its case most of the time as it lacks so many adjustments. For special comparative work I often use a tandem microscope. This, without lens, cost only \$10, second hand. As to lenses and eye pieces, the best are necessary. I have achromatic sets from $3 \mathrm{~mm}$. to $16 \mathrm{~mm}$. and lower power ones up to $48 \mathrm{~mm}$. If I want the greatest depth of focus I use an $81 / 4$ " $5 \times 7$ camera lens, and magnify the image with the tandem microscope to whatever size I wish. The eye pieces should be in steps from o to 24 times. An outfit with all the needful attachments will cost from $\$ 3,000$ to $\$ 5,000$, including camera. It is advisable to get or make the special equipment as needed. I have seen all sorts of setups, homemade and otherwise, some of them getting good results, but the things that will enable you to do the same things over and over quickly and accurately, in handling the microscope and camera, are the things that count. The careful mounting of microscopes and camera is most essential. What the cost of an outfit will be is 


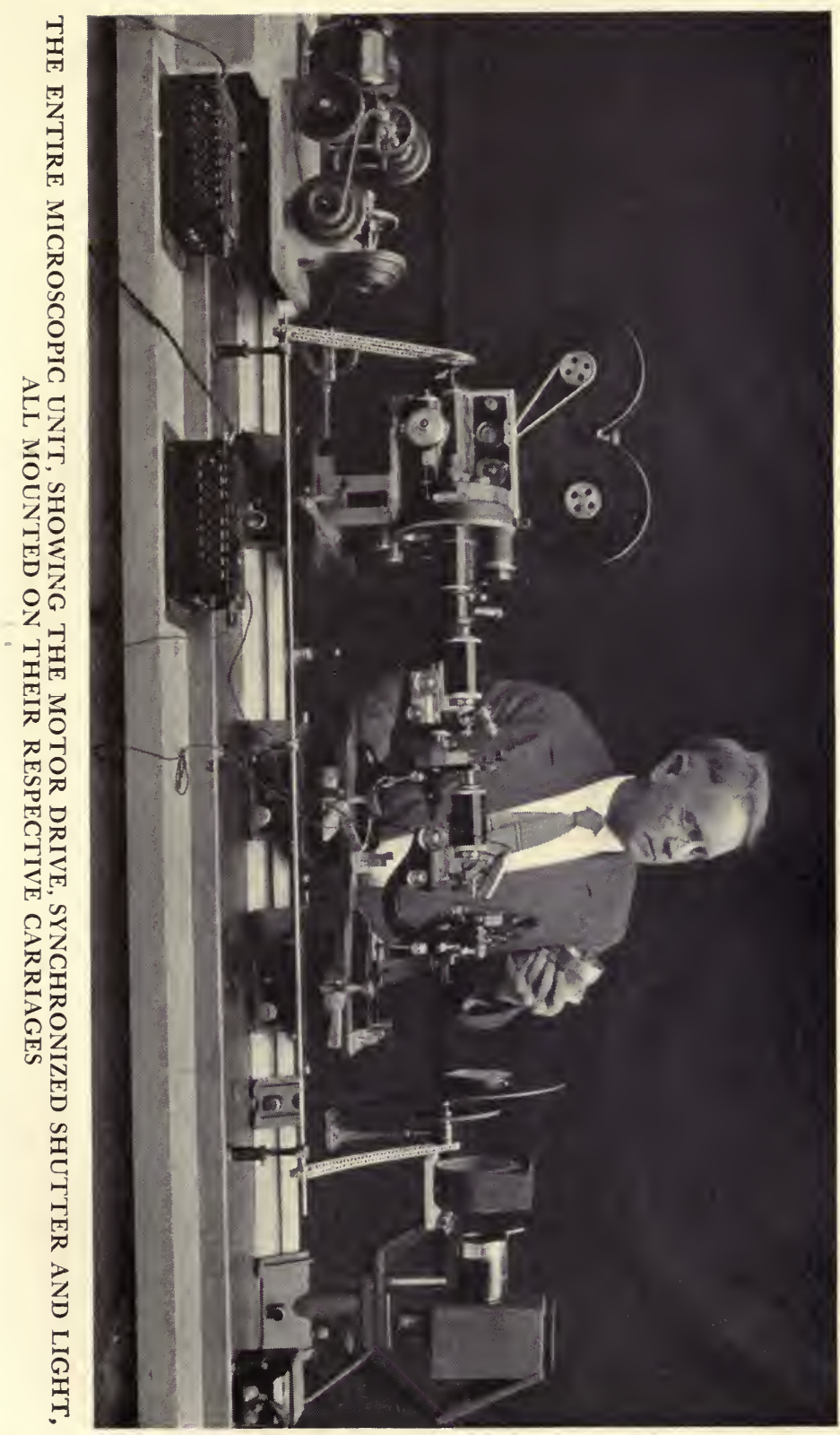



hard to say-the mountings may cost up to \$300and if you are doing it for a life work it is well spent, even considering that a homemade wooden outfit may cost only $\$ 5$.

Microscopic Motion Photography is a science requiring the greatest amount of skill and patience, combined with an immense amount of special apparatus. A microscopic unit is never complete, each subject is apt to require some special device, and must be so assembled that you can photograph anything as large as a fly down to the bacteria that develop under a hair on his toe, and to be usable at distances of from $1 \mathrm{~mm}$. to infinity. I can picture the moon with mine, getting an image to nicely fill the field.

For real service, you must be able to get a focus with direct or dark field illumination with magnification from the original size up to 1,500 times, within twenty seconds of placing the subject on the stage. The stage itself should have mechanical up and down and horizontal as well as revolving movements and all so arranged that these may be motor driven at any speed. This is necessary if you wish to make steady panoramic motion pictures, as it is impossible to turn the small adjusting screws by hand and get a steady picture.

Both microscope and camera should be on car- 
riages, sliding back and forth on the same track and so arranged that both may be raised or lowered in very small fractions of an inch, and moved in contact with a light trap device on the camera instantly. The microscope should have a viewing prism between the eye piece and the camera, so the image may be watched all the time, if necessary.

There should be an auxiliary shutter synchronized with the camera shutter between the light and the microscope, keeping the subject in the dark except at the instant of exposure.

The entire unit, microscope, light, camera, carriages, and track should be hinged solidly, allowing it to be tilted up for liquid subjects, although the horizontal position is more convenient for most work.

Spotlights or reflecting prisms in the microscope are necessary for top lighting of opaque subjects and cooling chambers for all forms of lighting; a complete set of lenses from oil immersion to at least $50 \mathrm{~mm}$. and eye pieces and condensers. These should be of the best make and kept perfectly clean.

Each one has his own method of accomplishing the desired result. I, of course, am no exception. I have developed a tandem microscope that has many advantages; one of the greatest is, I am able to get the required magnification in the camera, with low 
power lenses, and for picture work, a greater depth of focus. I am able, for example, to get all levels of a pollen grain sharp when the image is $1 / 3$ of an inch long in the camera, showing the nucleus, a yard long on the screen.

This tandem device also allows me to use a dark field illuminator, which I designed and made, that passes much more light than any other on the market. It was figured for a $16 \mathrm{~mm}$. or lower power lens and is so easy to use I can prepare my slide, walk from the bench to the microscope, put it on the stage, and start the camera with a magnification of up to 1,800 times, in twenty seconds-quite an object when working with a subject that does not live long, or its action about to begin.

Most workers laugh at the tandem microscope. They do so without having tried it, and I am not selling it, or the idea, only getting results. I am not troubled by their smiles. One of the Eastman research men said it was all wrong-that two and two made four, and there was nothing gained, but one of the younger men in the same department said, "Yes, two and two make four, but three and one do also, and perhaps that method will give a better picture."

Any microscopic unit must be mechanically accurate and solid; each element slides on its own car- 
riage, and is in perfect alignment, from the light through the microscopes, to the center of the film, and so made any one of the elements may slide back and forth, be taken off and replaced in the same perfect alignment.

The camera must be the very best. If in $35 \mathrm{~mm}$., either a Bell and Howell, or a Mitchell, and very heavily mounted. These cameras have no vibration in their movements, and will carry film up to thirty frames a second without undue wear.

The Mitchell has the advantage of the lens staying in one position to focus while the camera slides to one side, but it costs about $\$ 4,000$. The Bell and Howell, costing half that, has a turret head for the lens to revolve in, but that method of focusing is not suitable for microscopic work, so I found it advisable to focus on the aperture, even though I have to look at it diagonally, but with a prism and a magnifying glass, I can work with perfect accuracy. I also have a reflecting prism that stops about $15 \%$ of the light; I can watch the subject through it all the time, unless it is something that requires all the light for a comparatively short time, watching till all is ready, then flipping the prism out of range, taking the picture, and flipping it back to see if all is well.

In most of my work I use the tandem microscopes, but for extremely high magnifications I use the oil- 
immersion lenses and the single microscope. It takes only a moment to change. It only means sliding the camera up to the first one-it meshes with the light trap just the same, so I use whichever method is best adapted to the subject.

Mounting a subject calls for special handling. I find an excellent way is to cement with just a little paraffin a glass ring about $7 / 8$ in diameter, and $1 / 16$ to $1 / 8$ " thick, on the slide, put vaseline on the ring, stand it on edge, and put a drop of water in the lower side. Then put my subject on the cover slip, invert it on the ring, the vaseline holds it temporarily, in a moist air chamber, with a drop of paraffin on either side-it is ready for work and in such an air chamber it will live for hours.

Sometimes it is necessary to provide fresh water continuously for subjects that require a long period for development; for example, the forming of the embryo in a fish egg, which took four days before it hatched. This was done by first cementing a tiny glass ring about $1 / 8$ " in diameter and $1 / 16^{\prime \prime}$ high, on the slide, then a large ring around it about $7 / 8$ " in diameter and $1 / 2$ " high, into which I had drilled two holes on opposite sides. Into these holes I cemented tiny funnels, bent upward, one a little higher than the other, the low one leading to a beaker to catch the overflow. 
It took some time to make this device, but I saw no other way to do it-putting the egg in the small center ring-a tiny bit of cover slip over the top to keep the egg in one position. The reservoir had a continuous change of water, from the beaker from which I led a slip of filter paper to the higher funnel. By regulating the size of the filter paper to the higher funnel, a drop of water could be let into the reservoir as often as required without moving the egg, which was continuously in contact with the water in the large chamber.

But this solved the problem of keeping the embryo alive and growing till it hatched four days later and showed, by the lapse-time method, in thirty-five seconds on the screen. In this picture the tandem microscope was used, as the lens, of necessity, had to be at considerable distance from the subject, and the necessary enlargement of the film was obtained by enlarging the first image made by the primary microscope.

The exposures were made at ten-minute intervals; the auxiliary shutter was used, so there was no trouble of the water heating, as the light passing through it was only eight seconds every ten minutes. The result was thirty-six feet of film from the start to the hatching, which really should have been made at a faster speed, as the action was faster. 
Each microscopic picture made is an engineering problem and the difficulties to overcome are in their way as great as building a bridge across a river. Many subjects require a great deal of time, first to gain a knowledge of their habits. Spirogyra for example; it is easy to take all sorts of pictures of it, some of them showing some action, but action that few people have seen, like the act of conjugation, is the most thrilling step in its life story, and it means hours of patient watching.

I am planning to add to my equipment one of the new automatic reflecting arc-lights, and a high speed camera, to enable me to work on bacteria. My present cameras will not carry film faster than thirty frames a second, without too much vibration, and my lights, with dark field illumination, are not strong enough to give full exposure at higher speeds which are necessary, and as I mentioned before, a microscopic unit is never complete-each subject requires special methods and apparatus, making it doubly expensive. 
, 


\section{VI}

CACTUS AND SUCGULENTS

(ข) 



\section{VI}

\section{Cactus and Succulents}

CActus and succulent lovers soon acquire a form of fever which seems to be reducing, I presume on account of the immense labor in memorizing the awful names they have. I used to think there were only two things a man had that were above reproach, his wife and his car, but now I know you should not refer to his cactus collection in anything but superlative terms if you wish to remain a friend.

Many cactus and succulents look much alike but there are five points that at once put cacti in a class by themselves and lacking any one of these determines whether they are something else. They are, first, the seeds have two cotyledons, with the baby cactus growing between them. Second, the fruit is a one-celled berry with no partitions between the seeds. Third, it must have spine cushions whether it has spines or not. Fourth, the ovary or seed pod must be below the petals and sepals. Fifth, it must be a perennial-many live for several or even hundreds of years, as the Carnegie Gigantea. Examine your specimen from this standpoint and you can very soon tell if it is of the Cactaceae family. 
In working with cacti one becomes very much attached to them on account of their wonderfully beautiful and often extraordinary blossoms. Often a tiny plant, not as large as a small hen's egg, will have a bud shoot up from it and a blossom larger than your fist of most exquisite texture and color, more delicate than the orchid, larger flowers than the iris and of more beautiful coloring than the rose. Flowers of the Epiphyllums, a foot across, with colors and shades not found in any other one family of plantsthe spines sometimes rival the feathers of the Bird of Paradise, often eight inches long, curved or dagger-shaped. The buds usually take two or three days to open, making what look like false starts, opening part way and closing, then a little wider the next day, and usually wide open the third day. Often the petals, almost like a butterfly's wing, flutter when they are wide open, not noticeably to the eye, but the unerring lapse-time camera registers some very interesting movements. The blossoms often live two or three days before they fade.

In the Cereus, there are many, many kinds, but our fondest memories of them go back to Honolulu and the hedge at the Punahou School where some nights 5,000 of them can be counted. My first experience was unique. We had arrived by ship the day before, our car loaded with cameras, microscope mo- 

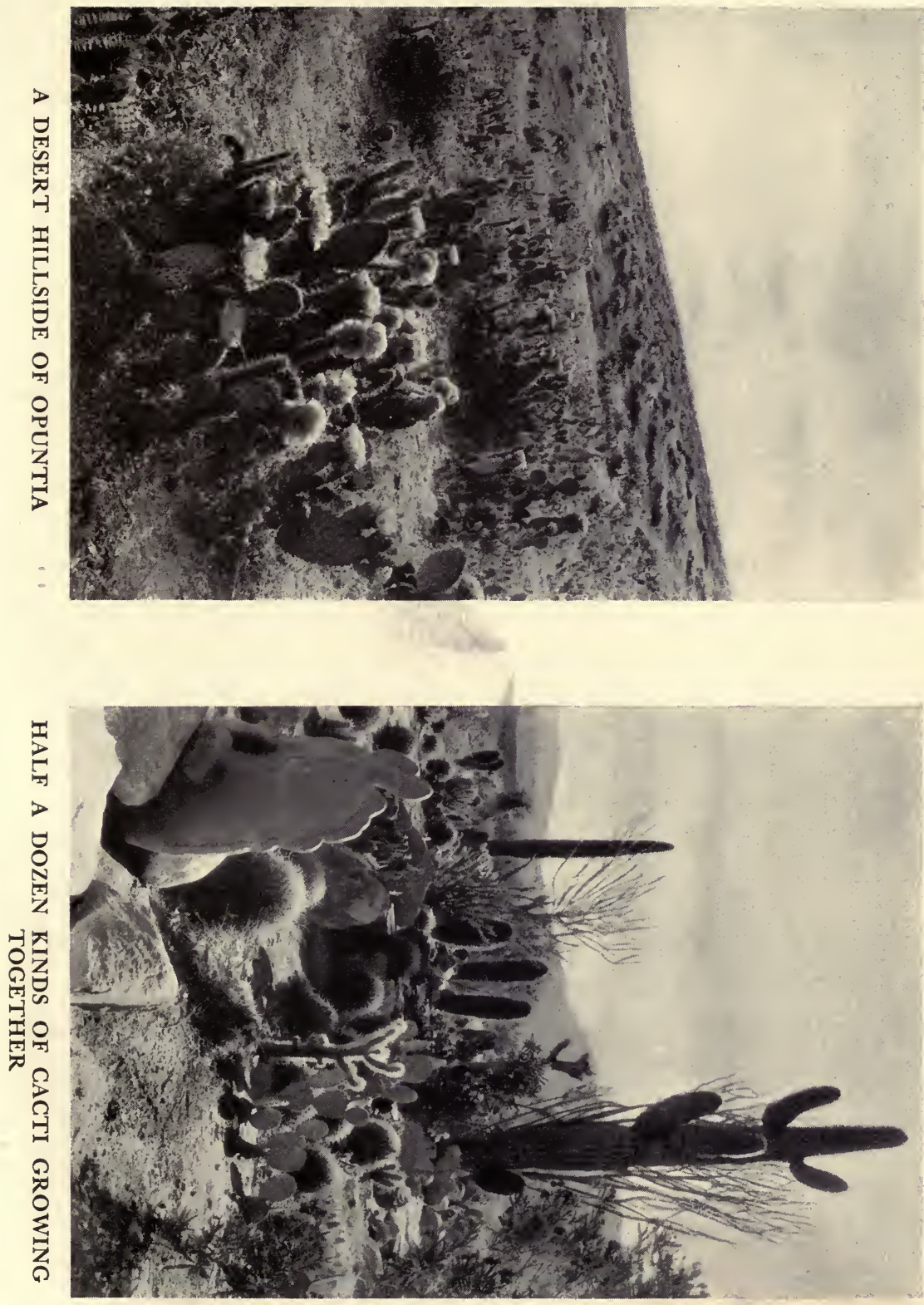
tors and all sorts of apparatus for my laboratory. We found a suitable place and unloaded and set up the cameras for lapse-time work that night. On our first morning we were up almost at daylight and went out to the school hedge to see what we could see. It was almost white with the mammoth blossoms, hundreds of them, and swarms of bees were all around them. I made my pictures as quickly as possible, knowing they would soon fade and then we went to the school office to get permission to cut buds to work on that night. Just as we arrived, one of the young lady teachers had an attack of illness and as our car was the only available one, we rushed her through town to the hospital, our siren screaming and a motor officer clearing and showing us the way.

Returning, we were told we could have anything we wanted and best of all we were introduced to Professor Wilbur MacNeal and Mrs. MacNeal, delightful people, conversant with Hawaiian flowers and deeply interested in my work, and through their efforts there was no possible chance of any of the cameras being idle.

That evening I made my first lapse-time picture of two buds, starting the camera at about five o'clock, making exposures every twenty seconds. By nine they were in full bloom and by 10:30 o'clock I thought they were beginning to close, so I slowed 
the camera down to two minute intervals and by nine the next morning they were withered and gone, dejected little wisps of a departed splendor. On the screen it takes just as long to see the opening and closing as it does for me to tell about it.

The next night I made a close-up of a single bud. The lights were placed rather far forward on either side. When it first opened it was like looking into a dark cave, all sides of which were lined with anthers. The opening petals and anthers allowed the light to shine in to the center of the flower, which now more than filled the screen. The effect was startlingly beautiful.

The following evening we were invited to Mrs. Damon's beautiful home on the "Island." There were a few acres, her home in the center, built all open in Chinese style, paths leading in all directions. There were literally thousands of the great Cereus blossoms in the trees fifty feet above the ground, others on the ground or anywhere they could find a place to cling. They looked like great snowballs after a wet, clinging storm. It was a moonlight nightFairyland was the only way to express it. Early the next morning we went there again and persuaded that dear lady who has done so much, especially for the Chinese in the Islands, to pose, holding some blossoms. They were almost as large as her head. 


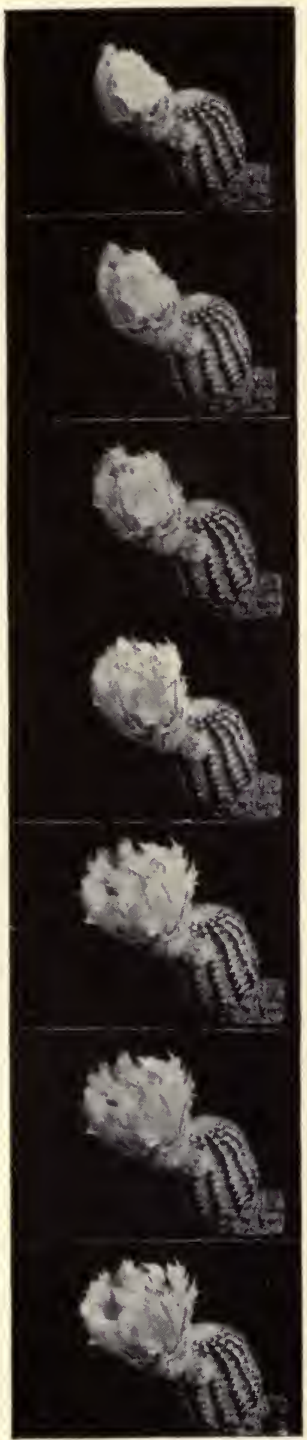

MOST CACTI

REQUIRE TWO

DAYS TO OPEN 

Picturing almost any of the Cereus is comparatively easy. It is not hard to judge when the buds will open, how large they will be, and how long they will last, as you can tell how to gauge the speed of the camera. I have had five buds of the Heliocereus specimens open one after the other in rapid succession. They were all on the same short branch and their brilliant iridescent coloring made a wonderful showing.

The Echinopsis multiplex is the most dramatic flower I have yet pictured. I had one with six buds of these shimmering pink cacti, all about the same size and all pointing in the same direction. The stem to the bud grows about six inches before the blossoms open and these six buds grew resembling snake's-heads toward the camera. It took them four days, the buds getting larger all the time. I placed them in a very beautiful rock garden, rocks and crystals of many colors. The camera that was facing the cluster was picturing them in Technicolor, so the color of the stones was being registered as well as the plant and buds and another camera at the same time was taking a side view.

The buds all opened into two rows one above the other of three each. The combined cluster was fourteen inches long and eight high. The opening took place between 10 P.M. and 7 A.M. It was a sight well 
worth staying up for and just filling up the upper half of the picture, those six perfect blossoms each nearly six inches in diameter, crowding each other and making one solid mass of beauty, where in the picture a few seconds before were those six snake'shead-like buds. The blossoms are of a delicate pink shading into a deeper tone and last nearly a week. After the flowering small baby-like plants start on all sides of the mother and they look like a mother and her family. They can be taken off so you will soon have quite a group.

The Rainbow cactus is another interesting one to work with. The plant may grow ten or twelve inches high; round, column-like with well defined bands of color around it so the plant itself is very ornamental. Sometimes two or three buds grow out near the top and open up into large carmine-red coloration, unsurpassed in brilliancy, changing with dazzling iridescence as the light changes on them.

Many cacti absolutely refuse to open by electric light in front of the camera. The little button cactus closes immediately it is brought in. One might think them "camera shy" were it not for their opening by a "Sunshine" light, however, and that same method can be used where the blue Mazda fails.

The succulents were not as interesting to me from the picture standpoint, so I have worked less with 


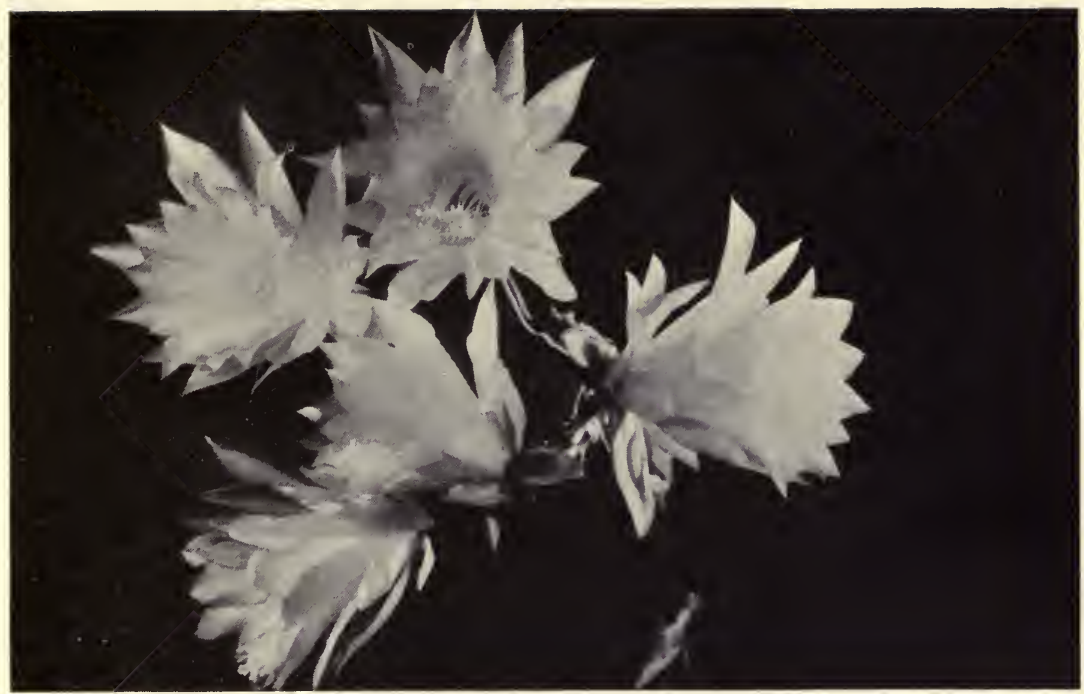

\section{NIGHT-BLOOMING CEREUS}

Beautiful Scarlet with Cerise Shadings, one of a hundred kinds

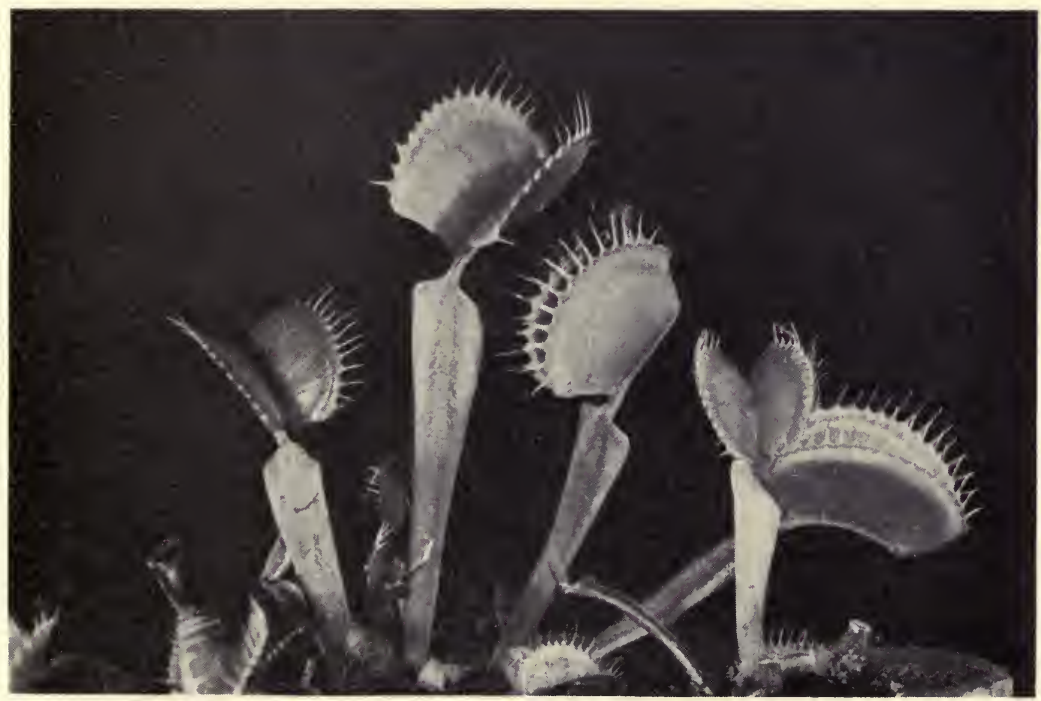

VENUS FLY-TRAP

The Leaves Close up and Imprison the Insect 

them. Some of them, however, are very odd and look like anything except a flower. The Stapelia have such peculiar habits and blossoms. They are interesting. The flowers are all queer shapes and colors opening rather suddenly, then closing into a rather tight ball. There is a peculiar disagreeable odor that attracts flies. The first one I worked on when the bud first opened, a large "blue bottle" fly deposited a mass of eggs among the hairy anthers. In eight hours they all hatched and there was a colony of crawling maggots in it. Really not a nice addition to my movie party, but attracting much attention. The flower closed tightly at this period so I do not know whether or not they found sustenance for their five days pre-pupa stage-this time of continuous eating which must sustain them during this period. 


\section{VII}

THE LEAF

ขै⿲二丨 



\section{VII}

\section{The Leaf}

LEAVES are uncountable in numbers, shapes and forms, but they easily group themselves into three general forms like a Blade of Grass, one of the Oak Tree type, and Needle-shaped like the pine. Environment has altered their size and form into millions of shapes and sizes. The fierce heat of the sun in the desert has decreased their size and often made them grow with an edge to the sun during the daytime and in the tropics they are large and in the dense jungles they strive to reach the sun in every way, while in our temperate zones they are apt to grow in mosaic, giving all the surface possible to the sun.

To us, leaves are the commonest things possible; so used are we to them we pass them by without a glance-a field of grain, a beautiful tree, a rose bush -we even examine the wheat, or estimate the lumber in the tree-we see the rose and almost never the leaf, and so the most wonderful thing of all, on which our lives depend, we seldom notice. And as the plant could not exist without them or some part that takes their place, like the outer surface of the 
cactus plant which serves the same purpose, we could not get along without the Leaf and what it brings to us.

Man could not devise a better method of presenting innumerable comparatively small surfaces to the sun than nature has in the arrangement of leaves supported by branches reaching out in every direction. If the forest is dense the trees bearing the leaves are tall; if only scattering, the branches are long. Each leaf must have sunshine to do its part in furnishing food for the whole tree or plant, so they arrange themselves into such a position as to get the maximum of sun required. We are accustomed to thinking of trees as motionless things, except as blown by the winds, and their growth so slow as hardly to be taken into account. A student of plant life realizes the opposite, and that a growing plant is full of energy. A large tree swaying in the wind is teeming with hidden life and undreamed of movement. It may have some 500,000 leaves. Using this formula $21 / 4$ times the circumference squared plus five times the circumference is equal to the number of leaves of a full grown tree. "Believe it or not." Count them if you don't. I will always look back with pleasure to one of my very few and most beneficial talks with the late Dr. Benedict, who was in charge of the Botany Department of the University 
of Cincinnati. I met him in the forest this time, and he was busy actually counting leaves to prove his formula. He was one of the few teachers who could so enthuse his classes they would climb to the topmost branch to count leaves if he thought it necessary, or do anything else to obtain knowledge. His untimely end was a great loss to the world.

A tree of four or five hundred thousand leaves would take up from the ground in a day of eight hours of sunshine some 500 pails of water. That means almost a pail a minute elevated to perhaps an average of 100 feet, some effort if we had to perform the labor. That amount of moisture is taken from the ground by capillary attraction, forced, pumped, or by osmotic pressure, however the action is expressed, and it is not well understood, but that quantity is lifted every day. It supplies needed moisture to the ever-growing and dividing cells, up from the root hairs that start it on its journey, through the roots, the trunk, the branch and to the leaf, that wonderful factory-more wonderful than any of our most modern ones, because it furnishes at once its own power and product.

The moisture's first duty is to keep the factory cool and moist, passing through the leaf and out of the tiny stoma or mouths of the leaf, which may be as numerous as 50,000 to the square inch of leaf sur- 
face. It passes through these tiny openings as vapor.

Analyze the energy to do this first work and what it takes in bare power and you would soon find all the motors, locomotives and man-developed producers of energy in the world would not equal that required for this branch of the work going on. What a field of conjecture, if that energy could be harnessed to do man's work-and it may be some day, who could tell what would happen! The most important duty of all is yet to come. In this wonderful leaf factory are all sorts of things going on. Like our factories, it has producing chambers where its product is being manufactured, storerooms where the surplus is stored away for future use, channels bringing in an endless stream of material, others carrying the surplus away. Volumes have been written and an enormous amount of research work done but still it is a mystery just how the sun shining through the small green bodies called chlorophyll grains in the leaf cell gives them the power to break up the carbon dioxide coming into the leaf in the air and combine it with the sap and change it to grape sugar or starch, one or the other or back and forth. That is what is going on, endless streams of material passing perhaps at the focal point of the green chlorophyll bodies which like huge burning glasses make this chemical change. In our laboratories it would take 


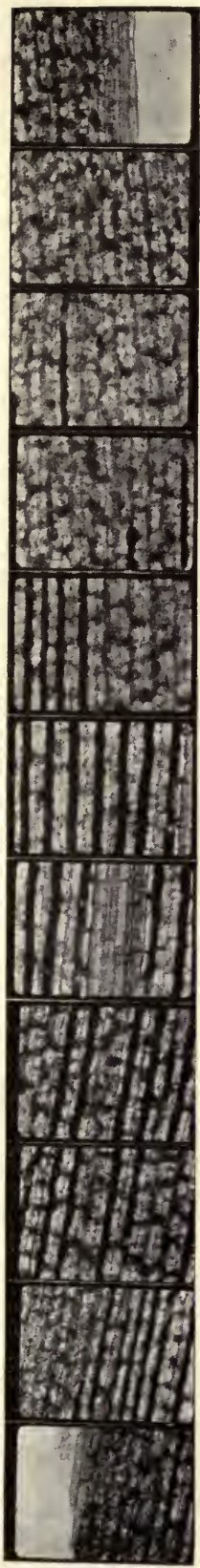
Leaf $1 / 8$ inch wide, magnified 500 times

Leaves of Buckeye unfolding from Cluster

Cells,

Chlorophyll

Grains and

Veins

Rivers of

Protoplasm

in mid rib

Other edge of

Leaf-

$1 / 8$ inch journey 

a temperature of 1,300 degrees centigrade to break down and build up that chemical change. Here in this wonderful leaf cell factory it is going on all the time, quietly and efficiently, making out of air and water its own food and storing its surplus supply away just as we do.

The cells of leaves themselves are irregular in shape and full of granular jelly-like substance called protoplasm, which is considered the basis of all life and is almost identical in both plant and animal tissue. To give an idea of how many and various shapes these cells are in a leaf and the action going on, imagine a small narrow leaf $1 / 8$ of an inch wide, under a high power microscope. You would see perhaps six or eight cells with a nucleus and twenty to seventy chlorophyll grains in each and if you looked carefully many other things. If you started looking at the edge of the leaf and then by mechanical means moved the leaf slowly the $1 / 8$ of an inch across the lens of the microscope-in that journey of $1 / 8$ of an inch you would see a thousand or more cells. At the beginning of the journey, on the edge of the leaf, the cells would be very narrow; going inland they resemble somewhat cells in a honeycomb, irregular in shape and outline. In each one is a continual procession of the chlorophyll grains going around and around endlessly. Continuing on you would pass 
veins, the channels bringing in and taking away the product of the cells, then more cells, more activity. The journey half done, you would pass the midrib like a wire rope built up of numerous channels with a constant flow up and down to supply the veins that feed the cells. Your journey of $1 / 8$ " is half done. The same view on the rest of the trip except the cells are getting smaller as you near the edge. A trip of that sort, seeing thousands of cells, twenty to seventy or more chlorophyll grains and a nucleus in each, all in constant movement, is a revelation of plant life. You also see, slightly out of focus, layers of cells, two to six of them, in lower levels. The focus limits only show one layer clearly, although they are only $1 / 1500$ of an inch apart.

A trip of this sort is impossible without the proper equipment. Perhaps I am the only one who has been able to take others on this quite wonderful and thrilling little journey of microscopic observation. My eye had the privilege of first watching for eight minutes while 2,240 pictures in 140 feet of film were being exposed, and now thousands can view with me, enlarged on a big screen, and in a minute and a half, this journey of $1 / 8$ of an inch.

Your path across the leaf seeing thousands of cells was perhaps as wide as the point of a pin. Estimate, if you can, the cells in a leaf, each one more com- 
plicated than the most intricate stop watch and much more going on in it. In our own bodies it is estimated there are twenty-eight trillion cells, each one having its own duty to perform, each one having a nucleus and protoplasm, but unlike the leaf cells without chlorophyll grains. Animal cells cannot manufacture their own food to feed the animal. They must depend on other animals or plant life. We could not exist on this world of ours without plant life. 


\section{VIII}

\section{BREAD MOLD}

ลีย 


\section{VIII}

\section{Bread Mold}

BREAD MOLD is a most interesting plant to work with and very easy to get. You do not need to hunt for it. It comes to your bait like a hungry fish. Expose almost any kind of food and the mold spores floating with the dust in the air settle on it and almost at once start to grow and soon spread all over the food, ruining it, of course, for human consumption. There are many other kinds, however, we could hardly get along without, like yeast to raise our bread, and the forms that turn cider to vinegar and ferment our wines.

I started to work trying to picture bread mold, knowing very little about it, which is a most excellent way of learning a good deal about it. A piece of bread was the bait to bring it to hand and without realizing what I have since found, that it is always necessary in picturing a life story of anything, I was starting to carry it through all its stages of life. I raised a great quantity of this fuzzy mold. It grew wonderfully well in front of the camera or under the microscope. I could watch all its stages of progress, growing very rapidly for a period, then resting 
a bit as the sporangia, little round balls, formed on the end of each filament. I could see and picture the circulation in the filament, the forming of the spores in the sporangia, while it was still growing; soon it turned dark, then black, and finally split open and discharged the spores-thousands of them from each tiny spherical ball. The circulation of the protoplasm was as regular and as easy to see as in a pollen tube. It was a steady flow back and forth in channels in the filament which was about one-hundredth of an inch in diameter. In the young, semitranslucent sporangia, it seemed to be moving in all directions as though it was boiling. This movement was visible only a short time, as it soon turned black and became opaque, hiding the actual forming of the spores.

While I was doing this work I was always looking for a zygospore but without success, when I found out that to get zygospores I must have the mold plants capable of producing them. This mold plant is really a very wonderful thing. It has two methods of reproduction-through the spores and the zygospores. Any form of bread mold will produce sporangium and it reproduces through the spores, but in order to get zygospores, I must have what you might call male and female plants, although that definition is not true because either is male or female, so it is designated as plus and minus strands in the plant. 

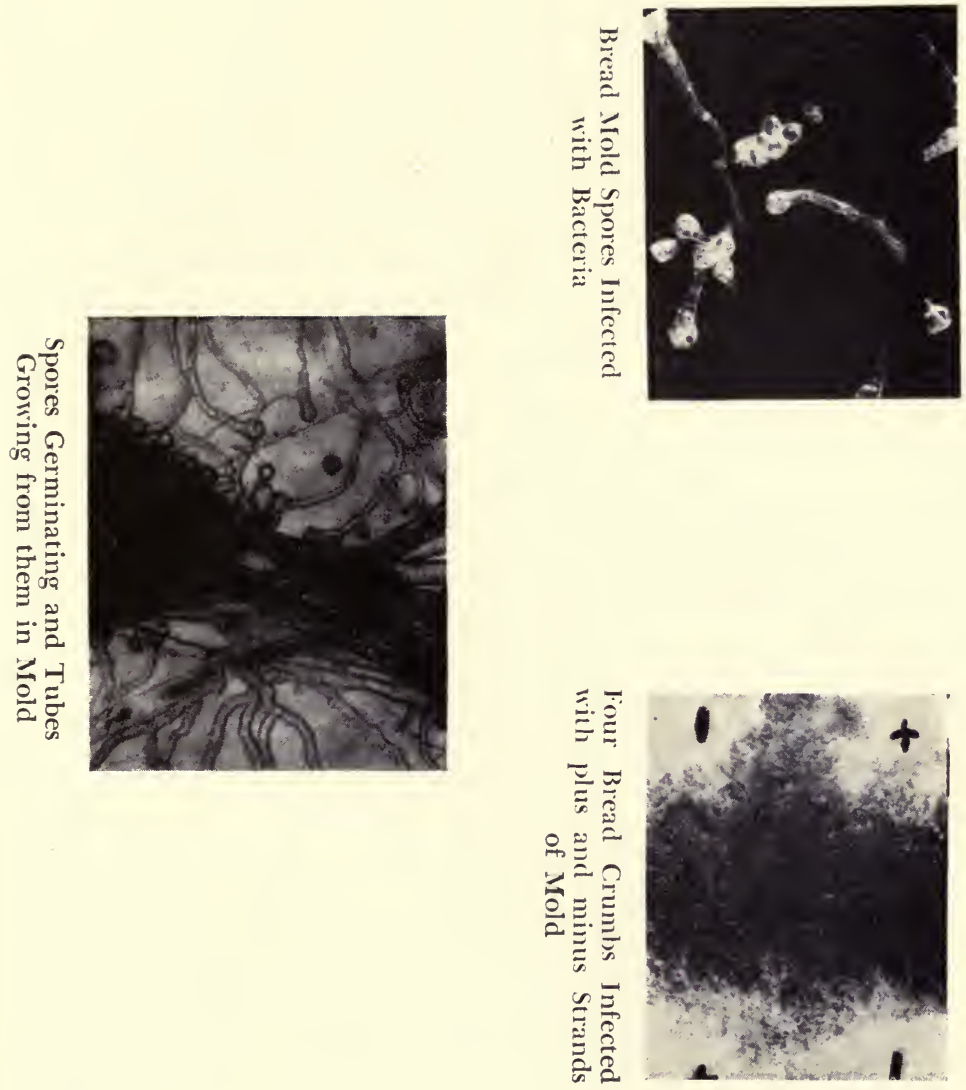
Strange to say, you very seldom get both kinds in the same neighborhood. It all runs to either the plus or the minus strand in any certain section of the country. So I had to send to one of the distant laboratories to get the needed strand with which to start my cultures. This media in hand, I infected two tiny crumbs of bread with each strand and placing them about three fourths of an inch apart, the filaments grew from each quite rapidly, spreading out in all directions and some of them from the plus strand would touch those from the minus and the union of those two strands produced a zygospore at that point. Watching the zygospore from under the microscope was extremely interesting. It was more translucent than the sporangia and the action going on inside of it was visible with back lighting up until the very last ripening process. The spores which formed inside the zygospores were just as numerous, and were discharged, as those from the sporangia. Gathering these spores and putting them in almost any kind of gelatinelike solution, they would germinate at once and a tube grow from them, which first would form a few little rootlike branches called the holdfast, and from these the filament would grow, a sporangia forming on its end. When working with these spores under the microscope, not taking any special care of them, one of my slides became 
infected with bacteria and then ensued one of the most moving and dramatic incidents of my microscopic observations. I watched them multiply and spread over all of the mold spores, killing them just as one might imagine a fever spreading through a human body. Spreading in a great cloud, it was an excellent example of two forms of plant life, one living on, and killing the other. When these sporangia and zygospores form even a very tiny colony they would be growing on a piece of bread no larger than a pea, but ripened, they scatter enough spores through the air to infect anything in that locality. They are carried by the wind, and are in the dust in every schoolroom. We are inhaling them continually, but as long as our bodies are kept healthy, they do not affect us. 


\section{IX}

X-RAY MOTION PICTURES

* 



\section{IX}

\section{X-Ray Motion Pictures}

No equipment for X-ray motion pictures is on the market and if the work is done it is first necessary to design and build the camera; make all the tests; get the X-ray equipment, costing from $\$ 75^{\circ}$ up; combine it with the camera; and a lapse-time unit, and start the experiments to learn how to operate it.

One day I was watching a large caterpillar changing into its pupa. This was not so exciting. It merely shed its skin, its legs and its horns and then went to sleep as it were, but it gave me the idea what a wonderful thing it would be if I could picture what was going on inside its body while it was changing into a great butterfly. I began to think about X-ray motion pictures. I knew nothing about X-ray work, and had not at that time taken a still picture in that way.

So I began reading everything I could get about it. Starting on a lecture tour about that time, my ideas of the requirements had crystallized into definite form, and on the Pullman I made drawings and details of the parts required, to scale. In New York I showed my drawing and talked with a doctor who had spent thousands of dollars in perfecting an 
X-ray camera. He told me his new camera costing $\$ 10,000$ would expose a $14 \times 17$ plate, move it out of the field, put in another at the rate of sixteen a second. I did not say anything but my mind at once grasped the impossibility of doing this, moving that large plate so quickly and replacing it with another. He realized, of course, that I knew nothing about X-ray work and told me I had better learn first to make still pictures.

At the General Electric Laboratories I met Dr. Coolridge. I told him what I wanted to do and he advised what kind of tube to get and offered to aid me in every way possible. A month later I started construction. The camera was designed to carry a roll of film 200 feet long and any width up to seven inches. I could not get film of that width perforated as regular motion picture film is, so I had designed an entirely new method of moving it forward and stopping, to take the picture. This did away with the "Loop" and the perforations and I could set it to draw the film a measured distance, stop it and repeat the operation as often as I wished. Later I was granted a patent on the device.

This enabled me to take a series of pictures any size I wished up to $5 \times 7$ and as often as required, from twelve a second, which seemed to be its limit of speed, up to thirty minute intervals. The distance 


\section{X-Ray Motion Pictures}

between exposures might vary $1 / 16$ of an inch but at the instant of exposure, two $1 / 32^{\prime \prime}$ holes were punched in the upper corners of each picture. These holes were perfectly synchronized with the location of the picture on the film so when it was copied to standard $35 \mathrm{~mm}$. film, a pilot pin went into each hole, giving me a perfectly steady picture, so the error of distance apart did not affect the picture. An X-ray camera uses no lens. The rays from the tube travel in a perfectly straight line. So far it has been found impossible to bend them, so in taking a picture the subject is placed as close as possible to the film. The light shines through it, making a shadow-graph on the film, bones casting a different shadow from flesh, etc. That is why it is necessary to use a larger film than the subject shadow-graphed.

My first picture was of a rose bud opening. I made a test exposure with the low voltage tube set at 9,00o volts. It took two minutes and twenty seconds so I started the camera at five minute intervals, starting one of the regular Bell and Howell cameras at the same time with Mazda light on a similar bud. The $\mathrm{X}$-ray camera would pull the film forward in this case three inches. I was using a four-inch roll so made $3 \times 4$ shadow-graphs, then the light came on, lasted $2^{\prime} 20^{\prime \prime}$, went off, the film pulled forward $3^{\prime \prime}$, winding up in the upper magazine. This was kept up for 
three days and nights. By that time I had 864 individual $3 \times 4$ shadow-graphs. The rose bud had opened into a very beautiful blossom, as had the one in front of the regular camera with just ordinary blue Mazda lights shining on it.

The negatives from both cameras were developed. The one on standard $35 \mathrm{~mm}$. film with its 864 individual pictures was fifty-four feet long and was of course easy to develop in the regular way, but the $800 \mathrm{X}$-ray shadow-graphs each $3 \times 4$ inches making a film four inches wide and 200 feet long required special equipment to handle. Finally I found a way that worked satisfactorily, but only after a good many experiments were made with dummy strips first.

The negatives turned out wonderfully well. The exposure was equal and correct throughout and it was especially interesting to watch for the first time what was going on inside the bud while it was opening as shown by the long series of shadow-graphs taken at the five-minute intervals. Even one versed in motion pictures could not see much change in consecutive pictures, but looking at every twelfth shadow-graph which would be an hour in the making, quite a change could be detected. When one works with something entirely new, and this was the first X-ray motion picture made, every point is studied step by step very carefully, including its pho- 

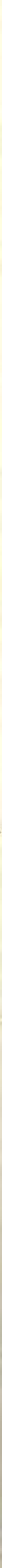

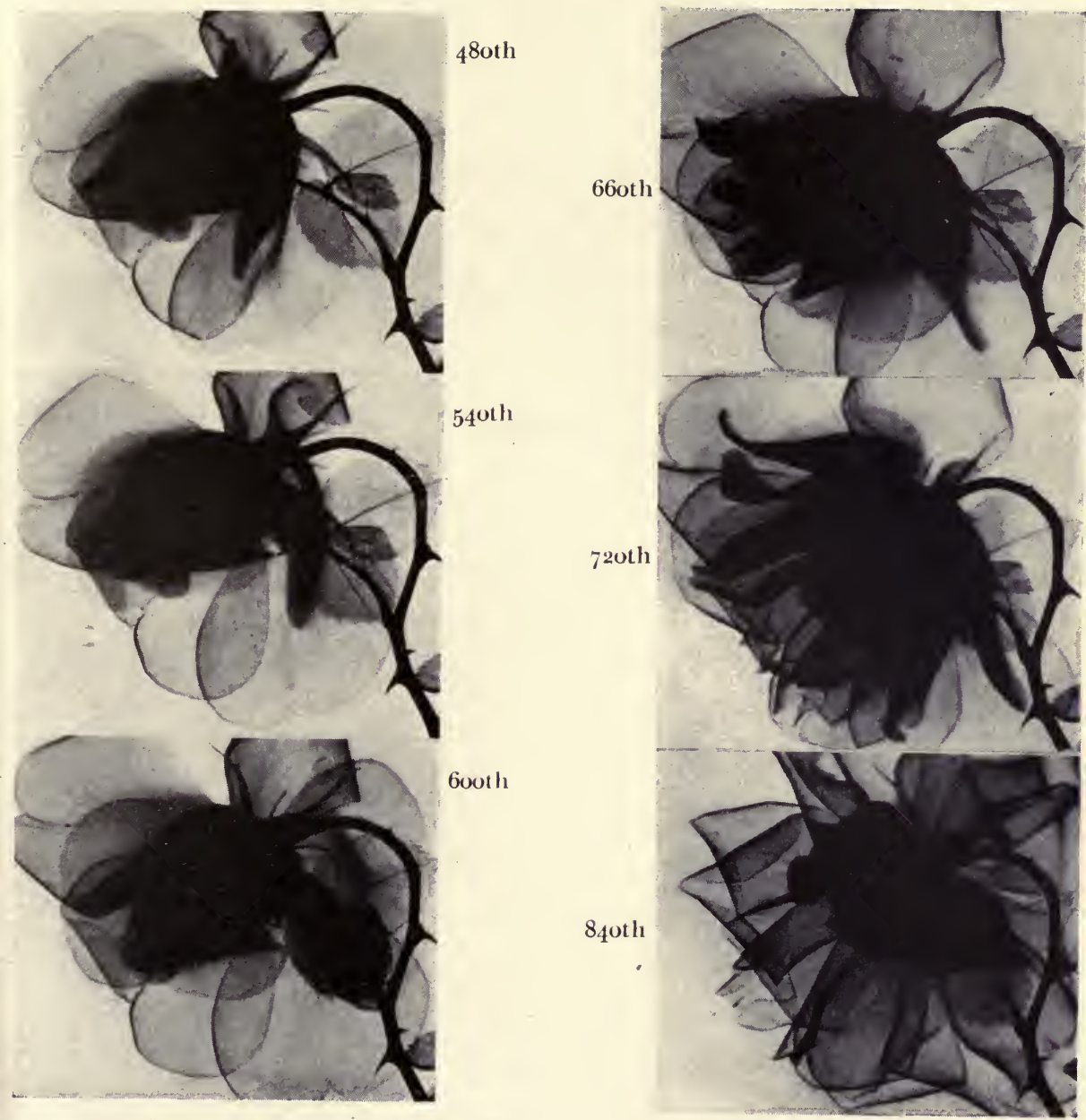

SHADOWGRAPHS OF A ROSE-BUD OPENING 840 X-rays made at 5 Minute Intervals for Three Days and Nights. Each Shadowgraph was Copied into the Standard $35 \mathrm{~mm}$. Film. The Blossom Lasted Three Times as long as similar ones not X-rayed 
tographic quality up to its final projection on the screen, checking for best results. A copying frame was made with a $3 \times 4$ opening. Two pilot pins were accurately placed to engage the holes punched in each shadow-graph and then each individual exposure of the 864 pictures in the long film was copied one by one in the standard Bell and Howell camera. It meant moving the film picture by picture, seeing that the pilot pins were engaged perfectly each time, making the correct exposure, moving the film, making the exposure 864 times. It took nearly a day of very careful, concentrated work to do it. That reduced film was developed, which was positive. A negative was made in the usual way from it, from which as many prints as desired could be made-an enormous amount of work, each step carefully done to make possible the final result.

On the screen the completed picture fifty-four feet long took less than a minute to show and you can imagine what interest invested that short period of time, realizing our eyes were the first to see that kind of picture. To make the comparison more complete we had first the regular view of the rose bud unfolding when the outside of the bud and petals were pictured, then the fairylike shadow-graph, when we looked right through the bud and saw the shadowlike movements going on, never witnessed before. 
We could see the shadow, looking through the bud, of the numerous petals gradually opening; other movements going on that required more careful analyzing to determine what caused them than we could give in that short time, but still would not have shown if taken at shorter intervals than the five minutes allotted. To get the full scientific value of the picture, it must be seen several times with the eye centered on one thing at one time and on another, the next. Only in that way can you get the full story of what a picture of that kind shows. This was well illustrated in another picture of the nucleus in a pollen tube. I had seen it countless times-the eye always on the nucleus. Suddenly, I saw a second nucleus preceding the first one. Now every time I show that picture, I see it as plainly almost as the larger one.

This work of developing, reducing and printing this first X-ray motion picture took five days. In the interval both cameras were running on other subjects. I had not paid much attention to the roses I had worked on except set them aside, when I suddenly noticed the $\mathrm{X}$-rayed blossom was still almost perfect, while on the other, taken in the usual way, the petals had fallen and the haw was forming. Still it did not make much impression on my mind, although they were the same kind of roses and of equal 
development when I started, but in each recurring picture I got the same results-prolonged life of the blossom. I spoke to Dr. Harper Goodspeed, who had discovered that passing X-rays through seed, produced mutations, or new forms of plants, perhaps as many as seventy to the hundred, while in natural life only one in one thousand is found. He was much interested, and we planned a series of controlled experiments to see if in each case we would get the same result-prolonged life.

The camera was at this time running on the fractured bones in the legs of two rats. Dr. Evans, the discoverer of Vitamin B at the University of California, had operated before his class on the rats. The young lady students as nurses had given the anesthetic, and he had fractured one bone in each leg, and I had the rats, Peter and Paul we named them, in lead tubes to protect their bodies from the X-ray, with their legs fastened to splints, so they were held in one position. I had been making exposures every fifteen minutes day and night for thirteen days, hoping to show the actual knitting of the bones. By this time I had found a way to open the camera every day and take out the exposed film for development. In this way I was able to watch the result of the experiment. The fractured bones did not meet as they should, but overlapped a trifle-were off-set. The 
splints had not held very well. At the end of the ninth day a shadow had formed from the end of the overlapping bone to the part above it and the experiment looked as though it were going to be a success in about two weeks more, when the fracture should have been completely knit. The work involved had been enormous. Imagine keeping any patient in a lead tube that length of time, keeping him fed, watered, clean, and happy, all of which must be done if the fractures were to knit. We had thought out this picture very carefully. I had made a vacuum device that kept one drop of water always ready for drinking purposes or for them to wash their faces, which they did after every meal. In fact, we became quite attached to them. Their names should have been Petra and Pauline. I used to pet them, rub their heads and ears at every opportunity. In fact, I often went down during the night to see if all was well and the camera running properly. A motor on a long run needs considerable care. The patients seemed to be getting used to staying constantly in one position, as they must, and everything looked, as doctors say, satisfactory.

On the morning of the tenth day, I noticed the flesh near the fracture that had healed nicely was looking very red and inflamed. It seemed to get worse every day and on the thirteenth day I saw 


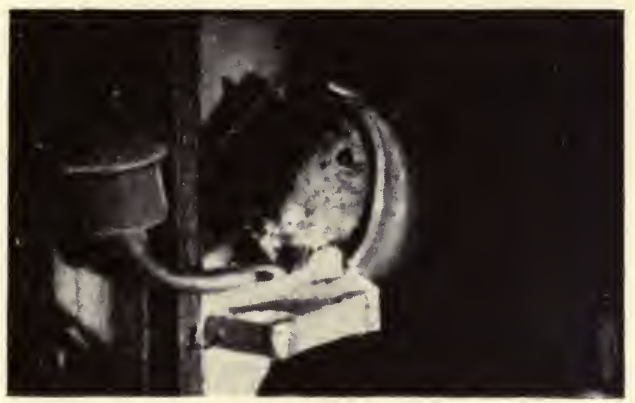

RAT IN LEAD TUBE TO PROTEGT HIS BODY FROM THE X-RAY

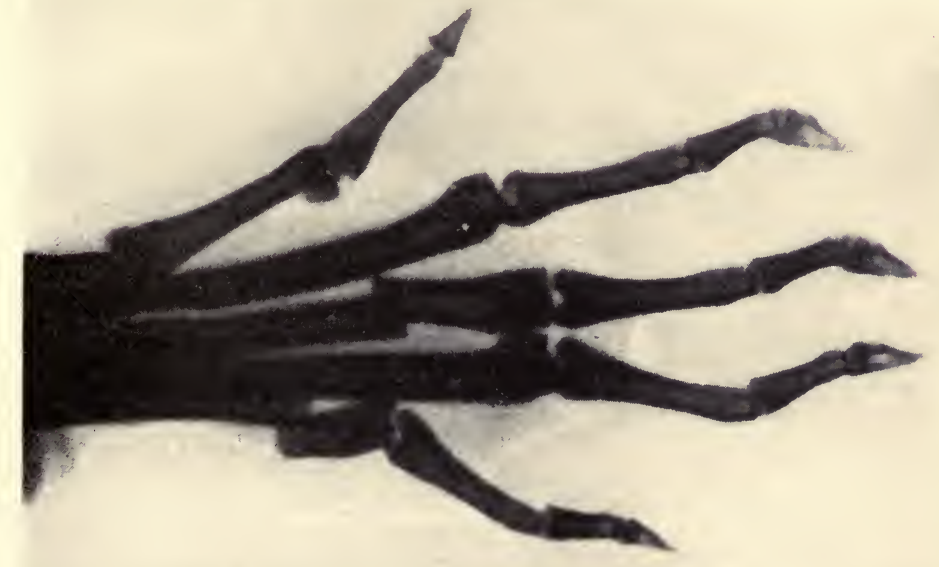

SHADOWGRAPH OF RAT'S FOOT SHOWING TWO FRACTURES 

there was no possibility of a successful result by continuing longer, so Peter and Paul came out of their leaden houses and the final result was a return to their University home where their useful little lives were terminated by the use of chloroform. Fare you well, Peter and Paul!

Was it worth the effort? Yes, many times, yes. Any work that may lead to our accumulated knowledge is worth any amount of trouble. What one man learns and gives to the world may be added to by someone else and the result prove of great value to many.

If I have an opportunity to do the experiment again, I will choose an animal with larger and more porous bones, like a hen. The bones of a rat are very small, about the size of the lead in your pencil. But to keep an animal in one position for nearly a month is a serious problem and not to be attempted without much thought and complete preparation.

Dr. Goodspeed and I now started a series of comparative experiments to test the effect of X-ray on the prolonged life of flowers. The conditions were controlled as much as possible in temperature and other points, choosing flowers as nearly equal as possible. The two cameras were started and another cluster was kept under normal conditions in the same room. We first worked with the California 
poppy, as from previous work I knew its habits thoroughly. The X-ray changed the habits completely, keeping the blossoms open for several hours longer than the ones in front of the Mazda lights or under the room's natural light. The experiment was to run three days and nights till the petals would have dropped off under normal conditions. The second day the X-ray tube exploded, so we did not do the full length of the experiment, but the flowers even with the shorter exposure outlasted the others about two to one.

The experiments up to this point cost me over \$20 per second for every second they were on the screen; to continue the work would require two extra tubes and parts, one of low voltage for thin subjects, and a high voltage delivering 70,000 volts to enable me to make shorter exposures, less dangerous to the subject in burning the flesh, than the longer exposure required by the low voltage tube. It meant an expenditure of some $\$ 1,500$ for added equipment, besides the labor and material for more pictures, each one of which could be looked on as another experiment. So further work was put over for a more opportune time. 


$$
\text { X }
$$

UNDER-SEA PHOTOGRAPHY

ฟै? 



\section{X}

Under-SEA Photography

THE equipment necessary for under-sea photography is water-tight metal boxes for each camera with optical glass windows and outside controls to focus and operate the cameras. If machine-shop made to your own plans, they will cost from $\$ 125$ to $\$ 300$ each, depending on the size and design, or they may be made in your own shop, at less outlay, but with more work. For yourself you will require a helmet costing from $\$ 40$ to $\$ 100$. I have seen a school boy make one out of a water boiler that worked well, although not advisable. Then an air pump that costs, with 100' of hose, about $\$ 100$. This may also be made in a high school machine shop. With an outfit like this and plenty of confidence, you can go down as far as 30 feet in safety.

If you cannot swim you can learn, but I did not find it necessary. I soon found I could walk on the ocean bottom, set up my tripods and cameras and take pictures almost as I could on shore. My undersea work described in this chapter was carried on a quarter of a mile off shore near the entrance to the 
beautiful harbor of Pago Pago on the Island of Tutuila of American Samoa.

To succeed took an enormous amount of preparatory work and study. Knowing all the requirements to make pictures, it meant adapting the cameras and myself to the under-sea conditions and a firm resolve to do and get results. The cameras must be protected from salt water, inside a waterproof metal box and still allow me to do all the things necessary, so I designed brass boxes for two motion, and one still, cameras and then a graphite-lined doubletrapped stuffing box that was water-tight and still allowed me to crank the cameras, focus them, set the shutter, make the exposure and handle them almost as well from the outside of the brass box as I could on land. The still camera took 36 pictures 1 " $\times 11 / 2$ " on Panchromatic film at one loading, enough for each under-sea trip. One of the cameras was motordriven, holding one hundred feet, the other was fitted with a double magazine for natural color work, although that special color method I was using at that time was not successful on this trip. This camera in its huge brass box weighed 170 pounds. On land I could just lift it an inch or two-under-sea it weighed only about thirty pounds, and it was really easier to put on its tripod than merely to lift the camera on land. After the cameras were all 


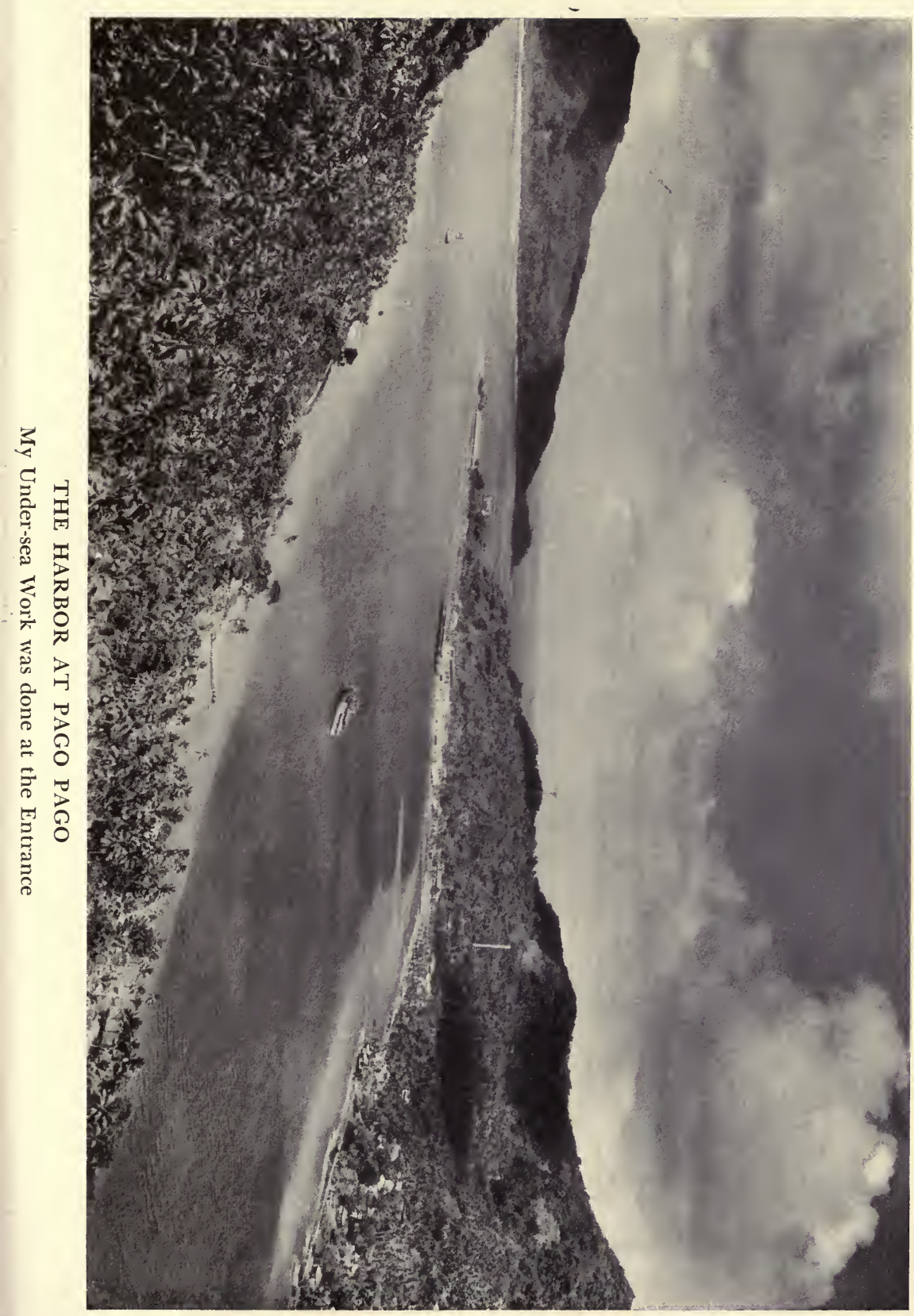


tested, pictures made through the optical glass windows to see that everything worked, I had to do likewise to myself. Get my head into a box with windows, the helmet-my arms and legs the outside controls. I bought a second-hand helmet, and it was so heavy I could not lift it and put it on my shoulder unaided. Then with a back and forth air pump and a hundred-foot hose I was ready to try out the whole plan. I had two rather above the average native boys, and in a launch I hired for the work, we went exploring for location. Walking on the coral at low tide convinced me I could not do it under sea. It was so brittle and sharp, cutting like a razor if I fell on it. So the first thing to find was a sandy bottom with a forest of coral within reach. After cruising miles we found a channel some fifty feet wide, nice sandy bottom, a forest of coral on each side and thousands of beautiful tropical fish everywhere. The water started at ten and gradually deepened to thirty feet and then pitched down I don't know how far.

The first attempt was in water twelve feet deep. We anchored the launch carefully across the channel, lowered the cameras to the bottom, threw the tripods overboard, then in my bathing suit, tennis shoes to keep my feet from being cut by the coral, I would get on the side of the launch, holding on to the gunwale, and one native boy would put the hel- 
met on my head while the other boy would start pumping air to me. The first boy was supposed to lower me slowly. He never did learn to do this part of his work carefully and would throw the hose and life line overboard and when he did this I would go down head first, landing on the bottom with the helmet full of water. When this happened I would have to get up on my knees and wait until the second boy had pumped in enough air to force out the water. I got used to it after a while but it was neither very comfortable nor assuring and my glasses always got wet with no way of drying them. Standing or sitting erect, the water came to my chin and a continued stream of bubbles coming out where the helmet rested on my shoulders I was really quite comfortable.

I had to learn first how to walk, taking short wellbraced steps; then to judge distances, things ten feet away looked twenty, and thirty-five or forty feet was the limit of vision. Everything blended off into darkness beyond that.

Holding a camera in my left hand I at first had to get it very close to my helmet window to find the various levers operating the controls. Reaching for one of them was like a baby trying to find his mouth. I would hit anywhere within a few inches of the 


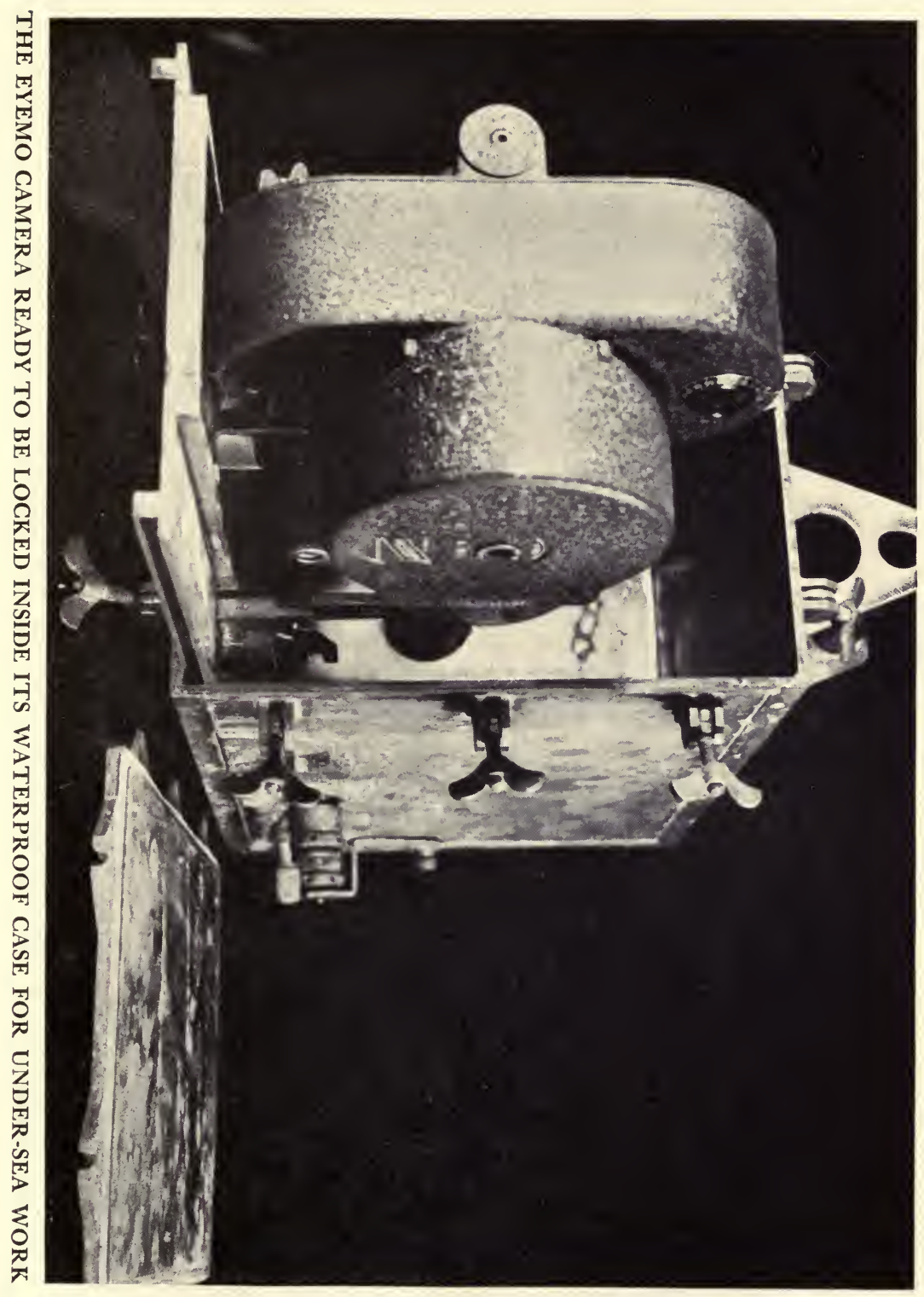


right spot and it took a good many trips before I was sure of myself and the distances.

My first dive was about thirty-five minutes, and after a short rest, down again for about the same time. The boys never did learn the signals so I had to climb the life line and it always astonished them when the helmet shot out of the water and I grabbed the side of the launch. At first I worked only the smaller cameras-the big one was so hard to lower to the bottom and lift from the water into the launch, although it was very easy to handle under sea. Finally I made a sort of stretcher to carry it from the laboratory to the launch and then up-ending the stretcher, the camera slid gently into the ocean. To raise it we would, after I had climbed on board, put the stretcher between it and the side of the boat, tie the rope to the upper end and bear down, lifting it this way and then sliding it on board midship.

I soon began to enjoy the work very much and would stay down two or three hours till I had used all my film or taken all the good locations within reach of my hose and life line.

Reaching the bottom I would pick up a tripod, metal to weight it, and a piece of ten-foot gas pipe for a cane and measuring rod, walk around till I found just the view I wanted-good coral, lots of fish and the right light, set up the tripod, measure 
the distance carefully, go back to get the camera, having to remember the direction as I could not see it even in that clear water if it was over twenty-five feet away, but I knew it was under the launch and I could see her in the "ceiling" above me. Then after putting the camera on its tripod, waiting till the conditions were right, take the picture, hunt for another location and repeat the various steps until the film was all used-a day's work done.

Fish were everywhere, swimming all around me, peeking into the window of my helmet, wondering perhaps what sort of new kind of fish I was. They were very tame, I could almost touch them, all colors -blue, yellow, black, red, even the delicate orchid and darker shades and so many combinations it was impossible to describe them. The larger fish were timid and I seldom saw them closer than twenty feet. There were many blue starfish, great colonies of anemones fastened to the coral and rocks. They were wonderfully beautiful, many of them red, pink, rose, and yellow, some pure white in fact; the colors under sea were beyond the power of brush, camera or eye to describe. The coral was a combination of colorsthe growing tips of each branch of the living, growing stone-forest was like a closely knit land-tree or shrub with pink, blue and red blossoms and buds almost covering it. 

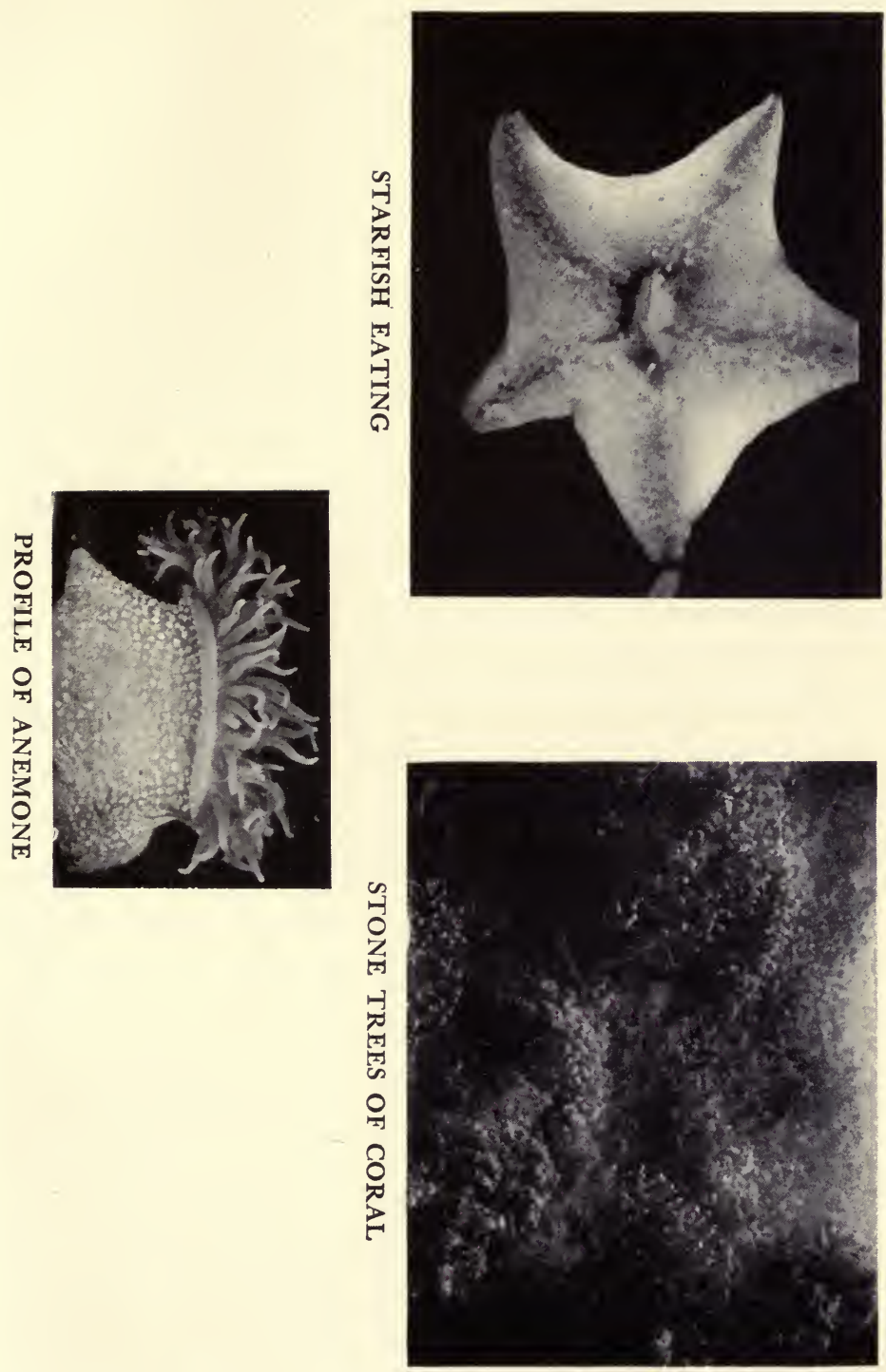

These stone-trees live and grow somewhat like their cousins in plant life in that they grow mostly from their tips or ends of their branches which are made up of millions of microscopic forms of animal life. Each one of these tiny bits of life has the power to take in through their bodies a small quantity of salt water, sieving out still smaller forms of life, getting their nourishment in that way and secreting a little lime, which forms their rock skeleton on the outside of their bodies, protecting them. They reproduce, live their life span, die, others take their places, build their stone-protecting homes, pass on, and in a year's time their living branches grow about half an inch. Of course, many are broken off, ground into sand, some of them buried in the sand, but still life and growth goes on till they reach the surface, Storms beat them to pieces, throw up the mass into a ridge, which year by year is added to. Seeds like cocoanuts, voto and others not affected by salt water, take root and soon we have the coral atoll of romance and story which nature has shaped like a horseshoe-an entrance and lagoon in the center where formerly was the ocean; man comes, the island grows, keeping pace with its inhabitants.

Under sea, in this work of picturing what is going on, I found colonnades like paths in the forest, great caves large enough to walk into, the sides and top 
covered with vast swaying colonies of anemone, hydroids, all sorts of life. Some of the anemone with their heads and mouths open just like a great chrysanthemum, their vascular, colored tentacles waving back and forth in the water just as the petals of the flower wave in the wind in life, only faster. Touch one and it contracts and disappears in front of you. These caves could well be the home of octopi and other denizens of the deep, waiting concealed to dash out on their prey. I did not explore these caves because I was entirely unarmed, and it was too dark to take pictures anyhow, so why venture in?

There were many kinds of coral, great round boulder-like masses of Brain Coral, beautiful in design, dull in color. The red Fan Coral, waving fanlike branches, that looked for all the world like some of the tropic plant vegetation, and other kinds too numerous to mention. In and around them all these beautifully colored fish, nibbling on the stone branches that did not fully protect the animals who had built them against attacks from larger fish. And so the struggle of life goes on, a constant war on the weaker or less protected forms, to sustain life in the stronger, on land as well as under sea.

There were many forms of shellfish, sometimes on the coral, other times migrating from one home to another. Some of them were wonderfully beautiful; 


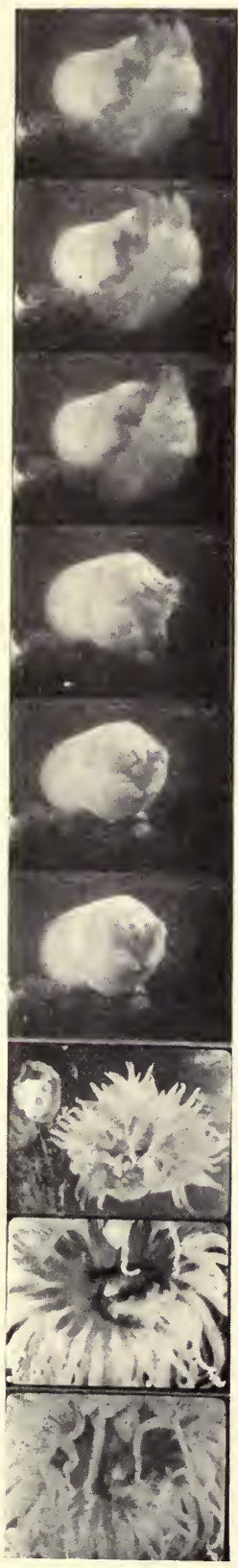

Lower left

a Round

2 inch

Anemone

Closing his

Mouth when

Disturbed

He Elongated

till he was

8 in. long

Then he

Constricted in the Middle

His Tentacles,

Mouth and

Lips

And Pulled himself in Two

Two Animals Where One had been

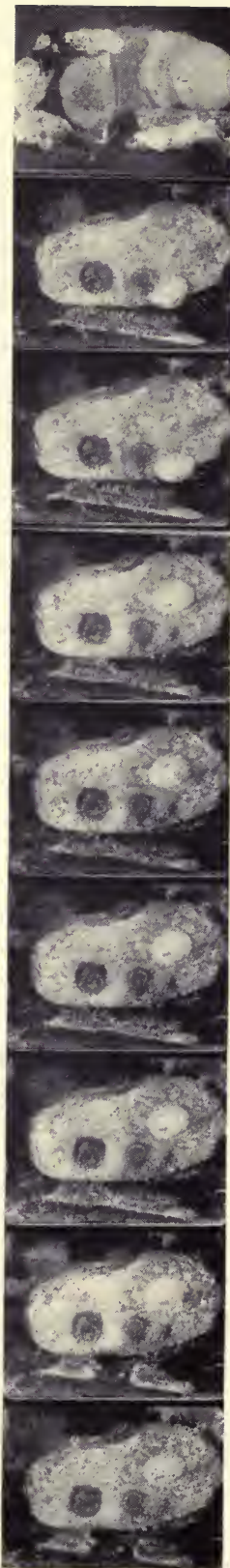



then the clams, not the kind we eat, but large ones with scalloped shells, half hidden in the sand, their mouths open waiting for some form of life to explore their internal anatomy, when the shells would suddenly close and they soon became part of that anatomy. These clams were dangerous. They were large enough to catch your foot if you stepped on oneyou would get a nasty bite and perhaps lose a toe or two.

The giant clams thirty inches in diameter, large enough to weigh almost a ton, could crush the large bones of your leg if they closed on it. I saw only one of these huge fellows and it would have taken a derrick to pull him loose and raise him into the boat.

There is danger in this under-sea work-the danger of sharks. Barracuda, the tigers of the sea, are eight or ten feet long and can easily take an arm or leg in each dash at you. Most dreaded of all are the great jelly-fish. One of those huge masses two feet in diameter made up of some $95 \%$ of water has tendrils ten feet long, and one of them, dragging across you as he drifts by, injects a poison that would partially, possibly wholly, paralyze you. The natives dread them more than the sharks. Still, with ordinary care there is no more danger than crossing a busy city street dodging one of "Henry's sharks," and others of the species. 
Fortunately, my native boys in the launch above me were experts in noticing the approach of sharks and all the other dangers of the sea. They had contended with them all their lives, but none came near, so I had no trouble.

The things I saw were so unusual, so interesting, so absorbing, that to wander around in perfect comfort and examine them was a most wonderful privilege. Anyone could do as I did with just the helmet, which although too heavy to stand under on land, under sea did not bother any more than my hat. It opens an entirely new and delightful field for research work.

The camera work itself I soon found had many difficulties to overcome. The correct focus and exposure, which seldom trouble for land work or under the microscope, gave all sorts of trouble under sea. The focusing scale set for the measured distance would be off-ten actual feet meant setting it for six to get sharp results. The exposure made on land the same day, would be far too much under sea. I had troubles aplenty until I remembered that the speed of a lens was the ratio of its aperture to its focal length, so what really took ten feet focus by the scale on land, only took six under sea. I had shortened its focal length, speeding it up in that ratio. Then on land, the closer the subject is to the lens, 


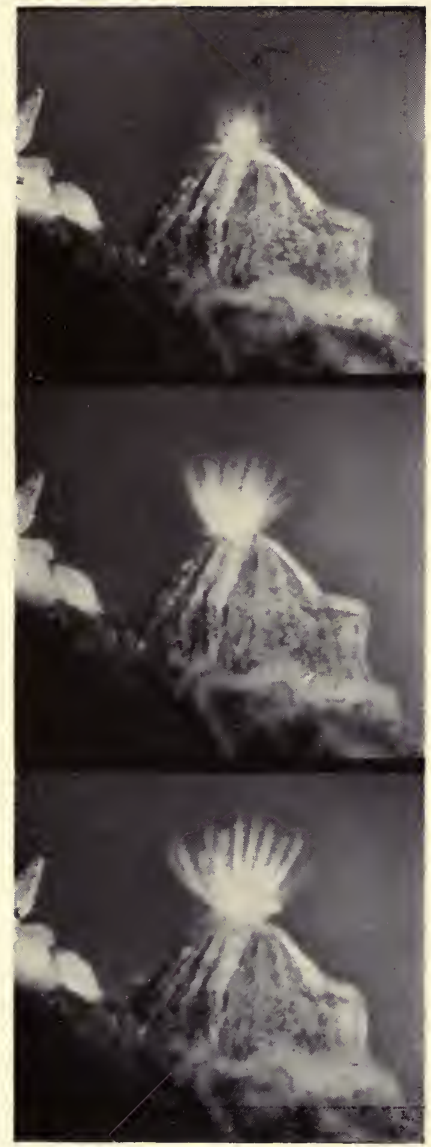

THE BARNACLE

Its Tentacles are in extremely rapid Movement as it Reaches out for Food 
․․ 
the more time it takes, while distance takes less time than near-by objects. Under sea it was just the reverse. Everything in the distance faded off into darkness.

I could develop only tests in the small hot darkroom I had, but I did it every day after a dive till I got the correct exposure, to get the correct focus. I measured the distance of a large mass of coral carefully; it was ten feet. I took my first picture at scale 15 , then 12-10-6-4 feet, developed them, and in later work used the ratio of the sharpest one to the scale on the camera. By the time I learned these points I was an expert diver. I could move the anchors of the launch, go anywhere I pleased and enjoy it immensely.

Three hours under sea was enough for a day. In fact three hours at any kind of work in that tropic country was all it was wise to do, changing to something entirely different for the rest of the day. So during the afternoon I would work in the laboratory or in my aquarium on material gathered in my dives. I seldom came home without considerable quantities of coral and shellfish, and my plankton net gave me a host of the small forms of plant or animal life to picture under the microscope. So the time allotted to the Samoans passed all too quickly. On a trip of this sort you are doing a special new 
kind of work. The apparatus necessary must all be made or obtained in advance. The difference in voltage of the local plant could upset the entire trip's results and to make any special thing that you could do at home in a half hour may take a week to do or get in the shops if there are any there in these out-of-the-way places. I had taken the precaution to find out all the conditions before starting, but even at the best I had only ten days' actual time to learn how to get my under-sea pictures. This was partly due to the weather as we had a week's storm when it rained almost continually. Still if I could not do what I wanted I could do something else, as a camera could take a picture of a tropical bud opening as well in the laboratory on a rainy day as if the sun were shining, or the microscope could do its part also.

Six weeks is a very short time to get established, find out where the material is, what new things there are that can be used, study their habits from the standpoint of getting or picturing their life habits. One should have a field man to keep a constant stream of material available. Untrained native help is unsatisfactory and white help impossible to get as there was not a single unemployed man on the islands, they all being connected with the navy. In fact, white people are not encouraged to come unless they have some definite work to do. They can- 


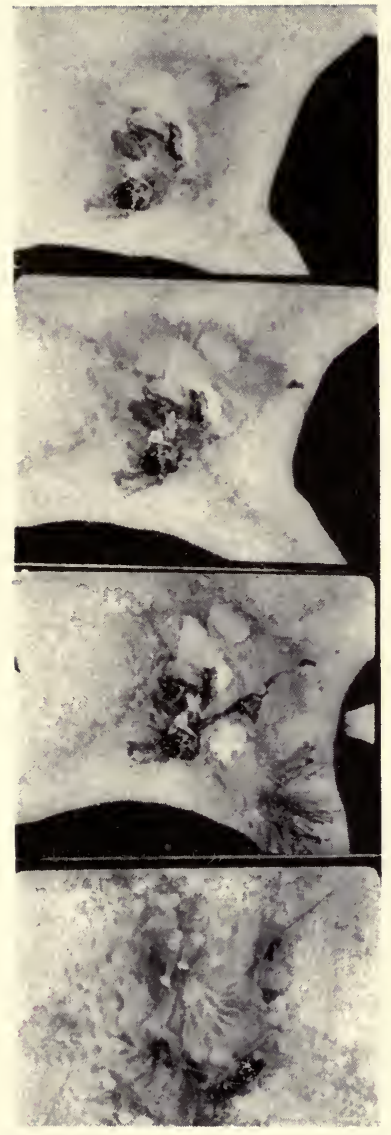

STARFISH EATING

Lower picture shows its Stomach coming out and enfolding pieces too large to go in its mouth

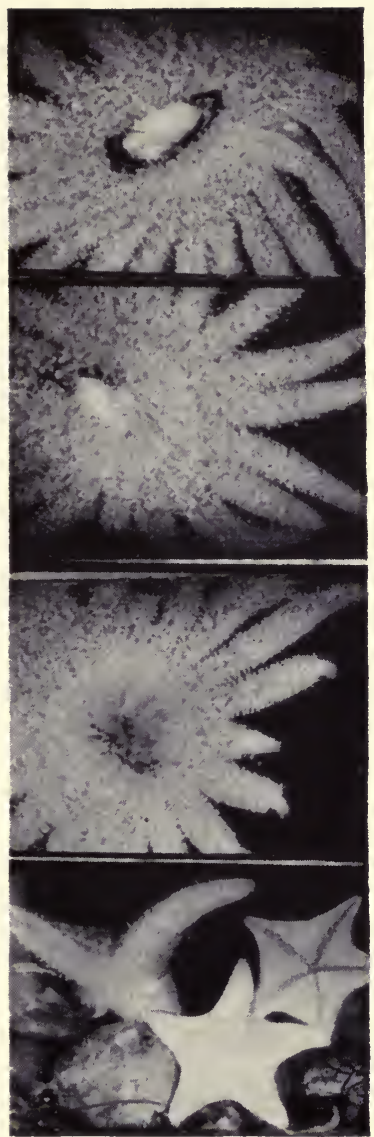

20-RAY STARFISH

Lower picture shows

Starfish at Play 
not buy land of the natives and if leased, the government sees the native gets a square deal. Everything possible is done to prevent irresponsibles intermarrying with the natives. None are allowed to land without putting up a cash bond, enough to pay their passage away. There are some missionaries coming to replace those that have served their time. Almost no tourists come on account of lack of hotels. Steamers southbound from San Francisco arrive with mail every three weeks and that is the grand market day for the natives. They gather in the Malai, a level grass-covered place in the village, and have their wares on sale-all sorts of things to tempt the tourist, tapa, kava bowls, Hula skirts, shells, coral, native fruit, model boats, war clubs, home-made jewelry, etc. It makes a colorful display, even the humble hens' eggs find a place in this market place. Everyone comes to see the show and gleans any news or gossip from the ship. To the natives it is one grand holiday and then how eagerly we wait for the native postmistress to sort the mail, read the papers and post cards before they reach us. After five hours in the harbor the ship goes on to Suva and starts her return trip from Australia, the south and northbound ships pass between Pago Pago and Suva, so two days later the northbound one docks and alas! all too soon ours picked up our car laden to the ceiling with cameras 
and microscopes, with still room for 44 kava bowls, 19 tapas, mats, Hula skirts-all sorts of things, for Christmas was coming and we were as much, if not more, eager for Island souvenirs than the greenest tourists. Many of our things were Alofas and very highly prized. Our good-bys were all made when I spied among the natives the boy who had worked the air pump for my under-sea work. He was a wonderfully perfect specimen of physical fitness, over six feet in his bare feet. I doubt if he ever wore shoesalways singing. One day when the handle came out of the pump and he fell overboard with it, he was back almost in a flash, badly frightened, for fear I would drown if the pump stopped and he would be to blame. He could swim like a duck and dive down in twenty feet of water, tie a rope on a camera or tripod and come aboard, saving me another trip. Once when the gasoline gave out for the outboard motor, he rowed it back alone, singing all the way. I paid him a dollar a day, which was big wages for him. I had forgotten to say good-by, so I hastened ashore, said my farewell to him, passed him my last package of cigarettes. I do not smoke myself. At the same moment he reached down, picked up a small kava bowl, passed it to me and said, "May God be with you on your journey home and ever afterwards. I trust you wish the same for me." It took my breath 

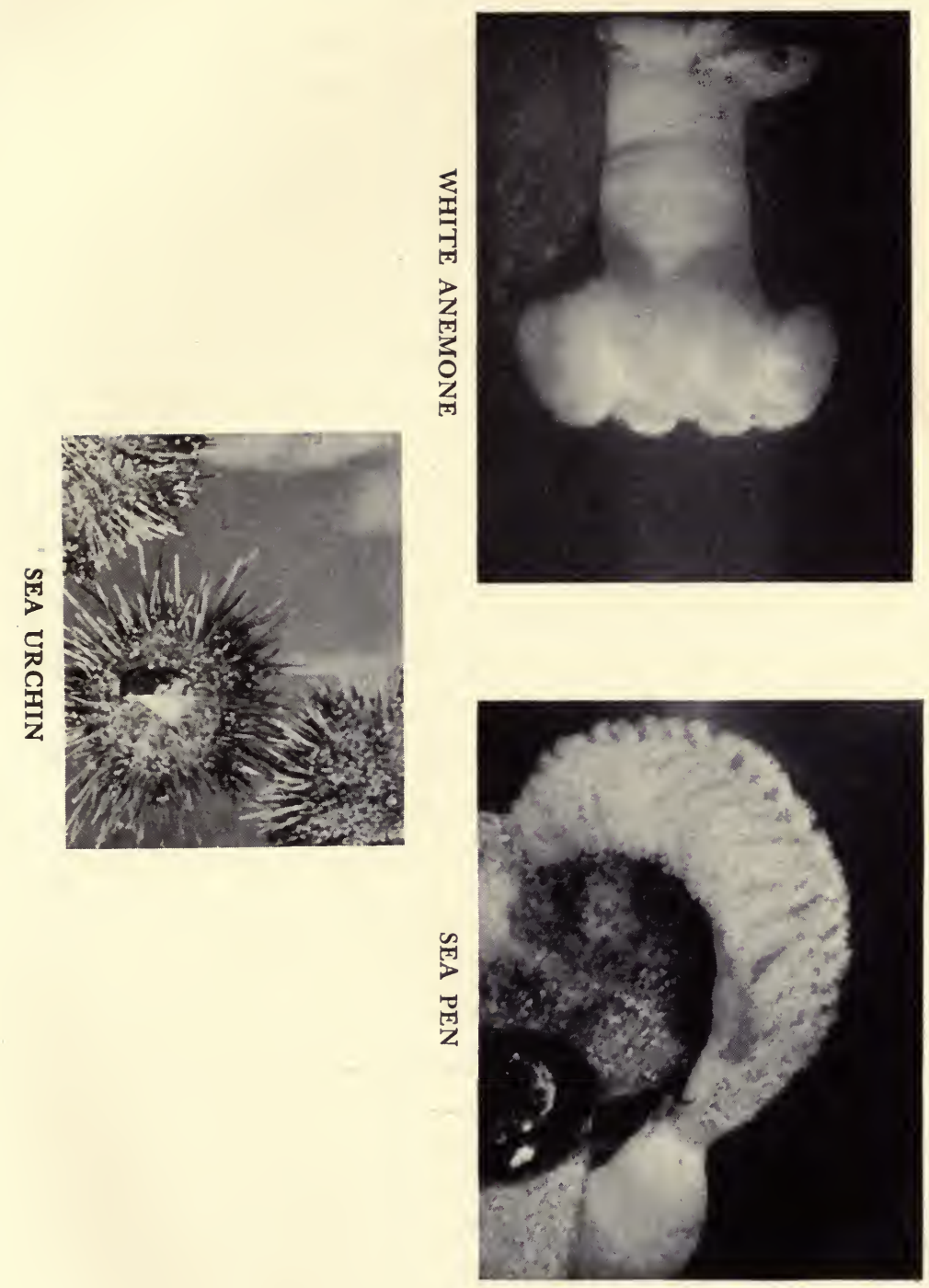

away. I think it was the first time I heard him speak English as he talked to Happy, my head boy who handled the life lines, in his native Samoan language.

"Happy" was a remarkable character, very well educated considering the schools available, very ambitious to get on. He was our cook and a wonderful one. Whenever we were entertained by the navy officers, and we were very often, Happy was taken along to see the cooking and serving was done perfectly. I think he was the best cook in the Islands.

His home was at Aua, three miles away. He went back and forth on his bicycle almost every night. His wife was above the average in education, appearance, and everything that makes a perfect home. He had three children, David, Esther, and a little baby. We often drove out to visit them. David was always ready to feel in my pockets for gum drops or chewing gum and we always tried to have some little Alofa, or gift, for them. Once Mrs. Pillsbury had won $\$ 3.80$ at an interesting and humorous card game at the Governor's reception, without knowing the game was for money. She was reluctant to keep it, but finally did and invested it in "sunshine suits," very abbreviated and colorful, for the children which was an ideal costume for them.

"Happy" was my guide and helper on many trips. We had long talks on conditions in the Islands, com- 
paring them with California. He had gone as far as the local schools could take him, but was never satisfied, so was reading everything he could get hold of. As the chaplain's cook and through other contacts he had made considerable of himself. Writing this about him has made me wonder what he is doing now, so I am writing to find out, addressing the letter to "Happy"-having lost my card having his native name.

All our good-bys were said, the steamer gave its parting blast, and we left beautiful Pago Pago Harbor with the deepest regret, hoping sometime to return to its wonderful little bays and picturesque people. Three weeks to San Francisco, twenty-one days to rest, write, and work up a lecture on Life in and Under the South Seas. 


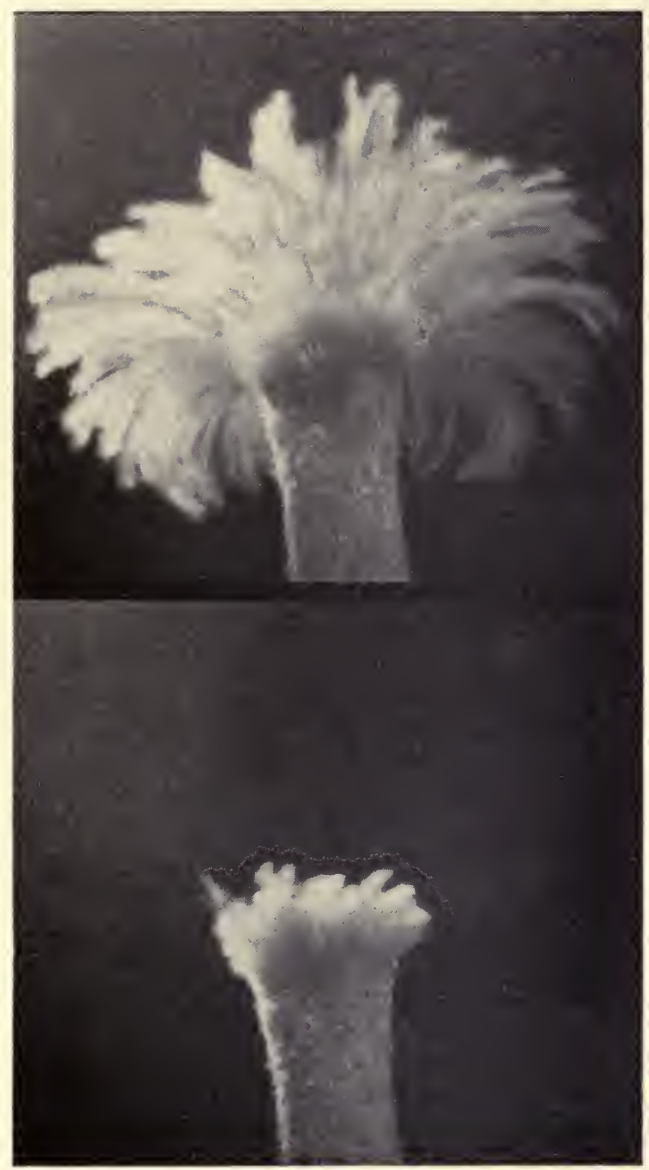

FEATHER DUSTER

It almost Disappears if Disturbed 



\section{XI \\ MARINE LIFE \\ กิ}




\section{XI}

\section{MARINe Life}

OF all subjects for research work, the ocean contains the greatest number and forms. Hardly a drop of water but contains some form of life, many of them most beautiful and interesting. The ooze on the bottom, many fathoms down, is made up of dead bodies, which are literally raining down toward the bottom in one continuous shower.

Plankton, or drifting life, is a food in the ocean that bears the same relationship to fish as grass does to grazing animals on shore. If there is a good crop of - plankton there are plenty of well-fed fish.

To work out the life stories of all these forms of life is impossible. They are as countless as the grains of sand on the seashore, so I am going to take one rather unknown and tell just a little of its life story -parts I have pictured.

The Urechis Carpo is a large fat worm about six inches long and one inch or more in diameter. It lives in a U-shaped burrow, some two feet deep in the mud flats near Monterey. It is comparatively easy to raise them from the egg to full grown animals, which is necessary to do in all subjects that are to be pic- 
tured and studied. The procedure is as follows: There are six little openings near its head where one carefully inserts a hollow glass needle, from a tube drawn out over a flame, and extracts a few eggs from the female and some milky white sperm from the male. These eggs are just large enough to see, if one has good eyes. They are about $1 / 100$ of an inch in diameter. They are flattened spheres in shape; under the microscope they look somewhat like doughnuts, a ring of more or less opaque yolk surrounding a mass of translucent protoplasm, and nucleus in the center. To picture them I cemented a glass ring on the slide that would hold about four drops of salt water, then put in a very few eggs, put on a cover slip and started to picture them. At first no movements are visible. The eggs are in their resting stage. I had broken off a tiny corner of the cover slip, leaving a very small opening. From a single drop of sperm from the male urechis which was diluted in a glass of water, I took a very small drop and placed it carefully near the opening, letting it come in contact with the water holding the eggs. Almost instantly the microscopic sperm could be seen shooting across to the egg and adhering to it. There might have been hundreds of sperm in that pinhead size drop of diluted extract but it took only one to fertilize the egg. Almost at once a change in the egg 

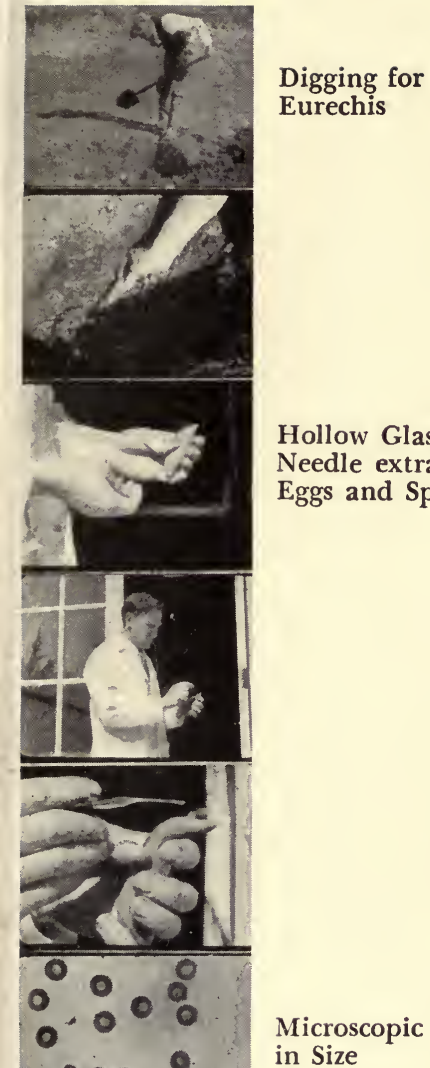

00

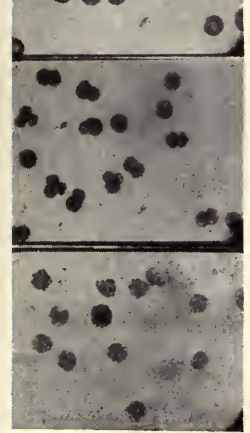

Microscopic in Size

Dividing into Two cells, then Four, etc.

A Thousand by Next Morning

Hollow Glass
Nucleus, Protoplasm and Yolk

Protecting

Skin has

Formed

Needle extracts

Eggs and Sperm

It elongates
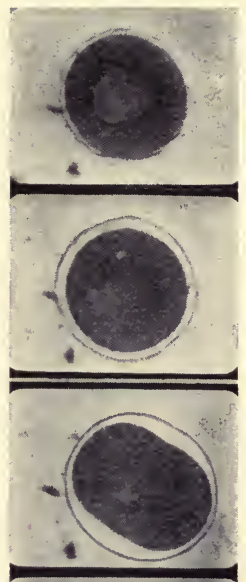

Divides into Two Complete Cells

Then Four, etc.

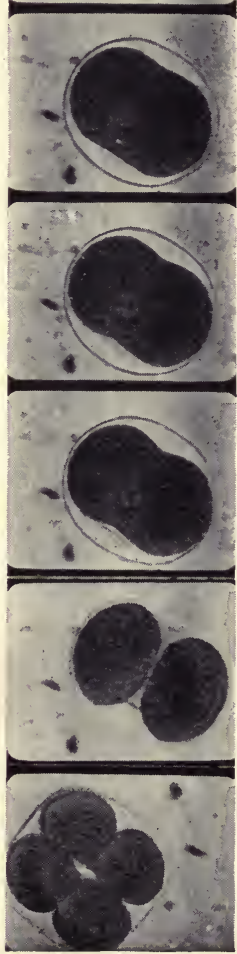

CELL DIVISION (METOSIS) IN THE EGG OF THE URECHIS 
s? 
was noticed. It soon lost its doughnut-like appearance. The yolk, protoplasm and nucleus seemed to swim or travel from place to place in the egg. This action continued about two hours. Meanwhile the outer skin of the egg expanded slightly, leaving a clear ring of space between it and the egg contents, protecting it in that way from over-fertilization.

In about two hours, the egg began to elongate, the movement inside became more rapid, the sides commenced to constrict and a line formed across the egg, the indentation continued until the two equal parts slightly separated and then touched again. These now almost round cells side by side within the outer oval skin started to divide, which in twenty minutes brought the oval shaped mass back into its original spherical form. This division was kept up for about ten hours. Now by the act of fertilization there were a thousand tiny cells still confined in the original size, skin-containing wall. Starting with the egg in its resting stage, fertilization, active life, cell division, metosis; and so life begins.

There is now such a complexity of cells it is impossible to pick out any one and the mass has in some way developed the ability to move and under the microscope that movement is quite rapid. Then the outer skin breaks, the egg so recently a mass of cells has hatched, and the life struggle of the new baby 
worm has begun. It swims about for a period more or less indefinite in form, a mass of cells, which in time assume shape, each cell growing and dividing and the new baby cells growing to the size of the mother cell. This is the way growth in plant and animal life is accomplished.

The full-grown worm feeds in an ingenious manner. Its mouth is small, too small to take in enough water to sieve out the required quantity of the microscopic plankton, so up near one opening of its U-shaped burrow it spins a funnel-shaped web, attaching the top to the sides of the burrow, the other end in its mouth. Its body then expands in rings just below its head. These two or three rings half an inch apart expand and contract, forcing a constant stream of water from the opening in the burrow through the web and then through its body and out the other opening of the U-burrow. Every half hour or so it swallows the web and any form of life therein collected, then spins another web and so on and on.

It takes as long to see this life story on the screen as it takes to read about it. There are several months' work in picturing it, but few of us could spare the time to watch in nature all these steps, neither could we get the same idea as by watching the story unfold on the screen in about three minutes' time. 


\section{XII}

A TRAVELING CAMERA

ลีก 



\section{XII}

\section{A Traveling Camera}

My first traveling camera was made some ten years ago. Its uses were limited on account of the scarcity of subjects that were improved in taking a picture by that method. It required a cable stretched very tightly between two trees, perhaps a hundred yards apart; the camera suspended from a carriage ran down or was pulled along, exposing as it moved. The effect was a stereoptic picture on the screen. It was fine in a forest where it was possible to get the cable supporting trees in the right place but there were many difficulties to overcome, vibration of the cable making it sway, extra work involved, etc.

Now I am using with very wonderful results a rail $9^{\prime \prime}$ wide and $10^{\prime}$ long, made of duraluminium. It is $1 / 4^{\prime \prime}$ thick, has adjustable legs at each end and one in the middle. The rail can be bent in a quarter circle either to allow the camera which is mounted on a motor-driven carriage on the rail to travel around the flowers, viewing them with a constantly changing background, or it can start ten feet away, approach the flower on a straight or curved line, showing a panoramic background if $I$ wish and finishing 
on two or three buds that have been carefully placed; these buds are then matched up in the laboratory with the lapse-time camera and open as though it were one continuous picture. There is a motor that drives the carriage at any speed and another that runs the camera at standard speed. It means batteries are required to run the motors, and it takes about an hour to set up the outfit, take the picture and pack up again. The picture is stereoscopic and in natural color on the screen as it shows three sides of the same object as it passes it and the subject is at a shorter distance from the camera than the background, which is changing all the time so it stands out in relief, and has the advantage of showing subjects in their natural habitat and in the same picture a few seconds later a close up of them without any sudden change of location. The entire outfit, made in my shop, fastens on the side of the car and everything about it was designed to set up and knock down as easily and quickly as possible. The hour's extra work is well worth the effort. 


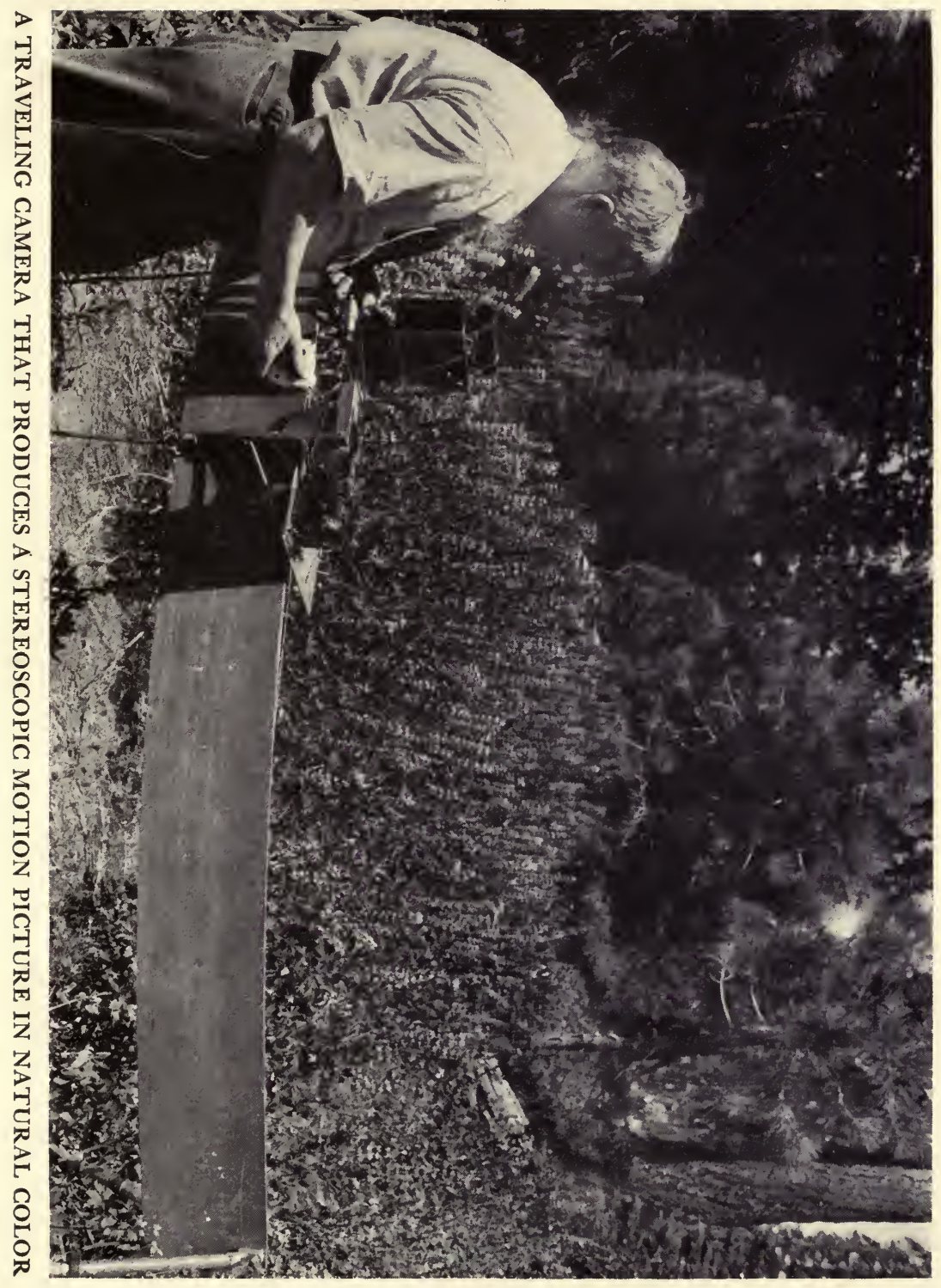



XIII

THE FLY

ขै? 



\section{XIII}

\section{The Flý}

The life story of the fly is told from the picture standpoint, and how the results were obtained. The work was done for Eastman Teaching Films, who furnished a scenario of fifty-nine scenes. They were all made and some fifteen others which seemed essential to the story, which was divided into four units: life history of the fly, structure of the adult fly, the fly as a health danger and control of their breeding. The footage of each scene was left to me. The total was to be one reel; it worked out to over two.

The story started with a long shot of a pigpen and it was typical of a truck gardener's idea of what a place of that sort should be. The cobwebs all around it were the only method of fly control, they added to its beauty (?). It was only a few feet square with a small, dark, cooler retiring place for the poor fat porker.

This home of flies and pigs was chosen because no flies were available in my home, while in the pigsty I could put an old-fashioned round top fly trap six inches in diameter down on a board and catch fifty 
at a time. They having crawled into the upper part of the trap, two minutes later I could repeat the catch.

The mud, slime and cobwebbed fence made a closeup of a filthy breeding place. A square foot must have had 5,000 flies in all stages of development.

An excellent portrait was made of the pig framed in the black opening to his sleeping quarters, a thousand flies swarming in the air around him and as many more on all sides of his domicile. They were so thick you could hardly touch a spot with a pencil without hitting them.

These pigsty scenes illustrate what well may have caused these conditions-"And then came a grievous swarm of flies into the house of Pharaoh and into his servants' homes, and into all the land of Egypt, and the land was corrupted by reason of the swarm of flies."

Pharaoh did not know that one fly in a season could multiply into $54,000,000$, that one pigpen or one stable might well have caused all his troubles in that country. His cities were being buried by the accumulation of waste. They had and still have to a great extent, the nice habit of taking everything, food, etc., into a city and removing nothing, piling waste on waste-a wonderful breeding place for flies. 
Neither did Pharaoh know that the dirt on one of the hairs of a fly's leg could by its simply walking over his food leave bacteria enough to pollute it and spread disease throughout his entire land.

These conditions so well expressed in the few lines of Pharaoh may well be duplicated in any uncleanly city or army encampment, or engagement where disease kills more than bullets.

The fly's eggs are deposited very quickly-as many as 120 in a mass, and it would be mostly luck if a picture close enough to show were made of it. The eggs are about twice as long as their diameter, shining white. They hatch in eight to twelve hours, depending on the temperature.

I found that 8 P.M. was the most likely hour to watch for this pestiferous event. The actual period of hatching took only five to fifteen seconds from the time the egg split till the almost transparent maggot wiggled out of his digestive tract. A black line was clearly seen, as he quickly crawled away to start five or six days of constant eating and growing. By that time they are half an inch long. Then they become sluggish and for two or three days they wander around looking for a place to rest during the pupa stage. When the actual time comes they simply go to sleep. The head contracts into the body and they become what looks like the egg from which they 
started, only larger, with slight rings around it. If they are disturbed at this period their head comes out to normal size and they have to go through this sleeping act again. In four or five hours they turn brown. No other visible change is seen for a week or nine days. Under the microscope, with back lighting, the embryo fly can be watched gradually forming. His legs, body and eyes can be plainly seen.

On the morning of the ninth day, they are due to emerge. I found I could get everything ready for the picture; turn on the lights and the extra warmth would at once start action. There is no preliminary signal, the cap suddenly snaps off or opens hingelike and the most exciting action, especially under low power magnification, begins. At first what looks like a white balloon expands and contracts very rapidly. It was this expansion that broke off the cap. This continues helping pull the fly out of its shelllike chrysalis. As the baby fly gets half out, the balloon-like sack stops its expanding, contracting movements and is gradually absorbed into the head, seemingly forming part of it. The eyes seem enormous in comparison with the parts already visible. Suddenly the entire fly comes out, and often on his back, the shell house above it. There it lies and, like an acrobat, whirls its former home round and round, trying to get rid of it. Even with so unpleasant a creature as 
the actor, this little scene is very amusing to watch.

At the instant of birth it is very active and rushes away in a flash. The entire blessed(?) event may take but fifteen seconds in occurrence.

The wings are the only part not fully developed at birth. They are folded up and in twenty minutes they expand and we have a fully grown fly. They are weak and the least disturbance, like fastening them on fly paper, even if carefully done, seems to stop development of the wings.

The fly's head is one fourth of his body and his eyes a good portion of the head. It is extremely difficult to picture his head and mouth parts in a living specimen large enough to show the parts and keep the rest of the body sharp. The eye is made up of hundreds of lenses from which the light glances off. They enable it to see in all directions without turning its head. Each lens casts its own image, so if a fly's eye is used in place of a microscope lens, one person approaching would look like an army. Whether the fly's instinct or intelligence tells him it is one object or not we have no way of knowing.

A fly eats almost everything. His proboscis is extended. The flattened funnel end covers considerable area and liquid foods are sucked up. If the food is dry and hard like cube sugar he spits on it first to 
dissolve it. This act of expectoration is very hard to picture sharply-it is done so rapidly and without visible warning.

The fly's body and legs are covered with hairlike bristles, making it easy and natural for him to carry dirt and germs. It is almost impossible, even if it were a clean insect, not to do so, and under the microscope, masses of filth are visible on the hairs and feet.

I wanted a panorama of a fly's leg, which is naturally very crooked and about $3 / 8$ of an inch long. The proximal part corresponding to our thigh just filled the field of the camera and the hind joints of the leg did also, leaving the foot in the center.

A microscopic panorama is impossible to make smoothly by hand, so I rigged a large pulley on the mechanical stage adjusting bar and with a separate motor reduction gear I timed the panorama part to take the same time as the other motor gear running the camera took to give thirty-five feet of film.

The result was a perfectly smooth panorama in which the leg seems to stretch out endlessly. It took most of a day to get everything working right, each timed to synchronize with the other and then some twelve minutes to take the picture.

The next step was to revolve the leg and foot 
to show all sides of the foot and foot pads. This was most difficult, as it had to be held perfectly true during its revolution. I made a glass chuck-like device to hold the leg, mounted it on a slide, put on a pulley and, with its separate motor, revolved it during the exposure. These steps take infinite time and skill and the apparatus can seldom be used for any other scene.

The suction pads on his foot surrounded by claws show how he walks on glass or other smooth surfaces.

The scene of the fly as a health danger shows it crawling on decayed cabbage, dirty open garbage pail, in and out of a spittoon, then on a plate of cookies, swimming in a milk pitcher, on the nipple of a baby's bottle; then follows that of putting a fly in a dish of sterile gelatine medium, showing him walking over it back and forth, and one a few days later shows the glistening colonies of bacteria that have developed in his foot tracks and the bacteria around the hairs on his foot.

Mobile and miracle working as a camera is it took animated drawings to express the increase of one fly to over $50,000,000$ in a year's time.

The control of flies in the story was not possible to carry out as well as I wished, so I made several extra scenes showing how easy a chemical spray killed them in the same pigpen used before, and 
some Boy Scout scenes of the burning and burying of garbage and cleaning of camp, approved home garbage cans, and screened windows and doors, ending with a "swat the fly" scene by a young girl in our living room. 


\section{XIV}

TECHNICOLOR AND OTHER METHODS

ats 



\section{XIV}

\section{Technicolor and Other Methods}

After reading the following part of this chapter referring to natural color in the $35 \mathrm{~mm}$. motion picture film, you will agree with the writer that with the present knowledge of the subject, and the material on the market, it is not advisable to attempt it. The results may be beautiful, but the expense prohibitive. When the Eastman Company puts out, in the $35 \mathrm{~mm}$., a film like Kodachrome, it will make natural color work in standard size practical for anyone.

Natural color has long been the dream of motion picture technicians. Thousands of workers and millions of dollars have been spent on various methods. There are hundreds of ways both in still and motion pictures of producing color more or less natural, each one claimed to be the best.

For my work in flowers, color is essential and I have worked with a good many methods. All of them have a great deal of grief. Many are almost worthless; others so expensive, even if they were successful, they would be prohibitive. In the methods now generally accepted as the best, Technicolor outranks 
them all. It divides the spectrum into two colors, red and green. The light from a color-corrected lens passes through a system of prisms that split the beam in equal parts. One half passes through a green filter and the other half through a red one before striking the film, so two pictures are made at the same instant through the same lens-exactly one picture frame apart. The color separation can be controlled by the strength of the red and green filter.

The taking of the negative is comparatively simple, the film runs through the camera twice as fast as the ordinary one, so you expose thirty-six to fortyeight frames a second, which requires a motor drive instead of the crank as in most cameras, and it also means the lens and the shutter must be open wider so as to get the correct exposure at the higher speed. The camera itself is larger and very heavy. Combined with the motor it is something of a chore to move it, and with its seventy pounds of batteries and tripod of almost equal weight one knows he is working every picture he takes.

The film is developed one point stronger than for the regular black and white work. The best method is to develop tests by time and temperature and then in total darkness develop the picture accordingly.

The negative scenes are assembled, spliced in se- 
quence, tested and notched for the correct printing light and cleaned carefully.

The printing requires a special double machine that makes two matrix prints at once. One made from all the frames that were exposed through the red filter on the downward travel of the negative and then it turns and on the upward journey the frames made through the green filter are printed. The matrix print is a special slow fine-grained stock. This is developed and treated chemically so as to leave it in very strong relief. It leaves the red parts of the picture much higher than the other colors and the half tones in proportion.

The matrix from the green filter is treated in the same way. These two matrix prints, although they may be 1,000 feet long and each have 16,000 frames, must match frame for frame.

Now the real print is to be made-the one used in the theaters. It is made on a fine-grained slow positive stock and consists only of the sound track $1 / 10$ of an inch wide on the left side of the strip and an opaque bar between, the space that is to finally be the picture. But no photographic picture at all is printed where it is to be on the strip, but it is just a blank covered with a very thin transparent emulsion.

This film with the sound track that is synchronized to fit the picture now goes to the color-print- 
ing machine and that is what it really is-a colorprinting machine. It is about eight feet high, fourteen inches wide and sixty feet long. The matrix print is fed in on top of the sound track strip, picture for picture, and the red dye picked up by the relief part is pressed into the transparent part of the sound track strip. The surplus color is washed off, then the strip is dried in the machine, coming out and being wound up on a reel.

On the other side of the same machine a duplicate matrix and sound track strip is getting the green color. It goes through the machine, then they are reversed and each get the other color on top of the first one.

The result is just the same as if half tones in a printing press were printing those two colors on top of each other on a piece of paper. You get all the combinations of red and green but no blues or yellows, although a slight yellow is given by later running it through a weak yellow bath.

These printing and coloring steps are complicated. They require the greatest skill and accuracy. Perfect results are obtained only with the utmost care in each step; negative and positive stock should all be perforated on the same machine and perfectly aligned. The subjects pictured must be lit to give sharp contrasts. Blues and yellows will not picture 
true, so should be avoided if correct coloring results are desired.

A three-color experimental camera has just been made by Technicolor. This makes three frames at once on three separate films with red, green and yellow filters. It should give almost perfect color rendering but with much added expense and weight.

The two spectrum cameras valued at $\$ 10,000$ each are not sold but rented with their skilled operators; for each piece of work or subject photographed, the negative costs just five times as much as regular stock and the print nearly four times the cost of regular uncolored stock. Under those conditions one going into color work must be prepared to foot the bills.

During one year I kept two cameras running almost constantly; one in the field part time and one in the laboratory on lapse-time subjects and the field one on lapse-time on my return from each trip. The lapse-time work was the first of its kind done with this Technicolor method.

I also made the first microscopic Technicolor pictures. This work was very difficult on account of reflections and the almost impossible place to see the image to focus. The movements of protoplasm in Technicolor are strikingly unlike those made in black and white. And further work with that method 
may show many new things of great interest. Under the microscope I have just taken a picture showing the change of color from green to red of the chlorophyll grains in a leaf cell. It shows them dying, gathering into a round mass and turning red. It is one scene illustrating autumn leaves which $\mathrm{I}$ also have turning from green to red in front of the camera just as they do on the trees. Many things of that kind are possible if one has the patience.

The Stencil method of coloring reached its perfection a few years ago by Pathé in Paris. I bought from the New York branch two of the machines. They could not use them successfully in America, lacking the skilled operators and patience required. I remodeled both machines, adding labor-saving devices, and finally got so we could do it efficiently. The method is complicated. An enlarging camera projects an image of each picture on a ground glass three times the size of the original. You sit at a bench, the image in front of you, and with a needle on the long arm of a pantograph follow the outline of each part of the subject. The other end of the pantograph is an electric needle that vibrates up and down sixty times a second, cutting an opening in a piece of blank film just the size and shape of the original. Turning a crank brings another frame and a new blank piece of film into view. 
The process is this: a short scene up to seventy feet long is chosen. Prints are made. One is inserted in the enlarging camera. A color sketch is made, deciding on the colors for the entire scene. Then starting with the first frame a stencil is cut for all the yellows, then all of the blues, reds, greens and all other colors. If five colors are to be put on, it means five stencils for each frame of the print. After the stencils are all cut and matched up perfectly, the color is put on in another machine. An endless velvet belt is the brush. The nap of the velvet, the hairs of the brush, the stencil made into an endless belt, is carried over sprocket wheels above the print to be colored. The liquid color is applied to a revolving brush that carries it to the velvet ribbon and applied through the holes in the stencil to the print, one color after another. If a good many prints are to be colored they are all joined together in one long reel so that number one picture always comes under number one opening in the stencil belt, which has to correspond in length to each print.

The print is dried after each color is applied and then the next color put on in the same way. Each step must be perfect in amount of color used and its tone when dry, or the color produced-putting one color on top of another-would be wrong. The colors must absolutely register. We found two people tak- 
ing turns at the stencil cutting on account of eye strain and applying the color, could cut the stencils and color a reel of pictures lasting eleven minutes on the screen, in four months' time. This made the cost prohibitive unless there was a market for at least one hundred prints, but the ability to get as many colors as the subject required made the result well worth while.

I have worked with several other methods. They had nothing but grief. The perfect color process is still a thing of the future. A three-color Technicolor would give almost perfect results as far as color is concerned, but the added cost of material and labor would be very great.

An attachment I made a year ago for the large studio model Bell and Howell camera enabled me to make most wonderful three-color separation negatives, both microscopic and lapse-time, of flowers in the $35 \mathrm{~mm}$. size, but by the time those three negatives were combined into one print the cost mounted up to about $\$ 1,000$ a reel, outside of my own work.

The above refers to the standard $35 \mathrm{~mm}$. film as used in the theaters and it is only within the last year that the narrow $16 \mathrm{~mm}$. safety film has been considered anything but amateur equipment. But with the introduction of the 1,000 watt and improved optical systems in projectors, making it practical for theater 
size pictures on the screen well illuminated and at projection distance of 100 feet or more, the $16 \mathrm{~mm}$. size has been considered as solving many lecture troubles.

The Eastman Company now have their Special camera selling at \$39o. The Bell and Howell Company have a semi-professional model and several others are on the market. The Eastman Special must have been designed by a camera user as it has everything he needs. The magazine may be removed without losing a single frame and another replaces it instantly. It can be focused directly on the aperture or a magnifying telescopic device used giving the exact view on a large scale. The shutter is adjustable for width of slot; the speed automatic for almost any speed from eight to sixty-four frames a second; interchangeable lenses and a turret head for a telephoto; lens extensions to work within a small fraction of an inch, getting microscopic results direct; footage counters and an individual frame counter; one to one shaft and crank, also eight to one crank and single frame shutter and as the tension of the spring runs down it automatically stops after ringing a bell. It has a Graflex-like focusing prism with a visible image up to the instant you start the camera. It also has several other so-called fool-proof safety gadgets. The entire mechanism is precision made 
and it really seems to have everything a serious worker needs; one can see the image during a lapsetime picture without losing a single frame, the safety shutter cutting out the image just before the exposure is made, which is a great help in growing plants when close up to them to make sure it has not grown out of the field. So far everything I could ask for is contained in this camera. I purchased one and could use three others in my lapse-time work, as to really accomplish very much several cameras must be running all the time, each one producing possibly five to ten seconds on the screen from an average day's run.

So to get the necessary number of cameras for my work I bought second hand the now discontinued Model A Eastman cameras and to enable me to focus I put on magazines, so opening the camera only fogged a few inches of film. I also changed the lensfocusing method, so instead of being limited to a distance of four feet I could work up to four inches and then putting on an eight to one reduction gear a single revolution gave me one frame. These cameras, at a cost of about $\$ 25$ to $\$ 30$ apiece and a couple of hours' work on each of them, gave me three cameras with which it is possible to do lapse-time work, but of course not as conveniently.

These special cameras with $16 \mathrm{~mm}$. width with the 
new Kodachrome film enable one to make natural color pictures direct, producing a positive in all its natural color without filters or special projectors. I have made sixteen foot pictures in large auditoriums with the best results, better than I have with portable 1,00o watt machines using standard $35 \mathrm{~mm}$. film.

The improvements being made every year by the manufacturers keep you busy trying to keep up with them, but the Kodachrome color film, where color is absolutely necessary as it is in my work with plant and animal life, has so reduced the cost that it brings it within the reach of a lecturer or special worker.

With the $16 \mathrm{~mm}$. and Kodachrome, 400' are equal to 1,00o of standard and allowing half the footage cut, in the final selection it leaves from six one hundred foot reels at $\$ 9$ each or $\$ 54$ as cost of the material for a reel (the film costs include the processing) against $\$ 1,000$ for best three-color standard film on the market. The Kodachrome film is not yet on the market in the standard size. At present no one is making duplication prints of the Kodachrome method but before going into $16 \mathrm{~mm}$. I did enough experimental work to know that I could make my own duplicate prints, which I am doing now.

Kodachrome film, as made now, is better than Technicolor or any other color method. Color rendering is far from perfect. It requires the exactly 
correct exposure, has almost no latitude, does not work well with any back or side lighting, shadows come out black and overexposure is flat and not natural in color rendering. All these results may be overcome only by the greatest care in the lighting and correct exposure. In landscapes, if the lighting is not right, either the location of the camera must be changed to get the necessary so-called flat lighting, the color film giving all the necessary contrast, or the photographer must wait until he can get the light coming from the direction desired-possibly on another day. This means often going more than once to procure the desired picture.

Photography with the Eastman or other standardized material is an exact science-no hit or miss proposition as it was once. It takes a given volume of light to make the correct exposure. Measure it in pounds or gallons or candle power or however you may wish; qualify its strength by the time of day, the season of the year; the opening or diaphragm of your lens through which it must flow; the time the shutter is open or other factors, and still, to get the correct exposure the film or plate must receive a certain volume of light.

Fortunately with the photo electric cells now on the market the strength of the light can be very accurately measured and with scaled disks, knowing 
the speed factor of the film, it takes only an instant to find the amount of time required to get the correct exposure from the readings on its face.

So that greatest of all troubles safely overcome, the other steps, focus, lighting, magnification in the microscope, preparation of the subject, etc., correctly done, the result can be safely guaranteed.

Very little actual photographic work has been done in natural color under the magnification made possible with the microscope. This is partly on account of the difficulties to overcome in getting sharp erlarged images, in monochrome, over the entire field with either direct or dark field lighting. These difficulties are greatly increased with additional factors like natural color with its low range of correct exposure, latitude, etc., making it difficult to get perfect results, while the more versatile panchromatic film, allowing to some extent a correction in the printing to correct errors in exposure, is usually considered the Mecca of microscopic photographic technique.

As most of the microscopic subjects to be pictured depend on slight variations in color to make them visible to the eye-surrounded as they are by other matter-the difficulties to overcome are very much increased as the picture in monochrome does not give a true rendering of the living subject. To the 
eye one sees the parts of the living cell-or whatever the subject is-more or less isolated from their surroundings and the part you are most interested in showing is often entirely invisible if pictured in what in the print is a monochrome field. I have in mind as an example a lapse-time picture I made of the embryo of the anchovy fish egg. After overcoming the mechanical difficulties of holding the egg still and supplying fresh salt water continually for the four-day incubation period under the microscope, I could watch and picture at ten-minute intervals the some 600 pictures ( 25 seconds on the screen). While the yellowish embryo with its large head and tail formed from a clear colorless egg, the picture, perfect photographically, lacked the yellow color of the embryo to segregate it from the surrounding protoplasm in the egg, while the eye watching it could distinguish the division of the egg into cells and their gradual grouping of themselves into the tiny fish-like embryo; to the eye beautiful and wonderful to see, step by step for the four days, all the organs and the baby fish build up in front of you. On the screen that action, taking only twenty-five seconds, was wonderful, but it lacked the color to enable the eye to distinguish the dividing line between protoplasm and the body already formed and its tiny organs taking up their life duties. 
In color those added features would have required at least twice the projection time to have grasped what was taking place, so the lapse-time interval between each picture could have been five minutes instead of ten. To have pictured its blood circulation and breathing the interval could have been one second, and taken during the latter part of its incubation and without changing the focus, for a period sufficient to give some twenty-five seconds on the screen, the entire picture from egg to fish then being shown in about a minute and a quarter. But in that seventy-five seconds what a story! The beginning of active life in all its ramifications; something only a few eyes have witnessed, and those never in such a connected story, so condensed and enlarged on the screen that its full significance can be grasped.

The necessity of color is evident to show what is actually going on whether it is in an egg or a pollen grain, and the problem is how to simplify the technique and make use of various forms of light to bring out the required results.

Microscopists know that to see a subject at its best various forms of lighting must be tried; direct light, dark field, polarized, ultra violet, and many, many other forms. And as light is waves of energy reflected from the subject, the length or shortness of those waves of energy must also be taken into account. 
With the Eastman set of Wratten filters, wave lengths of energy of varying length may be produced and a set of a dozen tests of the subject will give a remarkable change in the detail or contrast in the picture from which the one showing what is desired best may be chosen. I would advise those tests being made on each subject. It takes only a few minutes to expose a few frames with each filter, or combination of filters, develop them and compare results. In the Velox prints the wave length is marked under each one. This will improve the monochrome results wonderfully.

As a colored subject reflects waves of energy also that produce the sense of color in the eye, and as the kind of light under which it is viewed affects our impression of its color, daylight often gives an entirely different impression from electric light and the numerous kinds of electric light. It is evident that a color film cannot give true results unless it is balanced for the kind of light for which it was intended and then used with that type of light exclusively, cutting out other forms.

Kodachrome film is now made in two emulsions; one the regular Kodachrome which is balanced for sunshine light between the hours of nine and four. Before and after those hours the sun's rays are much redder and the resulting picture is too red on pro- 
jection if a true color rendering is desired. But if sunrises or sunsets are made that additional red is not an objection, possibly adding to the beauty of the picture.

The type A Kodachrome film is balanced for photo flood light or clear Mazda light, so does not require the $4 \mathrm{X}$ compensating filter the regular emulsion does when using artificial light, which is a great saving in the time of exposure required. For my special lapse-time work on flowers the photo flood light being so short-lived is not suitable for intermittent exposures that often take a week or two to get a twenty-five-second scene in projection. So I used two or three small 75 watt frosted Mazda lights with reflectors to prevent the light shining into the lens. The lighting could be controlled on the subject by hanging two below the center and one slightly above giving the desired flat lighting required for Kodachrome Type A. In working with panchromatic film where side backlighting gave a more pleasing result a small spotlight could be used from the rear as long as it did not shine into the lens. This back lighting gives a more pleasing arrangement to the eye, but in Kodachrome is too contrasty. In using Type $\mathrm{A}$ Kodachrome reference has been made to the kind of artificial light used to get balanced correct color reproductions. Also in micro- 
scopial work the necessity of much experimental work is to emphasize certain parts of a subject to make them more definite on the screen. This means using the kind of light that will give the desired result. As light is waves of energy, the length of the wave will give one result and a longer or shorter wave still another. So one is justified in choosing the wave giving the desired result, or to eliminate some waves and allow only others to illuminate the subject. By stopping all the horizontal waves and allowing only the vertical ones to pass we have what is called polarized light. Some of the results from using it are most remarkable, although it is a new tool and not enough work has been done in color to say just what advantages it has or what it will show. It has opened the door for many new discoveries. In plant or animal tissue the cell walls show up much more clearly than in direct or dark field lighting, while possible other parts of the cell will show not as clearly, although that is still an unsettled question.

One short picture I made last summer showed very definitely that protoplasm does pass from one cell to another, which is still a disputed question with biologists. Crystals forming in a drop of water as the water evaporates and viewed with polarized light are the most beautiful objects I have ever seen; all the colors of the spectrum shoot across the drop, 


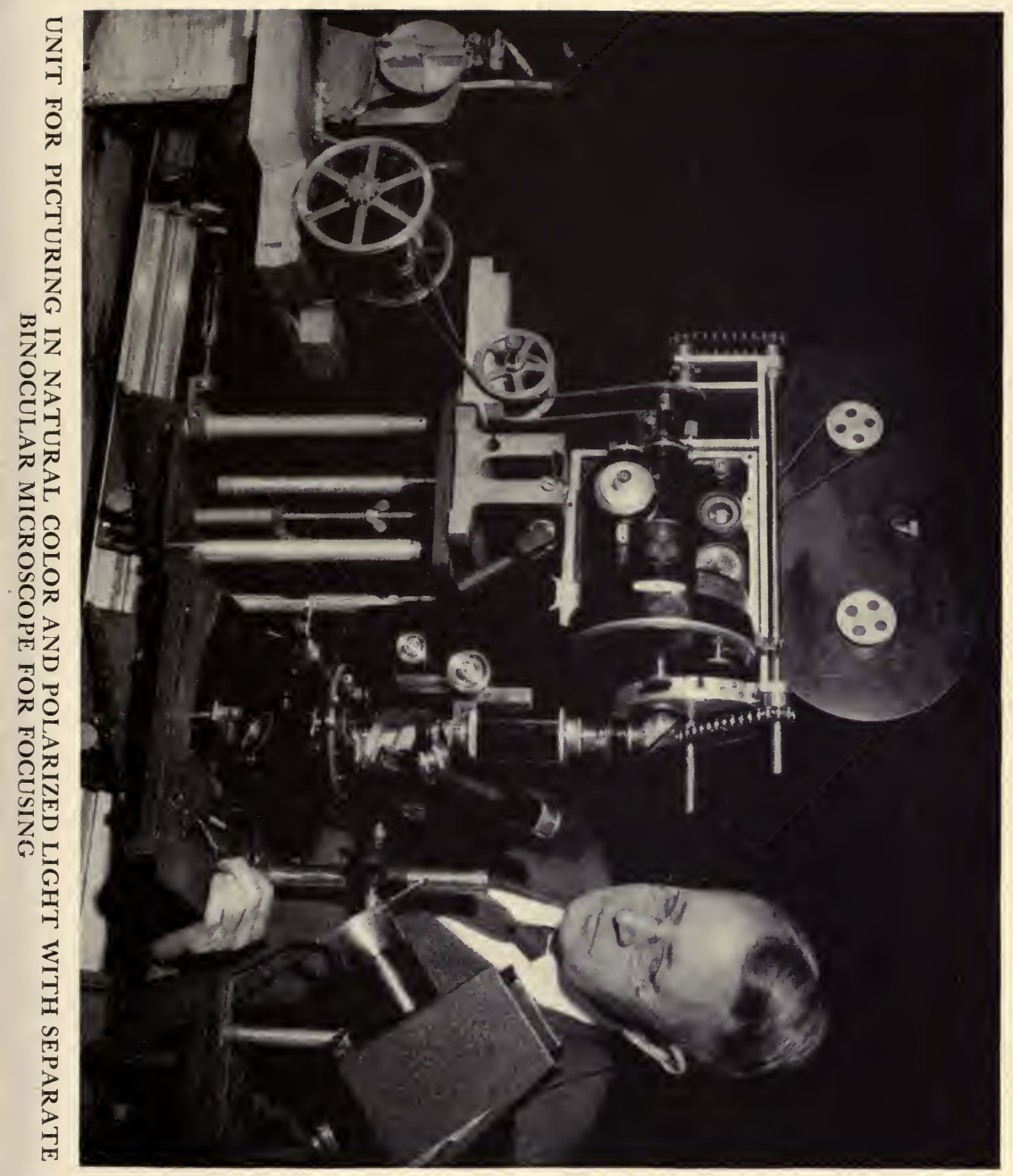



appear and vanish or change as the water evaporates. Diamonds or rubies could vie in color with what the eye can see, and I know of nothing as fascinating as watching the crystals form and grow. No two drops will be the same and they may take only a few seconds up to many minutes to form. Sugar is one of the most beautiful crystals of all to watch. With regular lighting you see only the shape of the crystal and not its color. So if you are looking for beauty in color and design polarize the light in your microscope and watch the wonderful color changes. Unfortunately if the camera is picturing its beauty you cannot watch it at the same time as you can with other forms of light. This makes the element of failure greater as one cannot tell when to start or stop the camera or the speed at which it should run, all of which factors should be known. One can watch the drop through a low-power binocular to determine the starting and end of the picture, but only see the crystal form and not its color, so the percentage of beautiful results may be small.

As many are not familiar with the term "polarized light" a short definition of it will be given. If you read your encyclopedia you will find several pages referring to technical matter and higher mathematics, but no simple definition of polarized light, 
leaving you still in doubt as to what it really is or does.

What it does or will show is still a matter of trying it to find out, as almost nothing has been done in picturing in natural color subjects so illuminated.

In a few and simple words polarized light is, considering light as waves of energy, a light in which all the horizontal waves have been eliminated and only the vertical ones allowed to pass through, illuminating the subject. A microscope designed for that work costs about $\$ 1,000$, or more with its attachments-rather a large sum for anyone except the most advanced worker and one able to have special equipment for each type of work. One may buy from Bausch and Lomb, Zeiss or Leitz, for much less than $\$ 100$, a Polarizer and an Analyzer, the former inserted in place of the condenser, and the Analyzer above the eye piece, revolving the latter until the nicols cross, giving the best illumination and the darkest background.

Certain subjects with this kind of illumination show things in color not as visible as in ordinary light. In plant and animal tissue it is much more difficult to see, but in thin sections of some minerals or crystals forming in a drop of water as it evaporates, the colors are so wonderful that any effort would be worth while just to see them. To be able 
to picture their beauty in all their natural color is a wonderful achievement.

I know of no field that offers more opportunity for research work and chance for new discoveries than picturing in natural color subjects illuminated with polarized light. The difficulties in getting correct exposures with polarized light are so increased over those of other methods that the percentage of failure is bound to be very high.

Just what polarized light, ultra violet, and other forms will do is still an open question; one of the new tools with which to experiment, "To play with," as the research workers for the General Electric Company at Schenectady say when a new invention is turned over to them to find out its uses.

In closing this chapter I strongly advise using a method I have found successful for artificially lighted subjects.

Make test exposures in normal and lapse-time close up and through the microscope, of a red, then a blue and then a yellow subject, making frontage enough of each to get a good idea when the result is projected. Make each subject three times, first with one third less time than you think is right, then your judgment on the correct time, then a third more, and for each subject measure the light with a very sensitive light meter, keeping careful records 
of every step, and for the microscopic subject take the reading of the light delivered at the aperture of the camera and the others close to the subject.

This means making nine tests of, say, five feet each, using type A Kodachrome film. It can be done on a 5o-foot spool.

In all future work of kindred colored subjects and regardless of the magnification in the microscope, only the strength of the light will have to be measured in the same way to figure the time necessary for the correct exposure and fixing the true color in the picture. 


\section{XV \\ CHEMICAL FARMING \\ จैก}





\section{XV}

\section{Chemical Farming}

GROWING PLANTS WITHOUT SOIL OR CULTIVATION

THE introduction of the element of chance of great gain into any work adds much to its desirability and when you add to this chance the possibility of wonderful returns or less work, or both, we have an opportunity or method for which we all reach out. Seeing enormous growths of plants and yields therefrom has stimulated a lively interest in this so-called new method.

Some three hundred years ago, Johan Batiste Van Helmod thought he had proved that plants grow entirely from water. Placing two hundred pounds of dried soil in a large container, he moistened it with rain water and planted therein a willow branch, protecting the cask (and contents) from dust with a metal cover. He then moistened it continuously with rain or distilled water for five years. At the expiration of this time he removed the tree whose weight had increased to one hundred and sixty-nine pounds. He now thoroughly dried the soil, and on weighing it, found it to be of its original weight, two hundred 
pounds. The tree meanwhile had gained one hundred and sixty-four pounds, not counting the fallen leaves. As the weight of the soil was almost the same as at the beginning of his experiment, Van Helmod contended that having added nothing bưt water, all the increased weight was due to water and to no other media. This experiment may be done by anyone of equal patience and might lead to the same conclusion, but if he would dry the tree, he would diminish its weight by about half; if he would then burn this dried tree a still greater residue would have disappeared in gases, leaving but a small part as ash.

Later investigators concluded that the weight which had been dissipated from the plant by heat might have been taken in from the air, which theory has been proven. The leaf, through its many mouths, or stomata, often over fifty thousand of them to a square inch, takes in a constant stream of air, from which it separates out carbon dioxide, and that gas, in the leaf, getting its power from the action of the sun thereon, enables it to combine with the plant's sap, producing minute portions of chemicals in the sap, with starch and sugar; this process is known as Photosynthesis. From this most complicated combination the plant is enabled to produce the enormous amount of its own, and in turn, our food. Just how 
this power in leaf is generated is not fully understood, but it is estimated that far more horse power is developed in all the leaves than that of the combined power of all the motors and locomotives in the world. So out of this food manufactured by the plant, of air and water, with the tiny amount of chemicals contained in the water, the plant can build up a tree out of a twig, a mighty oak from an acorn, bushels of wheat from a few seeds, tons of potatoes from their "eyes"-cut one "eye" to a piece-or almost a ton of tomatoes grown in ten square feet of space.

The very special problem is how to feed the plant that it may be enabled to utilize its power to produce sugar and starch given it by the sun. The sun has the latent energy; if the leaf has the requisite material, the result will be accomplished.

Everything except the air taken in by the plant must come to it through the root hairs, with more than fifty thousand doors to the square inch of the leaf through which the air is taken. The openings in the root hairs are yet smaller-too small to be visible through the ultra microscope-so the nourishment taken in that way must be in solution to enable it to enter them, showing why the soil must be moist for the root hairs to absorb it.

The next problem is that of the plant's require- 
ments and conditions and how most economically to meet them. Much of this knowledge you can obtain by burning a good healthy plant. As many as thirty elements may be found in the ash, even silver, in traces. Scientists are divided in opinion as to the number of essential elements-some are necessary, others may be beneficial, but a plant to be vigorous must have certain elements in greater or less proportion, depending upon the type of plant. Some elements have only recently been discovered to be necessary, as Boron, which must be present for the plant to succeed, though in very small quantities$55 / 100$ of one part in a million is necessary, while $75 / 100$ of one part in a million is detrimental. A homely comparison would be that of one pea in one hundred gallons of water to make pea soup. Nevertheless, without the very slight admixture of Boron, the plant cannot flourish, so in making a liquid diet for plants some elements are added as you might use a shot gun-some of the shot would scatter, producing results, and at any rate, do little or no harm.

It being essential to have these chemical foods in solution so that the root hairs can take them up, it seems logical that the best way is to feed them in liquid form, making assimilation easy, while that surplus energy can go into the development of the 
crop, which otherwise would be required to convert the food chemicals into solution.

Every plant requires sunshine (to manufacture its food) and a firm support to hold it, usually in a vertical position, and moisture to convert its food into an easily assimilable form. If these three requirements are supplied in their best form, including air, nature will take care of the results bountifully in blossoms or food.

Among the necessary chemicals now known are these four: $\mathrm{Ca}\left(\mathrm{NO}_{3}\right)_{2}, \mathrm{KNO}_{3}, \mathrm{MgSO}_{4}, \mathrm{KH}_{2} \mathrm{PO}_{4}$, which might be classed as fertilizing elements and will be found in the ash of most plants in approximate proportions of 6-4-2-1, although the quantities may vary considerably according to the type of the plant. It is not to be expected that a cucumber and a tomato will need exactly the same dishes of food. In forcing a plant in a nutrient solution, the above four elements may be given in varying quantities, as one would give fertilizer in soil grown plants, with the same good or bad results. Of the dozen or more other elements fed the plants the proportions must be more accurately controlled, as a surplus of any one of them may produce disastrous results. The safe quantities are so small it is difficult to weigh them except in a large quantity, then dissolved in 
water and a little of this solution added to the greater proportion of the fertilizing ones.

As early as 600 B.c., it was believed plants obtained all their food from water. Many people are surprised when told that plants cannot take up solid particles of fertilizer through the roots, but must have it first in solution; this fact led to the growing of plants in nutrient solutions, entirely without soil, of which published records were made as early as 1699 A.D.

Experimental work to discover just what plants need has been carried on for many years by Plant Nutrition students, using water as a medium because it is impossible for exact findings to get even two shovelfuls of soil containing identical elements. This most interesting and painstaking work has principally been done by germinating seeds between moist blotters, then transplanting the tiny seedlings to small prepared holes in corks inserted in jars, and held in place by a wad of cotton. Jars of this sort are fairly good if covered with black paper, keeping the solution in the dark, thus preventing the formation of algae. Although plants may be grown to maturity in this way, it is at the best unsatisfactory.

To obtain good results from these experiments. they can hardly be carried on in smaller than twentyfive gallon tanks, which may be fitted with a float 
valve and then connected with the water supply, an average plant from one of the several tanks and noting progress, giving more or less of each chemical, from one standard solution known to produce good results for that type, the best solution may be ascertained. Tanks of this state may contain at one time six or more different types of plants for experimental purposes. If sixty $3 \times 4$ foot tanks were all coupled together to the water supply and arranged in rows five feet wide and twelve feet long, the center row having a given formula of $\mathrm{Nu}$ trient Solution of the twelve known necessary elements, disregarding others, and each row beyond, on one side being given one third more of one element, keeping all the other elements identical, and each row beyond the center on the other side given one third less of one element, the others the same, and taking the average plant from the several types of plants used, the best combination of the twelve known necessary elements may soon be found. As inuch of the experimental work so far has been done in small jars of possibly a quart or a gallon of solution, containing but one plant, no real average could be made.

In my own first experiments I followed this method, but found it impossible to keep the water 
at the right level, or to accurately weigh out the small changes of some of the elements, although my scales could give the weight of the lead pencil marks of my written name. My personal work was badly handicapped also by the lack of available space. I found that while my steep hillside garden gave a wonderful view, room for tanks was very little, consequently my recourse to tiers of two-quart, widemouthed Mason jars.

This soilless plant growth method had been thought suitable only for experimental work until Prof. W. Gericke demonstrated its practicability in a larger way, using large, shallow tanks about six inches deep and of a convenient size, covering them with coarse wire netting, and that with excelsior, straw, chaff or almost anything of that nature. Supports were provided for the plants. Into this sizeable reservoir of water, he placed a bottle of Nutrient Solution, with two small holes (or tubes) through which it seeps, to gradually supply the plant needs. This bottle, holding about one pound of the four fertilizing agents and a very small quantity of the Solution in which the other necessary elements were dissolved, gave an excellent way of feeding during the period of growth.

Prof. Gericke has attained remarkable results with this method; the growth and maturity of, notably, 


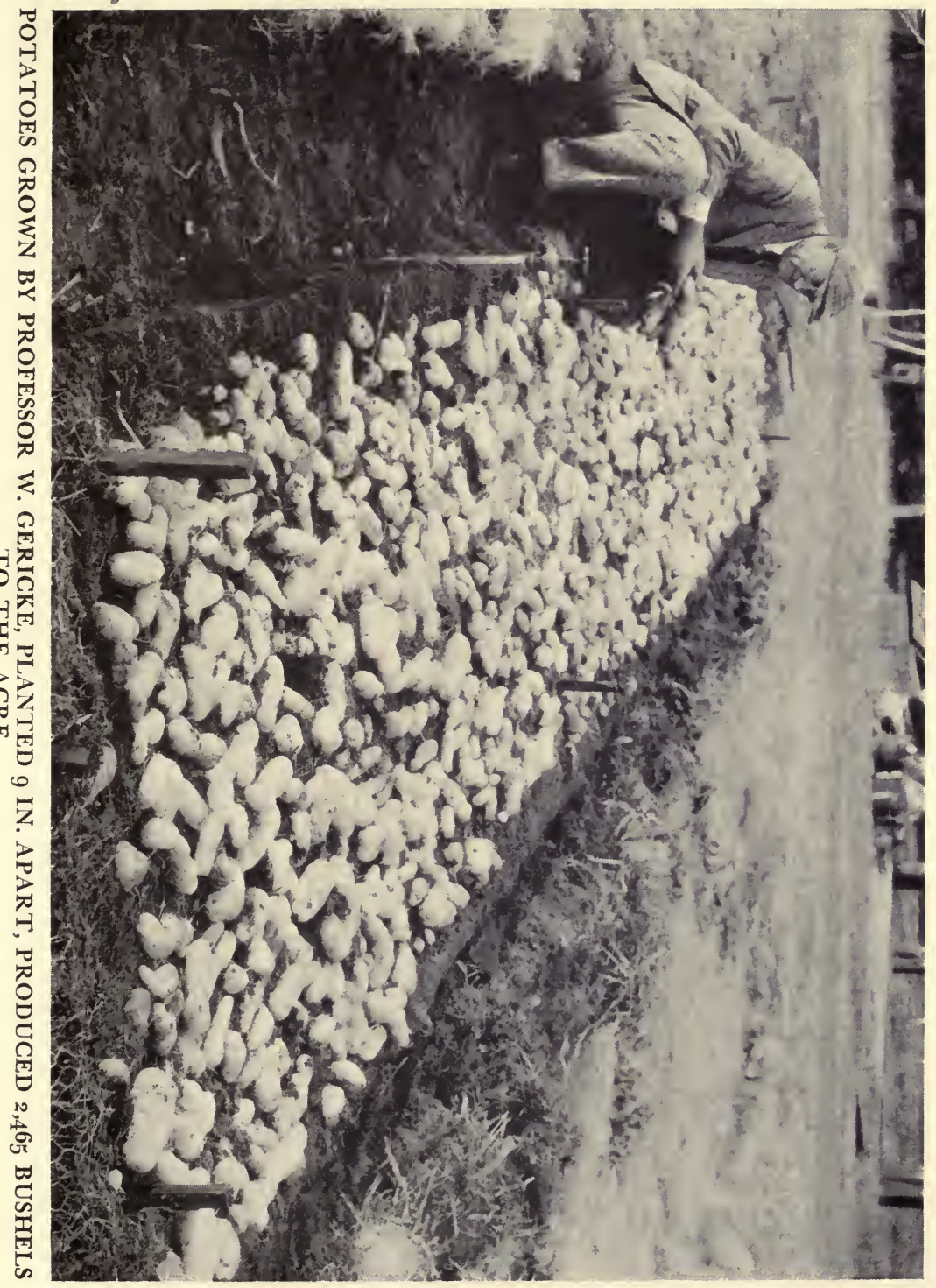



potatoes and tomatoes has excelled everything of its kind known. In the proportion of two to three thousand bushels of potatoes to the acre, and in a space ten feet square he produced nearly a ton of tomatoes, of marvelous, brilliant color, and most delicious flavor. Gladioli grew over six feet in height, and tobacco to a height of twelve feet, doubling the normal yield and of improved quality.

For my own work with this method, as with the Story of the Fly and the Termite, or any other subject, I worked out its life story. Of necessity I raise my own flies, termites, plants, etc., watch with the eye of the camera, as well as my own, every stage or step, and like a physician, study and note each symptom, as he would that of an infant, too young to tell him what was wrong: "Ask the flower" is no idle answer to the perplexities besetting a chemical farmer, and so one soon learns to recognize the plant's trouble by its color and general appearance, as the physician does that of his inarticulate patients, so to meet their requirements. In the Tomato, spotting and yellowing of the leaf means it is suffering from potash hunger, while a deepening of the green color, with additional purple in lower surface, indicates a phosphorus deficiency. With a lack of calcium, in extreme cases, leaves become pointed, dry, soon die and drop. Lack of iron in plant diet soon turns leaves 
and entire plant yellowish. As the effect of iron soon wears away, more must be added from time to time. This can be done by mixing iron tartrate, iron chloride, iron rust, with water, perhaps every week, enough to keep the plants a healthy green. As iron tartrate is expensive, over $\$ 3$ a pound, it is as well to use the other forms, they being much cheaper, and having an equally good effect.

This soilless culture being a technique to be patiently acquired, it is well to start in a small way. My own experience soon showed me that it was useless to try to work with any small containers, the plants growing so fast and drinking so much water that it was very difficult to keep it at its required level. When the plants are first placed in their tanks or other containers, water should almost touch the wire netting, and be kept at that level until the roots grow into it, when the carton or bottle of chemicals may be added, laying it on its side anywhere in the tank. From the two small openings, holes, or tubes, the solution will gradually seep out, and although the water is apparently perfectly still, there is enough circulation, due to the movements of the growing roots, to equalize the distribution of the Nutrient elements eddying it about to all points, from the nearest to the farthest from the central supply. 


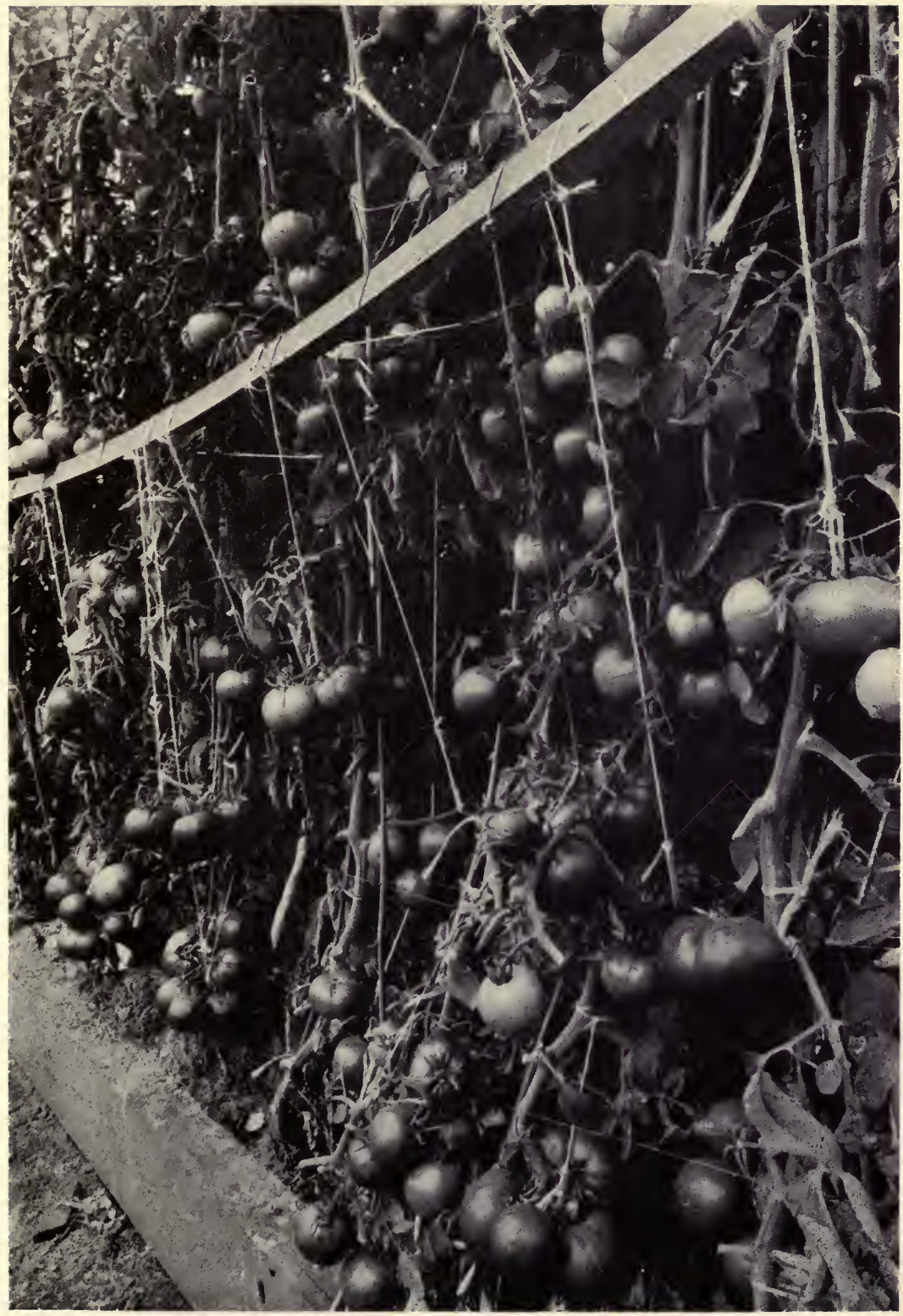

TOMATOES GROWN IN TANKS BY PROFESSOR W. GERICKE PRODUCED ALMOST A TON OF TOMATOES IN 100 SQ. FEET 

As the plants grow they absorb considerable water, if in a tank six inches in depth at the beginning, dropping down to two inches at which level it should be maintained, not allowing the tanks to be flooded, either by rain or artificially. For this reason it is best to have a drainage pipe that can be turned down (an elbow at two inch level, with a nipple, answers admirably) after the plants are well started. This arrangement of an air space of about four inches between the water and wire netting is beneficial to the roots as they are growing in a moist dark air chamber, reaching for water, and a sudden flooding is definitely detrimental. Being covered by a layer of excelsior, consequently dark, the solution breeds neither algae nor mosquitoes, but remains fresh and clear through the growing period.

In the case of soil-grown plants, they must reach out their roots to gather their nutritive elements, often to considerable distances; the failure to find this or that, to it, necessary element is the cause of poor crops, or under-color or development of flowers or plants. In tanks, containing all their needed elements, their roots are shorter, more numerous, allowing much closer planting, a decided economy of space; even plants having in soil a long tap root change their habit and form a close out-spreading mass. The limit of their nearness together seems to 
be governed by the available air space, or in the case of potatoes, the space available in the excelsior in which they form. These lowly vegetables, given space ten inches each way, have given at the rate of two thousand bushels to the acre and at nine inches, twenty-four hundred and sixty-five. A tank with an excelsior layer ten inches thick, allowing the potatoes ample vertical space for growth. Planted four or five inches apart, produced at the rate of about four thousand bushels to the acre; but such crowding, curtailing both sun and air, is not advisable in large tanks.

For my own experimental and photographic work, I made wooden tanks about four feet long by one foot wide, with a depth of six inches. In these, I placed wire baskets, like those you might use on your desk, for letters, fitted into the tank's space. These I filled with excelsior, and being portable, enabled me to take the baskets out and examine the plant's roots. Sometimes I put them in a smaller container to pose before a lapse-time camera for recording growth, or put them in our living room, giving living, growing, instead of cut flowers.

While this method has many advantages for my work, it is not suitable for potatoes, or similar crops, not giving them sufficient space; also I found in these tanks that the water level is more difficult to 
control, as one as small as four and a half gallons required daily attention. Some of my flowers grew four times as high, with many more and larger blossoms, than in soil. In some plants, the growth was so rapid and tall that every one had to be carefully supported, though ordinarily a single wire ten inches above each basket, made as a part of it, did that duty, those inside being held by those outside. In the large tanks, a wire or strong cord four feet high held potatoes in position.

Prof. Gericke's tomatoes were a wonderful show of real beauty, symmetrical in size, brilliant in color, firm and fine. He had three cement tanks, two feet wide by ten feet long, six inches deep, with a narrow passageway between tanks. The plants, when six to eight inches high were transplanted into the tanks on the 19th of December, being grown with the idea of a winter marketing. They were spaced a foot apart each way, giving twenty plants to each tank; thus he had sixty plants in an area ten feet square. To force their growth he had about sixty feet of electric heating wire in each tank with a thermostat control, keeping the water at $72^{\circ}$; the greenhouse in California was kept as cool as possible, screen doors always open.

By the first of March, the plants had made a growth of twelve feet; by the fifteenth, much of the 
crop below the six-foot level was ripe. Each plant was tied to a small iron pipe and each colorful cluster contained six or seven luscious tomatoes and had to be tied up as their weight would have broken them from their stems.

A record of each vine was kept, and was found to have produced from seventeen to twenty-five pounds each, continuing production until they were a year old, the vines then being over twenty-five feet long, growing across the ceiling of the greenhouse. At this rate of production and at the winter wholesale price of fifteen cents a pound, an acre would yield $\$ 50,000$. At this time the retail price was twenty-five to thirty cents a pound and these soilless products were far better than imports in flavor, size, and firmness. Prof. Gericke had not at this time (1934-35) published his exact findings or formulae.

He had, at this same time, tobacco twelve feet high with twice the usual yield; his cucumbers were no better than mine, which I consider a failure as they were no better than others grown in soil and same climate, that of Berkeley being too cool for successful production of them.

The tanks may be of wood, or wood sprayed with cement. If of iron, the iron rust will be beneficial though galvanized iron should not be used. Tanks should not be painted on the inside, there form- 
ing therefrom an oily residue, quite detrimental to plant growth. Hot "chunk" tar works well and makes a satisfactory, water-tight tank. Cement tanks give an alkaline reaction, to counteract which, a dilute solution of sulphuric acid may be used. As some plants require an alkaline reaction and others acid, the conditioning of chemical farming must be carefully attended to. In this, experience is almost the only teacher.

Since beginning my experiments with culture without soil, and showing in my lectures pictures illustrative of the method, Paramount also showing a story in their News Reel, and several articles having been published, I have been deluged with requests for the formula and instructions, until my daily mail must rival in volume that of the most glamorous movie star and I find it impossible to answer them. This has necessitated the publishing of a pamphlet with complete instructions, but even this help is not adequate. Not to be put in the position of withholding beneficial information as to culture and competent blending of the necessary ingredients of the formula, I have put up in cartons, containing about four and one half ounces, enough for a twenty-five gallon tank. This I can send for $\$ 1$ each. Although the cost of the chemicals is comparatively small, the time consumed and expense of prep- 
aration leave little profit. I am hoping that all those interested will in this way be enabled to carry on their own experiments.

Just what this method of plant culture without soil or cultivation really means is hard to conceivea three by four foot tank could supply a small family with potatoes, in California two crops yearly. The average city dweller in the so-called "back yard," perhaps thirty feet square, could raise all the vegetables and flowers needed. The same thing could be done on flat roofs. Any soil is as good as the best for this method where tanks may cover rocks, ash heaps or what not, and it also gives a new and interesting occupation. Insect pests are not as injurious to healthy growing plants as to those struggling to abstract sustenance from poor soil; and when the "hang" of it is really learned the possibility of larger crops and blossoms is excellent. Watching plant growth is almost as much pleasure as that of your own children's. There are certain to be some failures, but also much success.

DETAILED INSTRUCTIONS FOR SPECIAL PLANTS

For Potatoes

Potatoes that gave a yield of from two to four thousand bushels per acre, figuring on the square 
footage of the individual tanks and not allowing any pathways between them, were handled as follows: excelsior or chaff supporting medium was made from 8 " to $10^{\prime \prime}$ thick, giving ample room for the tubers to form. The planting was done, cutting the potatoes up into one eye for each plant and then placing them from 8 " to $10^{\prime \prime}$ apart each way. They were of course embedded in the excelsior, and the roots grew down through into the water as the plants grew upward through the excelsior. Planting them this close together made a solid mass of potato plants some four feet high. The entire growing period was about five months, just as it would have been in soil. Toward the end of the season the plants died down, and when they were just about gone, it was time to harvest, which was done by merely scraping the excelsior to one side and picking the potatoes up. Having grown in the excelsior they were so clean they hardly needed washing, and it really seemed a matter of how far apart we planted them what the crop in bushels amounted to.

It was necessary to run a supporting wire about two feet high around the outside edge of each tank; the inside plants supported themselves. The planting season is exactly the same in the tanks as it would be for soil in your climate, and the growing period 
was not lessened at all. The crop was very much increased. As potatoes require an alkaline solution, that was obtained by eliminating the sulphuric acid.

\section{For Tomatoes}

The tomato plants grown in the ordinary flats in soil were transplanted when 6 " to 8 " high. The excelsior layer was only two or three inches thick, and a little opening made with your finger will enable you to work the roots of the small plant down through the excelsior, the wire netting and into the water. Then the excelsior was simply patted up around them to hold them vertically. Planting for a winter market in a greenhouse, they should be placed in the tanks in November or early in December. In our California climate, the water was kept at a temperature of about $70^{\circ}$ and the greenhouse as cool as possible. All the ventilators were open day and night. The water was maintained at this temperature by approximately 60 feet of insulated heating wire with a thermostat control on the tanks. The tomato plants grew very rapidly, and those planted here in Berkeley reached the ceiling of a 12 foot greenhouse by the first of March. By the middle of March most of the crop was ripe. The crops from individual plants averaged from 17 to 25 pounds 
each. They were planted 12" apart each way, each tank having two rows of tomatoes and a very narrow passageway between them. Tomatoes in March were retailing then at twenty-five cents a pound. In December when the plants were then a year old, they had grown across the ceiling and down and were 25 feet long, still covered with green and ripe tomatoes, although rather small at that time. Each plant was supported on a half-inch iron pipe clear up to the ceiling and then across and down. Each cluster of tomatoes was so heavy it had to be supported also, there being from five to eleven tomatoes in a cluster. Tomatoes requiring an acid solution, it was necessary to add solutions of diluted sulphuric acid occasionally and also the iron rust, the quantities determined only by your judgment. Again the growing period was not shortened, taking just as long in the greenhouse as they would have in soil in a greenhouse.

In growing turnips, beets, radishes, carrots, and that type of vegetable, none of the results were especially successful. In other words, no larger crop was procured than would have been in soil. Considerable more experimental work will have to be done before I could recommend working with them. Onions did quite well. 
With flowers, or flowers of a tuberous nature like Begonias, Tigredias, Cannas and that sort of plants, the results were especially good. The increased size of the plant and blossoms was very noticeable. The greenhouse near Capitola, California, was entirely planted to Begonias and they were very successfully grown and used for hybridizing purposes and gave especially large plants and blossoms.

The English Daisy did very well also, getting stems nine inches to a foot long and very much larger blossoms than those in soil and many more of them. However, it must be remembered that this work is still in its infancy and a great deal of experimental work must be done before it can be recommended for successful growth by the general public.

\section{SIMPLIFIED GENERAL CULTURE SOLUTION}

The following culture solution if used correctly is recommended for certain forms of vegetables and flowers, but it must be understood that this new method is still in the experimental stage and no guarantee of results can be given. The formula below is only suitable for a chemist to compound and if it should be done in a drug store the price would be prohibitive. The quantities of many of the things are so small it is almost impossible for anyone not 
equipped with the right kind of scale and used to this kind of work to compound them.

\section{$\mathrm{Ca}\left(\mathrm{NO}_{3}\right)_{2}$ \\ $\mathrm{KNO}_{3}$ \\ $\mathrm{Mg} \mathrm{SO}_{4}$ \\ $\mathrm{KH}_{2} \mathrm{PO}_{4}$}

$\mathrm{AL}_{2}\left(\mathrm{SO}_{4}\right)_{3}$

KI

$\mathrm{KBr}$

$\mathrm{Ti} \mathrm{O}_{2}$

$\mathrm{Sn} \mathrm{Cl}_{2}{ }_{2} \mathrm{H}_{2} \mathrm{O}$

$\mathrm{Li} \mathrm{Cl}$

$\mathrm{Mn} \mathrm{Cl}_{2}{ }_{4} \mathrm{H}_{2} \mathrm{O}$

$\mathrm{H}_{3} \mathrm{BO}_{3}$

$\mathrm{Zu} \mathrm{SO}$

$\mathrm{Cu} \mathrm{SO}{ }_{4} \mathrm{H}_{2} \mathrm{O}$

$\mathrm{Ni} \mathrm{S} \mathrm{S}_{4} 6 \mathrm{H}_{2} \mathrm{O}$

Co $\left(\mathrm{NO}_{3}\right)_{2} 6 \mathrm{H}_{2} \mathrm{O}$
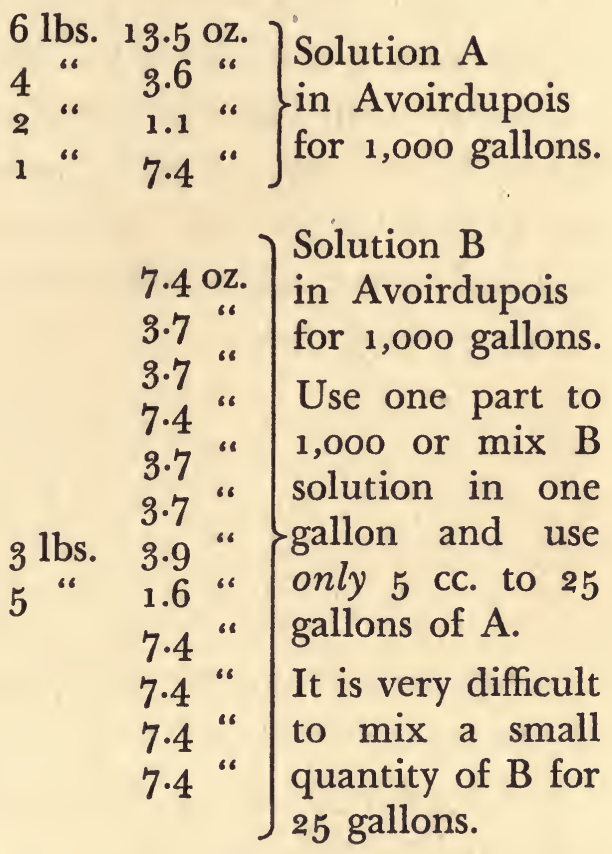

A solution of Iron Tartrate or Iron Chloride 293 gr. to 1 gallon of water is added in proportion to one tablespoon full to 100 gallons of combined " $A$ " and " $B$ " at first, and more from time to time as needed, enough to keep leaves a healthy green. Check solution for $\mathrm{pH}$ with litmus, if too acid add $\mathrm{KOH}$ or $\mathrm{CA}(\mathrm{OH})_{2}$.

The Anthony Co., of Streator, Ill., make an excellent tank with a float valve and the tanks may be 
coupled up so one valve keeps them all at the correct level.

A 4 ounce carton of the dry chemicals in the same proportions is enough for the growing period of a 25 gallon tank. Put two small nail holes through the end and place on its side in the tank. When planted the water should almost touch the wire netting and as the plants grow allow the water to drop to two or three inches deep.

A carton of these 16 elements carefully compounded for a 25 gallon tank ........ . 75 Iron Chloride for one quart included with carton. These directions with the formula ... .25

Solution A contains the fertilizing elements and B the eight essential elements and four beneficial ones. Supplied at above prices in limited quantities only for experimental work.

My latest experiments show that more of the inexpensive solution A may be added two or three times during the growing period, to advantage.

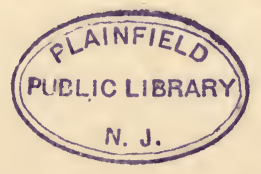






. 



\section{8}

P64 PUBLIC LIBRARY

(87448)

\section{PLAINFIELD, N. J.}

BOOKS are exchanged as follows: Adult DeB partment-Week days, 9 a. m. $\rightarrow$ p. m.; Sundays and holidays (July Fourth, Thanksgiving and Christmas excepted), 2-6 p. m. Juvenile Department-Week days, 9 a. m. -6 p. m.

All books excepting those marked "Seven-days' book" may be retained two weeks, and may be renewed for the same length of time. A fine of 1 cent a day will be charged for each book kept overtime.

A book cannot be exchanged on the same day on which it was taken out.

(3) 
